TÁRSIS RAFAEL SILVA TRAVASSOS OLIVEIRA

MODELAGEM DO SUPORTE DE TÚNEIS COM COMPORTAMENTO VISCOELÁSTICO USANDO O MÉTODO DOS ELEMENTOS DE CONTORNO 
TÁRSIS RAFAEL SILVA TRAVASSOS OLIVEIRA

\section{MODELAGEM DO SUPORTE DE TÚNEIS COM COMPORTAMENTO VISCOELÁSTICO USANDO O MÉTODO DOS ELEMENTOS DE CONTORNO}

Dissertação apresentada à Escola Politécnica da Universidade de São Paulo como parte dos requisitos para a obtenção do título de Mestre em Engenharia de Estruturas 
TÁRSIS RAFAEL SILVA TRAVASSOS OLIVEIRA

\section{MODELAGEM DO SUPORTE DE TÚNEIS COM COMPORTAMENTO VISCOELÁSTICO USANDO O MÉTODO DOS ELEMENTOS DE CONTORNO}

Dissertação apresentada à Escola Politécnica da Universidade de São Paulo como parte dos requisitos para a obtenção do título de Mestre em Engenharia de Estruturas

Área de Concentração:

Engenharia de Estruturas

Orientador:

Prof. Dr. Marcos Aurélio Marques

Noronha 


\section{FICHA CATALOGRÁFICA}

Oliveira, Társis Rafael Silva Travassos

Modelagem do suporte de túneis com comportamento viscoelástico usando o método dos elementos de contorno / T.R.S.T. Oliveira. -- São Paulo, 2009.

$103 \mathrm{p}$.

Dissertação (Mestrado) - Escola Politécnica da Universidade de São Paulo. Departamento de Engenharia de Estruturas e Geotécnica.

1. Método dos elementos de contorno 2. Viscoelasticidade das estruturas 3. Túneis I. Universidade de São Paulo. Escola Politécnica. Departamento de Engenharia de Estruturas e Geotécnica II. t. 


\section{DEDICATÓRIA}

Dedico este trabalho a minha irmã Bianca, ao meu irmão Tiago, a minha grande companheira e futura esposa Darlene, a minha avó Maria Hieldes e a meus pais José Travassos e Maria Magda. 


\section{AGRADECIMENTOS}

A Deus por todas graças alcançadas ao longo de toda minha vida, por seu amor incondicional e por ser meu porto seguro nos momentos difíceis.

Aos meus pais José Travassos, Maria Magda e Maria Hieldes por simplesmente existirem e, principalmente, pela educação, amor e apoio em todos os momentos, na verdade para vocês não bastaria um obrigado. Maria Hieldes a senhora não é avó e sim mãe.

Ao meu irmão Tiago por vivenciar comigo as dificuldades encontradas durante boa parte do tempo que dediquei ao mestrado em Engenharia de Estruturas. Muito obrigado por sua amizade, companheirismo, compreensão, dedicação e paciência. À minha irmã Bianca por sua presença insubstituível, ainda que centenas de quilômetros nos separem fisicamente, por suas palavras, sempre tão divertidas.

À minha futura esposa Darlene Begot, por tudo, por abrir mão de muita coisa para estar aqui ao meu lado compartilhando alegrias e tristezas. Sem você tudo seria mais difícil. Eu te amo muito.

Ao meu orientador, Prof. Marcos Aurélio Marques Noronha, por sua amizade, atenção, compreensão e paciência durante o desenvolvimento desta pesquisa.

Ao grupo de pesquisa do Prof. Marcos Aurélio Marques Noronha e aos integrantes do Laboratório de Mecânica Computacional (LMC), em especial aos amigos Marco Antônio Brasiel Sampaio e André Sarkis Müller, pela companhia nas programações efetuadas e estarem sempre dispostos a ajudar.

Aos professores Henrique Lindenberg e Waldemar Coelho Hachich por todas as contribuições no decorrer deste trabalho, especialmente no exame de qualificação.

À Universidade de São Paulo e ao Departamento de Engenharia de Estruturas e Geotécnica. 


\section{RESUMO}

Mesmo com os avanços na aplicação de métodos numéricos em engenharia, a simulação computacional da escavação de túneis ainda apresenta um baixo grau de precisão e de representação. Os modelos de escavação de túneis normalmente utilizam domínios com extensão infinita ou semi-infinita. Esta característica impacta negativamente as simulações numéricas baseadas no Método dos Elementos Finitos (MEF), pois uma superfície fictícia deve ser utilizada para limitar a geometria do modelo. De maneira inversa, a modelagem dos domínios infinitos é naturalmente integrada nos modelos baseados no Método dos Elementos de Contorno (MEC), já que apenas uma representação discreta dos contornos de um modelo precisa ser considerada. Em geral, as simulações computacionais realísticas de obras de túneis envolvem uma combinação de materiais estruturais e geotécnicos como solo, rocha, concreto estrutural, concreto projetado e elementos estruturais metálicos. Assim, os modelos de túneis podem ter camadas de materiais com propriedades diferentes, intactos ou fragmentados. O objetivo deste trabalho é realizar modelagens bidimensionais da estrutura de suporte de túneis com comportamento viscoelástico usando o MEC. O presente desenvolvimento também apresenta um novo algoritmo para simulação da interação maciço-concreto projetado usando uma abordagem pura do MEC. Esta pesquisa está incorporada em um projeto maior, voltado para o desenvolvimento de novos algoritmos para simulações numéricas precisas da escavação de túneis. Os desenvolvimentos anteriormente realizados por Noronha e Pereira (2003), Pereira (2004), Müller (2004) e Carbone (2007) foram fundamentais para o desenvolvimento do presente trabalho.

Palavras-chave: Engenharia de Túneis; Método dos Elementos de Contorno; Viscoelasticidade; Métodos Numéricos; Concreto Projetado. 


\begin{abstract}
Despite the progress in numerical methods applied to engineering, computational simulation of tunnel excavation still presents a low degree of accuracy and representativeness. Tunnel excavation models normally use infinite or half-infinite domains. This feature negatively impacts numerical simulations based on the Finite Element Method (FEM), since a fictitious bounding surface must be used to truncate the model geometry. Inversely, infinite domain modeling is intrinsic to the Boundary Element Method (BEM), since it requires a boundary-only representation. A realistic computational simulation of tunnel excavation involves structural and geotechnical materials like rock, structural concrete, shotcrete and rebar rock bolts and anchors. This implies that tunnels models may be composed of layers with different material properties, intact of fragmented. The main goal of this work is to carry out $2 \mathrm{D}$ modeling of tunnel support using the BEM and viscoelastic material models. The work also presents a new algorithm to simulate the rock-shotcrete interaction based on a pure-BEM approach. This research is integrated into a bigger study, which integrates new software developments for accurate numerical simulation of tunnel excavation. The previous research development proposed by Noronha and Pereira (2003), Pereira (2004), Müller (2004) and Carbone (2007) were particularly relevant to the present study.
\end{abstract}

Keywords: Tunnel Engineering; Boundary Element Method; Viscoelasticity; Numerical Methods; Shotcrete. 


\section{LISTA DE ILUSTRAÇÕES}

Figura 1.1 - Plataforma computacional desenvolvida pelo grupo do Prof. Noronha.

Figura 1.2 - Visão geral da plataforma computacional desenvolvida pelo grupo do Prof. Noronha.... 14

Figura 1.3 - (a) acidente na construção do metro de São Paulo; (b) repercussão internacional . ...... 16

Figura 2.1 - Túneis antigos no Brasil: (a) Rodovia União e Indústria; (b) Estrada de ferro D.

Pedro II. 18

Figura 2.2 - Modelo bidimensional de túnel raso: (a) MEF; (b) MEC; (c) MED. ................................ 19

Figura 2.3 - Tratamento convencional para análises não-lineares no MEC com células internas. ..... 21

Figura 3.1 - Efeito arco: mobilização da resistência ao cisalhamento do maciço ............................... 29

Figura 3.2 - Direção das tensões principais: (a) antes da escavação; (b) após a escavação............. 30

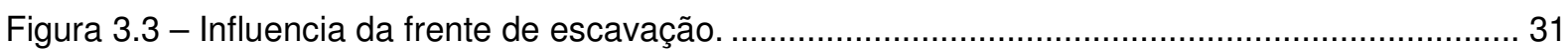

Figura 3.4 - Máquinas Tuneladoras - Tunnel Boring Machines. ................................................. 32

Figura 3.5 - Seqüência construtiva típica de um túnel pelo método construtivo NATM. ............... 34

Figura 3.6 - Modelos básicos unidimensionais: (a) Elástico, (b) Plástico, (c) Viscoso....................... 36

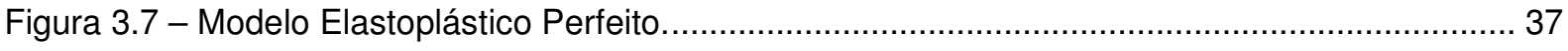

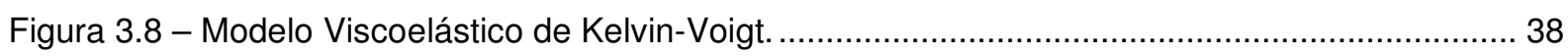

Figura 3.9 - Modelo Viscoelástico de Três Parâmetros. ................................................................ 40

Figura 3.10 - Modelo Viscoplástico (sem comportamento instantâneo). .......................................... 42

Figura 3.11 - Modelo Viscoplástico (com comportamento instantâneo). ............................................ 43

Figura 3.12 - (a) Modelo estrutural; (b) Discretização do modelo com elementos de contorno; (c)

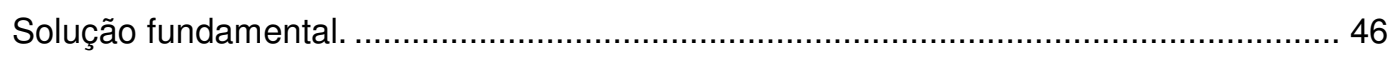

Figura 3.13 - Escavação de túneis em três estágios - Problema de multi-regiões. ............................ 54

Figura 3.14 - Problema com domínio formado por várias regiões. ................................................ 55

Figura 4.1 - Modelagem de túneis: (a) concreto projetado; (b) tirantes e barras de ancoragem. ....... 57

Figura 4.2 - Seqüência de passos requeridos pelo método da pressão fictícia. ................................. 59

Figura 4.3 - Seqüência de passos requeridos pelo método da redução de rigidez do núcleo............ 60

Figura 4.4 - Seqüência de passos requeridos pelo método da redução do carregamento ................ 61

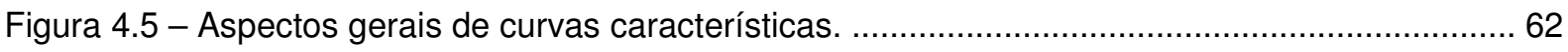

Figura 4.6 - Comparação entre diferentes características do suporte e seqüências de escavação

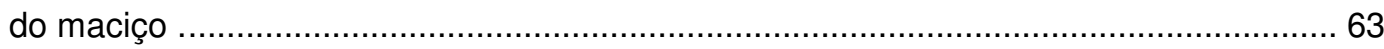

Figura 4.7 - Representação do modelo físico de túneis............................................................. 67

Figura 4.8 - Representação do modelo característico adotado no trabalho. ......................................... 68

Figura 4.9 - Representação do modelo característico sem multi-regiões......................................... 70

Figura 4.10 - Visão geral do algoritmo proposto por Carbone (2007). ............................................. 71

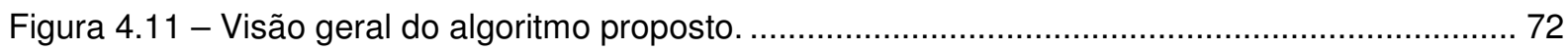

Figura 5.1 - Geometria, discretização e propriedades da estrutura para domínio único. ..................... 74

Figura 5.2 - Deslocamento longitudinal do ponto A (domínio único). ............................................... 75

Figura 5.3 - Malha de elementos finitos e deslocamento longitudinal do ponto A para $t=450$ dias

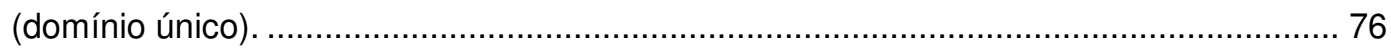


Figura 5.4 - Geometria, discretização e propriedades da estrutura para dois domínios iguais. 77

Figura 5.5 - Deslocamento longitudinal do ponto A (domínios iguais) ............................................. 77

Figura 5.6 - Deslocamento longitudinal do ponto B (domínios iguais) ............................................. 78

Figura 5.7 - Geometria, discretização e propriedades da estrutura para domínios diferente................ 79

Figura 5.8 - Deslocamento longitudinal do ponto A para domínios diferentes. ................................. 80

Figura 5.9 - Malha de elementos finitos das duas regiões e deslocamento longitudinal para $t=$

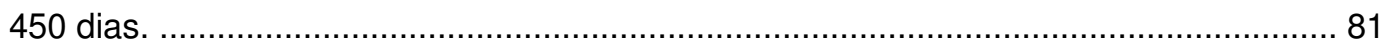

Figura 5.10 - Geometria, discretização e propriedades do cilindro para domínio único....................... 82

Figura 5.11 - Deslocamento radial da parede interna (domínio único) ............................................ 83

Figura 5.12 - Malha de elementos finitos e deslocamento radial da parede interna para $t=90$ dias

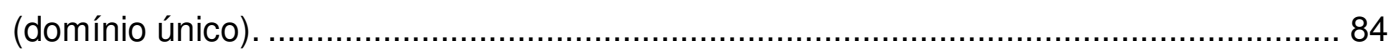

Figura 5.13 - Geometria, discretização e propriedades do cilindro para domínios iguais. .................. 85

Figura 5.14 - Deslocamento radial da parede interna para dois domínios iguais................................ 85

Figura 5.15 - Deslocamento radial do ponto B para dois domínios iguais........................................ 86

Figura 5.16 - Geometria, discretização e propriedades do cilindro para domínios diferentes............. 87

Figura 5.17 - Deslocamento radial da parede interna para dois domínios diferentes. ....................... 88

Figura 5.18 - Deslocamento radial da parede interna para dois domínios diferentes. ....................... 88

Figura 5.19 - Malha de elementos finitos e deslocamento radial da parede interna, $t=90$ dias......... 89

Figura 5.20 - Geometria, discretização e propriedades do túnel com dois domínios......................... 90

Figura 5.21 - Deslocamento vertical do ponto A. ..................................................................... 91

Figura 5.22 - Malha de elementos finitos e deslocamento vertical do modelo para $t=100$ dias. ........ 92

Figura 5.23 - Geometria, discretização e propriedades do túnel com quatro regiões. ........................ 93

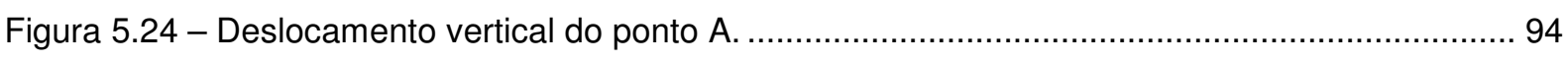

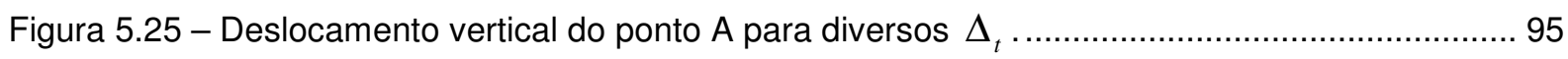

Figura 5.26 - Malha de elementos finitos e deslocamento vertical para $t=100$ dias......................... 95 


\section{LISTA DE TABELAS}

Tabela 3.1 - Equações do MEC para as três sub-regiões do problema …....................................... 56

Tabela 5.1 - Deslocamento longitudinal do ponto $A$ para $t=450$ dias (domínio único). ..................... 75

Tabela 5.2 - Deslocamento longitudinal do ponto B para $t=450$ dias (domínios iguais) .................... 79

Tabela 5.3 - Deslocamento longitudinal do ponto $A$ para $t=450$ dias (domínios diferentes). ............ 80

Tabela 5.4 - Deslocamento longitudinal do ponto $B$ para $t=450$ dias (domínios diferentes)............ 81

Tabela 5.5 - Deslocamento radial da parede interna para $t=90$ dias (domínio único)...................... 83

Tabela 5.6 - Deslocamento radial na interface entre os dois domínios para $\mathrm{t}=90$ dias................... 86

Tabela 5.7 - Deslocamento radial da parede interna para $t=90$ dias (domínios diferentes)............. 88

Tabela 5.8 - Deslocamento radial da parede interna para $t=90$ dias........................................... 89

Tabela 5.9 - Deslocamento vertical do ponto $A$ para $t=100$ dias. .................................................. 91

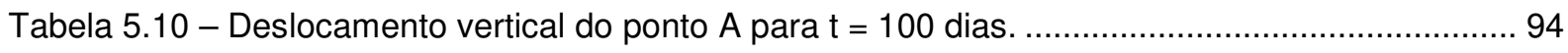




\section{SUMÁRIO}

1 INTRODUÇÃO

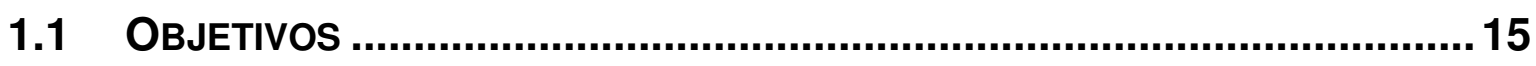

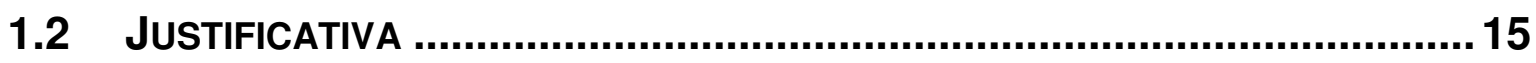

1.3 ESCOPO DO TRABALHO ………….................................................17

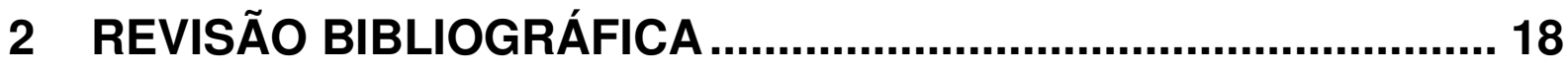

2.1 SimULAÇão NumÉrica EM ENGENHARIA de TÚNEIS..............................19

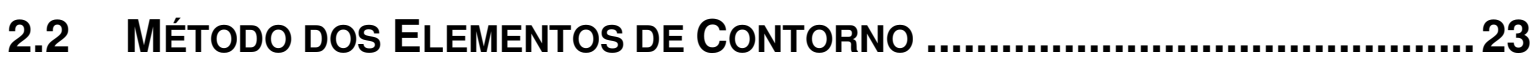

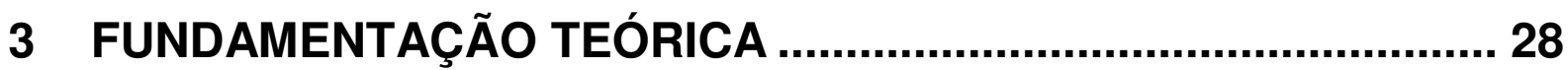

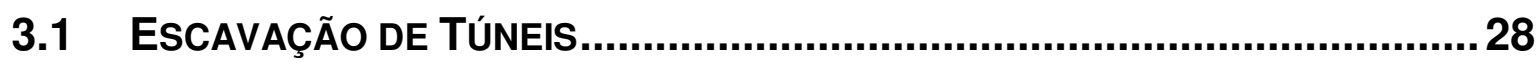

3.1.1 PRINCIPAIS SISTEMAS dE ESCAVAÇÃO DE TÚNEIS ..........................31

3.1.1.1 Máquinas Tuneladoras - TBMs (Tunnel Boring Machines).........32

3.1.1.2 NATM (New Austrian Tunnelling Method) ..................................33

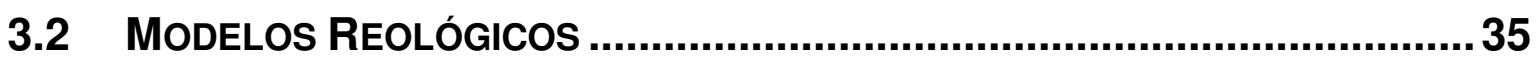

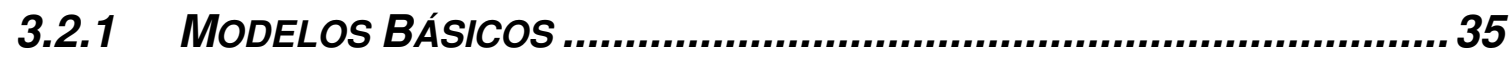

3.2.2 MODELO ELASTOPLÁSTICO DE PRANDTL-REUSS.............................37

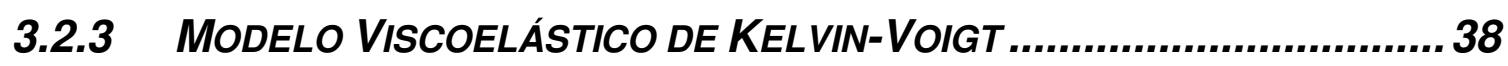

3.2.4 MODELO VISCOELÁSTICO DE TRÊS PARÂMETROS............................. 40

3.2.5 MODELO VISCOPLÁSTICO (SEM COMPORTAMENTO INSTANTÂNEO)... 42

3.2.6 MODELO VISCOPLÁSTICO (COM COMPORTAMENTO INSTANTÂNEO) .. 43

3.3 MÉtOdo dos Elementos de CONTORNO ……………......................... 45

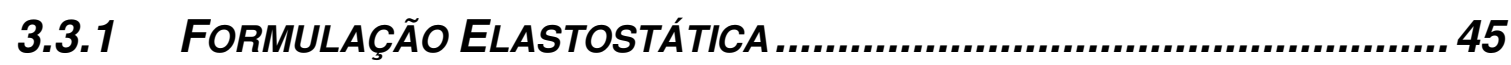

3.3.2 FORMULAÇÃo VISCOELÁSTICA (REPRESENTAÇÃO NO CONTORNO)... 51

3.4 Problemas de MULTI-REGIÕES ...................................................... 54

4 MODELAGEM COMPUTACIONAL DO SUPORTE DE TÚNEIS ... 57

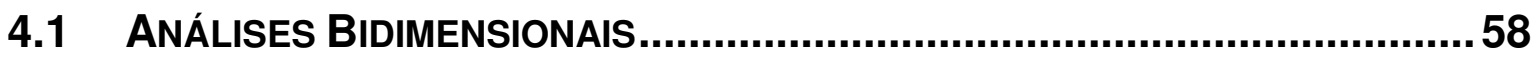

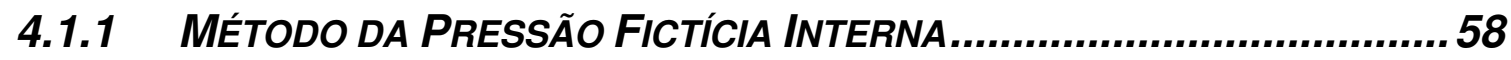

4.1.2 MÉTODO DA REDUÇÃO DE RIGIDEZ DO NÚCLEO.............................59 


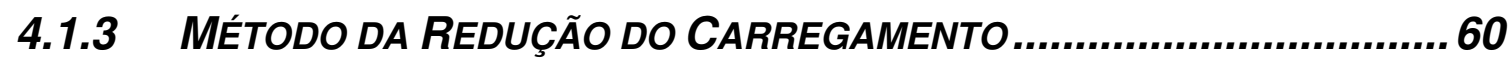

4.2 MÉTOdos de ANÁlISE dA INTERAÇÃo ENTRE O MACIÇO E O SUPORTE.. 61

4.2.1 MÉTODO DE CONVERGÊNCIA-CONFINAMENTO ...............................61

4.2.2 MÉTODO PROPOSTO POR SCHWARTZ \& EINSTEIN (1980)................. 64

4.2.3 MÉTODO PROPOSTO POR PÖTTLER (1990)................................... 65

4.2.4 MÉTOdo PROPOSTO POR CELESTINO (1992)................................. 65

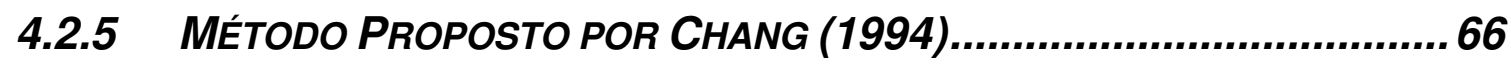

4.3 MOdELAGEM BidimENSIONAL DO SUPORTE DE TÚNEIS COM O MEC .......67

5 EXEMPLOS NUMÉRICOS........................................................ 73

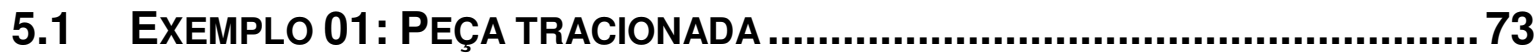

5.2 EXEMPLO 02: CILINDRO SOB PRESSÃO INTERNA .................................. 82

5.3 EXEMPLO 03: TÚNEL COM DUAS REGIÕES..........................................90

5.4 EXEMPLO 04: TÚNEL COM QUATRO REGIÕES........................................93

6 CONCLUSÕES ...................................................................... 96

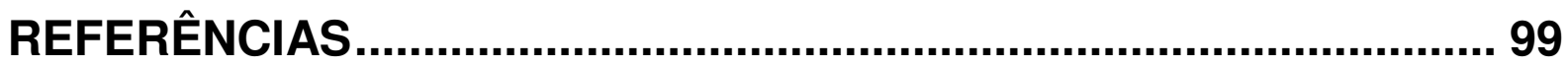




\section{INTRODUÇÃO}

Apesar dos grandes avanços na aplicação de métodos numéricos em engenharia, a simulação computacional de escavação de túneis ainda apresenta dificuldades no que diz respeito à precisão e ao grau de representação dos modelos numéricos empregados. Em simulações tridimensionais com o Método dos Elementos Finitos (MEF), os modelos de construção de túneis com um grau relativamente alto de representação podem envolver dezenas de milhões de graus de liberdade. Mesmo com as ferramentas computacionais mais avançadas disponíveis atualmente, a simulação numérica destes modelos é praticamente inviável devido às limitações de tamanho e velocidade de processamento. Assim, alternativas melhores em modelagens numéricas são almejadas. Dentre as alternativas existentes, destaca-se o Método dos Elementos de Contorno (MEC), já que apenas uma representação discreta do contorno dos modelos precisa ser considerada (OLIVEIRA; SAMPAIO; NORONHA, 2008).

Um aspecto essencial intrínseco aos métodos numéricos na engenharia de túneis é o da modelagem de materiais, que ocorrem intactos ou com diferentes níveis de fraturamento. Por se tratarem de estruturas mistas, simulações computacionais realísticas de obras de túneis envolvem uma combinação de materiais estruturais e geotécnicos como solo, rocha, concreto estrutural, concreto projetado e elementos estruturais metálicos. A adequada representação matemática destes materiais normalmente envolve os modelos constitutivos básicos utilizados em engenharia, caracterizando o comportamento dos materiais através de modelos elásticos, elastoplástico, viscoelástico e viscoplástico (NORONHA, 2007).

Os modelos de escavação de túneis normalmente envolvem domínios com extensão infinita ou semi-infinita. Com isso, o uso do MEF fica limitado já que uma superfície fictícia deve ser utilizada para limitar a geometria do modelo. Por outro lado, o MEC é naturalmente indicado para a análise desses modelos, pois a sua principal característica é a representação da geometria e das variáveis de um modelo apenas através da discretização do seu contorno. 
O presente trabalho está incorporado em um projeto maior (Figura 1.1), no qual há o desenvolvimento de um novo software para realizar simulações numéricas em engenharia de túneis. A plataforma computacional que está sendo desenvolvida pelo grupo do Prof. Marcos Noronha na EPUSP, procura incorporar os mais recentes algoritmos para análises lineares e não-lineares com o MEC, incluindo novos algoritmos de pré- e pós-processamento, específicos para representações baseadas puramente em discretizações de contorno. Devido à simplicidade dos modelos do MEC e aos novos algoritmos utilizados, modelos com alto grau de precisão poderão ser analisados com um esforço computacional bem mais baixo que o necessário nas simulações com o MEF.

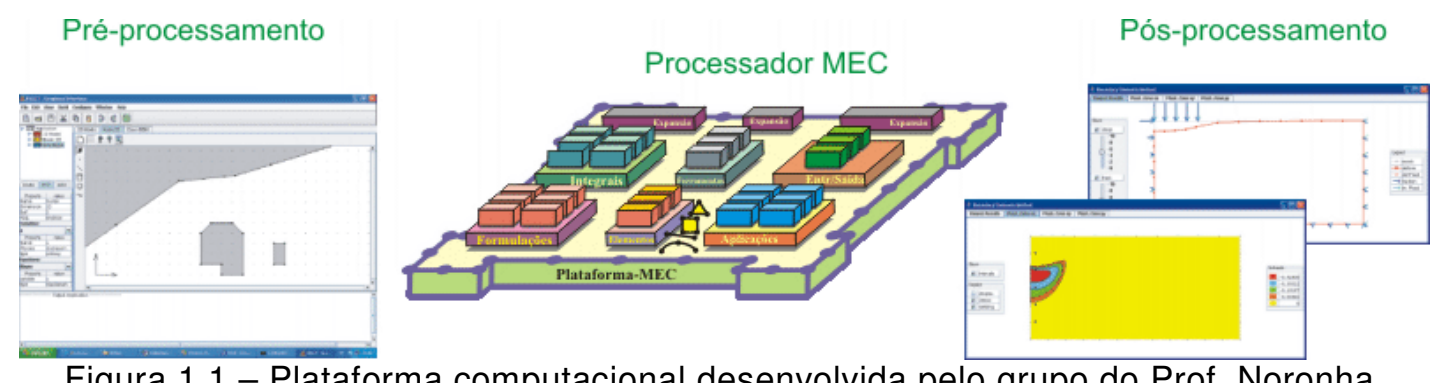

Figura 1.1 - Plataforma computacional desenvolvida pelo grupo do Prof. Noronha.

Devido à incorporação de técnicas avançadas de desenvolvimento de software através da Programação Orientada a Objetos (POO), a plataforma computacional mencionada, também conhecida como TunMech, permite a incorporação dos diferentes aspectos envolvidos na simulação computacional da escavação de túneis. Assim, além dos módulos de pré- e pós-processamento, o módulo principal de análises da plataforma pode incorporar modelos reológicos complexos com efeitos de não-linearidade, problemas acoplados envolvendo fluxo de água em meios porosos e também problemas de contato devido à interação entre equipamentos de escavação e solo/rocha (Figura 1.2).

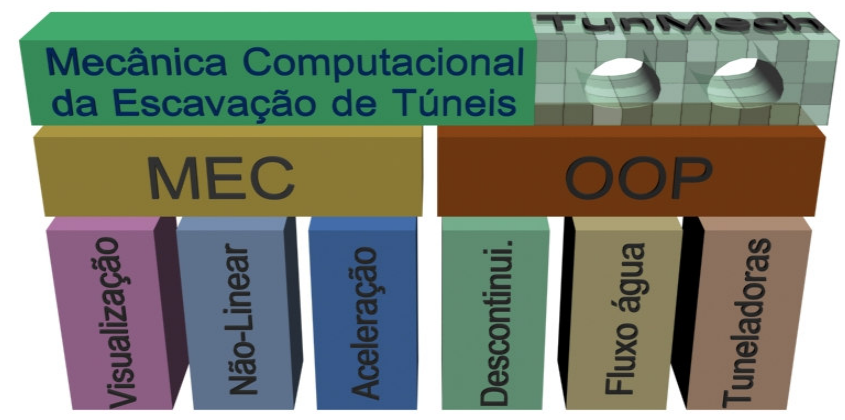

Figura 1.2 - Visão geral da plataforma computacional desenvolvida pelo grupo do Prof. Noronha. 


\subsection{OBJetivos}

O objetivo geral deste trabalho é a modelagem bidimensional da estrutura de suporte de túneis com comportamento viscoelástico usando como fundamentação teórica o Método dos Elementos de Contorno (MEC).

Fazem parte dos objetivos específicos:

$\checkmark$ Desenvolvimento de um novo algoritmo para simulação da interação maciçosuporte com revestimento em concreto projetado baseado no MEC;

$\checkmark$ Utilização e adaptação da plataforma computacional que vem sendo desenvolvida pelo grupo do Prof. Marcos Noronha;

$\checkmark$ Implementação computacional de multi-regiões na plataforma, considerando as três fases da abordagem orientada a objetos: Análise Orientada a Objetos (OOA - Object Oriented Analysis), Projeto Orientado a Objetos (OOD - Object Oriented Design) e Programação Orientada a Objetos (OOP - Oriented Object Programming) utilizando Java como linguagem de programação;

$\checkmark$ Simulação de exemplos com comportamento viscoelástico para representar o concreto projetado;

$\checkmark$ Verificar os resultados encontrados na plataforma computacional com análises com o MEF e com soluções analíticas;

$\checkmark$ Cooperação com o Departamento de Estruturas da Universidade Tecnológica de Graz, Áustria, coordenado pelo Prof. Gernot Beer.

\subsection{Justificativa}

Com o desenvolvimento dos centros urbanos as áreas superficiais ficaram densamente edificadas e o uso do espaço subterrâneo para infra-estrutura tornou-se necessário. Com isso, o domínio da tecnologia de construção de túneis é um aspecto de importância estratégica para o desenvolvimento da infra-estrutura básica de cidades e estados. Além dos grandes benefícios econômicos devido ao 
encurtamento de distâncias e do uso racional do espaço subterrâneo, as soluções baseadas em túneis geram o menor impacto ambiental possível.

Outro aspecto que caracteriza a importância da engenharia de túneis é ainda o elevado fator de risco destas obras, no que diz respeito aos acidentes e suas conseqüências. Este aspecto é especialmente atual no Brasil, devido ao acidente na Linha 4, Estação Pinheiros, do metrô de São Paulo ocorrido em 12 de Janeiro de 2007 (Figura 1.3a). Este acidente teve repercussão não apenas em nível nacional, mas foi objeto de atenção da comunidade de engenharia de túneis do mundo inteiro, tendo sido divulgada nas principais revistas técnicas internacionais (Figura 1.3b).

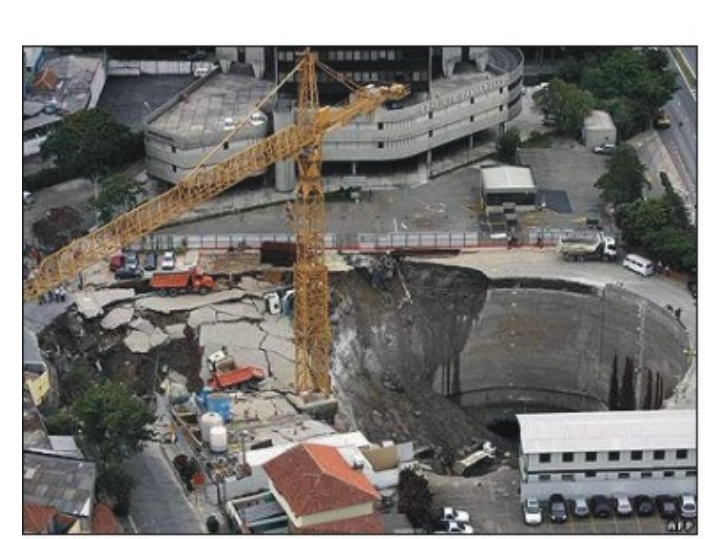

(a)

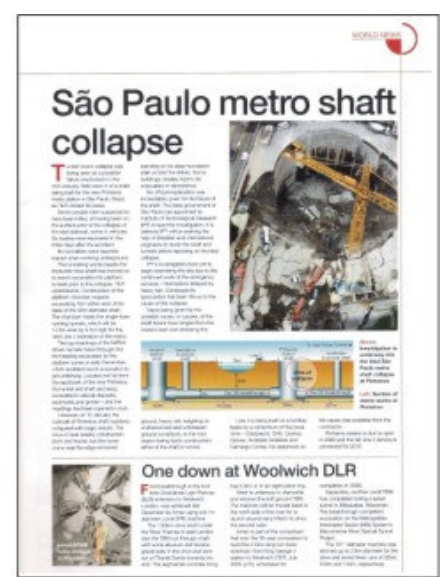

(b)

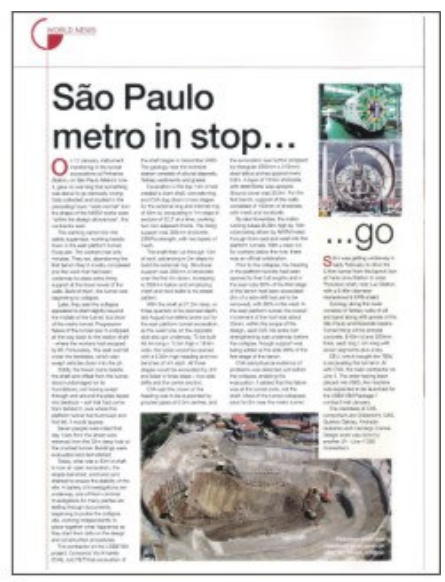

Figura 1.3 - (a) acidente na construção do metro de São Paulo; (b) repercussão internacional ${ }^{1}$.

Atualmente o MEF é o método numérico mais utilizado para solucionar diversos problemas da engenharia. O MEF, matematicamente fundamentado em princípios variacionais, baseia-se na subdivisão do domínio do sólido em regiões chamadas de elementos finitos, as quais estão interconectadas por pontos ou nós.

Como todos os métodos numéricos, o MEC possui vantagens e desvantagens. Porém, observa-se que o MEC ainda é pouco utilizado quando comparado ao MEF, mesmo em situações favoráveis a ele, como nos modelos de túneis, por exemplo. Isso ocorre muitas vezes, devido à falta de conhecimento sobre o método. Este aspecto também é um fator motivador para o estudo do MEC.

\footnotetext{
1 fonte: M. A. M. Noronha, "Mecânica Computacional Aplicada à Engenharia de Túneis”, São Paulo, 2007.
} 
Desta forma, destaca-se a importância da simulação numérica em conjunto com a experiência acumulada pela comunidade de engenharia de túneis. Os métodos numéricos são ferramentas auxiliares cada vez mais utilizadas no desenvolvimento de projetos, tanto pela disseminação e popularização dos recursos computacionais quanto pela redução de custos e tempo de análise em relação à simulação através de análises experimentais (NORONHA, 2007).

\subsection{ESCOPO DO TRABALHO}

Abaixo será descrito de forma bastante sucinta como está organizado o trabalho:

No Capítulo 2 é feita uma revisão bibliográfica sobre simulação numérica em engenharia de túneis e Método dos Elementos de Contorno (MEC).

No Capítulo 3 é apresentada a fundamentação teórica para o desenvolvimento da dissertação, fazendo parte deste capítulo os tópicos: escavação de túneis, em que é apresentado, entre outras coisas, os principais sistemas de escavação de túneis; modelos reológicos; formulação do Método dos Elementos de Contorno; e por fim problemas de multi-regiões.

A forma como a modelagem computacional do suporte de túneis foi tratada neste trabalho será apresentada no Capítulo 4 juntamente com uma abordagem sobre análises bidimensionais e métodos de análise da interação entre o maciço e suporte.

No Capítulo 5 serão apresentados quatro exemplos numéricos, os dois primeiros para validação do algoritmo proposto e dois últimos para modelagem bidimensional da estrutura de suporte de túneis com comportamento viscoelástico usando como fundamentação teórica o Método dos Elementos de Contorno (MEC).

Por fim, o Capítulo 6 apresenta as considerações finais do trabalho. 


\section{REVISÃO BIBLIOGRÁFICA}

No século XIX, iniciou-se na Grã-Bretanha, a construção sistemática de túneis em larga escala, motivada pela revolução industrial e pelo desenvolvimento dos primeiros sistemas ferroviários. Celestino et al. (2006) mostra que o Brasil também acompanhou este desenvolvimento com a construção de túneis nos estados do Rio de Janeiro e Minas Gerais por volta de 1860, para a implantação da Rodovia União e Indústria e da Estrada de Ferro D. Pedro II (Figura 2.1).

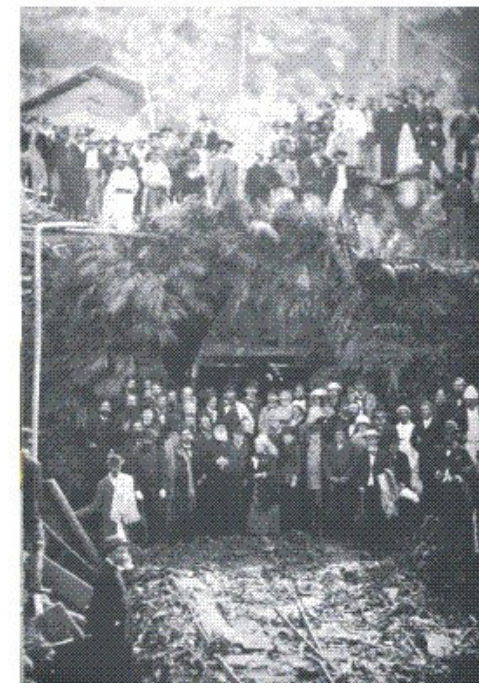

(a)

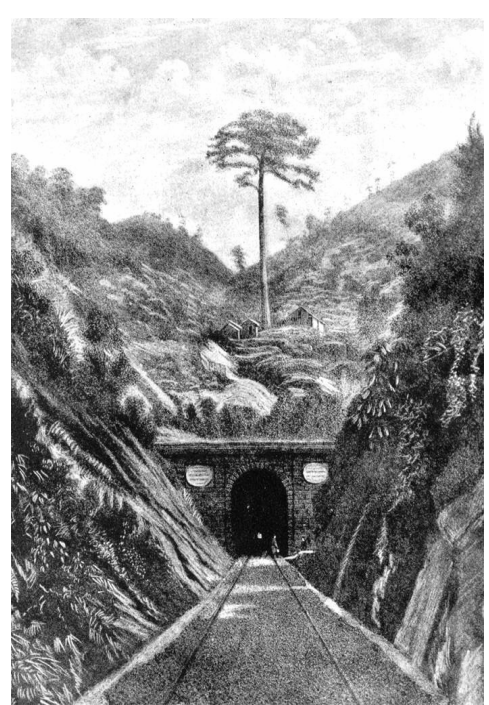

(b)

Figura 2.1 - Túneis antigos no Brasil: (a) Rodovia União e Indústria²; (b) Estrada de ferro D. Pedro ${ }^{3}{ }^{3}$.

Desde então, as obras de túneis sofreram um aumento significativo devido ao crescimento mundial, como por exemplo, a expansão global da malha de transportes rodoviária e metroferroviária, usinas hidroelétricas, mineração subterrânea, sistemas adutores e de saneamento, etc. No Brasil, o estabelecimento da moderna engenharia de túneis ocorreu na década de 70 , com a construção do metrô de São Paulo e do Rio de janeiro (CELESTINO et al, 2006).

\footnotetext{
${ }^{2}$ Rodovia União e Indústria, inaugurada em 1861, fonte: M. Noronha, "Mecânica Computacional Aplicada à Engenharia de Túneis", São Paulo, 2007.

3 Túnel Grande (Túnel N. ㅇ 12) pertencente a estrada de ferro D. Pedro II, com 2.233,60m, inaugurado em 17 de Dezembro de 1865, com a presença da Princesa Isabel e do Conde D'Eu, seu marido, fonte: M. F. Figueira, "Memória Histórica da EFCB", 1908 apud http://www.anpf.com.br/histnostrilhos/historianostrilhos 15 fevereiro2004.html, acessado em: 30/06/2008.
} 
Como conseqüência desta expansão verificou-se uma grande demanda por métodos consistentes para o projeto e construção de obras de túneis. No final do século XIX e início do século $X X$, realizaram-se vários esforços para estabelecer os fundamentos da Mecânica dos Túneis, através da investigação da distribuição de tensões e dos deslocamentos ocasionados por estas obras. Também foram propostos vários critérios de projeto e de dimensionamento de estruturas de suporte.

\subsection{SimulaçÃo NumÉRICA EM ENGENHARIA dE TÚNEIS}

Quando se iniciou na Grã-Bretanha a construção sistemática de túneis, os recursos computacionais não existiam e conseqüentemente nenhuma simulação numérica do comportamento dessas obras era realizada. Mais recentemente, na segunda metade do século $X X$, a revolução da informática gerou um forte impacto na engenharia de túneis, oferecendo métodos numéricos avançados para o cálculo e projeto dessas obras (BEER, 2003). Dentre estes métodos destacam-se o Método dos Elementos Finitos (MEF), o Método dos Elementos de Contorno (MEC) e o Método dos Elementos Discretos (MED). Para ilustrar a diferença entre os métodos numéricos mais utilizados, a Figura 2.2 apresenta um modelo bidimensional de um túnel raso. Como pode-se observar, o MEC apresenta uma representação bem mais simples e reduzida que o MEF e o MED que exigem a discretização do domínio do modelo.

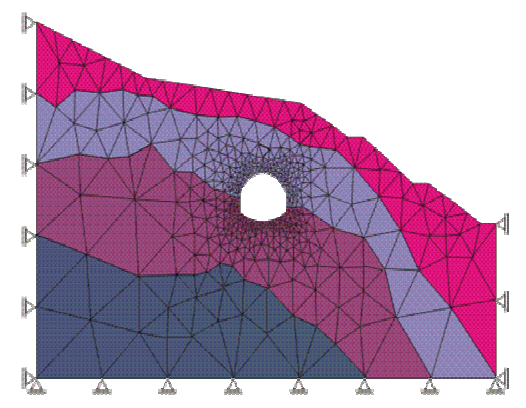

(a)

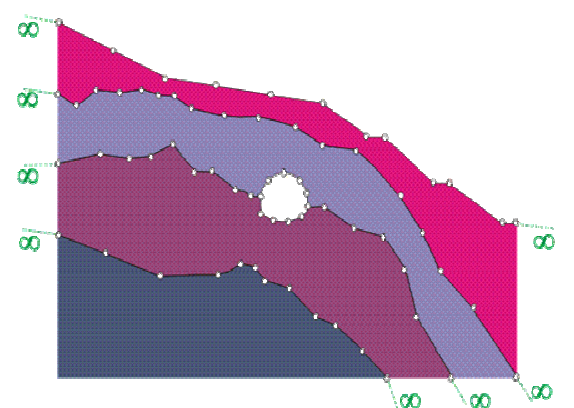

(b)

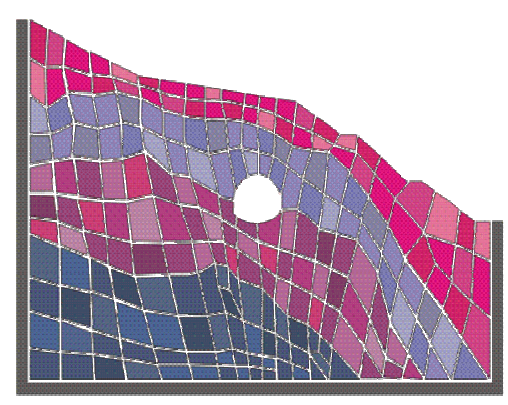

(c)

Figura 2.2 - Modelo bidimensional de túnel raso: (a) MEF; (b) MEC; (c) MED ${ }^{4}$.

\footnotetext{
4 fonte: Sampaio, Oliveira, Noronha, "Modelagem de Máquinas Tuneladoras usando Mecânica do Contato e Método dos Elementos de Contorno", São Paulo, 2008.
} 
O MEC e o MED têm sido usados em situações especificas, onde pode-se obter um maior grau de precisão no modelo. Já o MEF, que é o método numérico mais utilizado para solucionar diversos problemas da engenharia, apresenta como uma das principais desvantagens a geração de malha, pois requer a discretização do domínio do modelo. A geração de malhas para o MEF é uma etapa crítica, principalmente na modelagem tridimensional, pois não existem atualmente, métodos totalmente automáticos para a obtenção de malhas consistentes de elementos finitos. Além disto, nos modelos de túneis o domínio normalmente é infinitamente extenso. Conseqüentemente, a modelagem com o MEF exige simplificações adicionais como a necessidade de truncar o domínio infinito com uma superfície artificial, normalmente resultando em condições de contorno artificialmente introduzidas no modelo. Assim, tem-se que a geração da malha e as novas condições de contorno adicionam um tempo importante no processo de modelagem, que na maioria das vezes é maior que o tempo necessário para a realização da própria simulação numérica (GOLSER, 2001).

Segundo Venturini (1983), não obstante a larga utilização do MEF, o MEC vem ganhando cada vez mais destaque entre a comunidade da engenharia geotécnica, pois se apresenta como uma alternativa importante contra os gargalos da geração de malha para o MEF. A modelagem com o MEC é mais simples, quando comparada com a do MEF, já que apenas o contorno do modelo precisa ser discretizado. Esta característica apresenta-se como sendo especialmente vantajosa no caso de modelos tridimensionais com domínio infinito. Além disto, o MEC apresenta resultados com excelente precisão para simulações de dinâmica, de problemas com altos gradientes e de mecânica da fratura.

Em contrapartida, o MEC ainda apresenta dificuldades em análises não-lineares, que são importantes para projetos de túneis, como por exemplo, na consideração de efeitos viscoplásticos. $O$ tratamento convencional para as não-linearidades com 0 MEC exige uma discretização auxiliar e cálculo de integrais no domínio coberto pela região onde ocorrem os processos não-lineares (Figura 2.3). Este tratamento reduz a principal vantagem do MEC que é a necessidade de discretização apenas do contorno do modelo. 


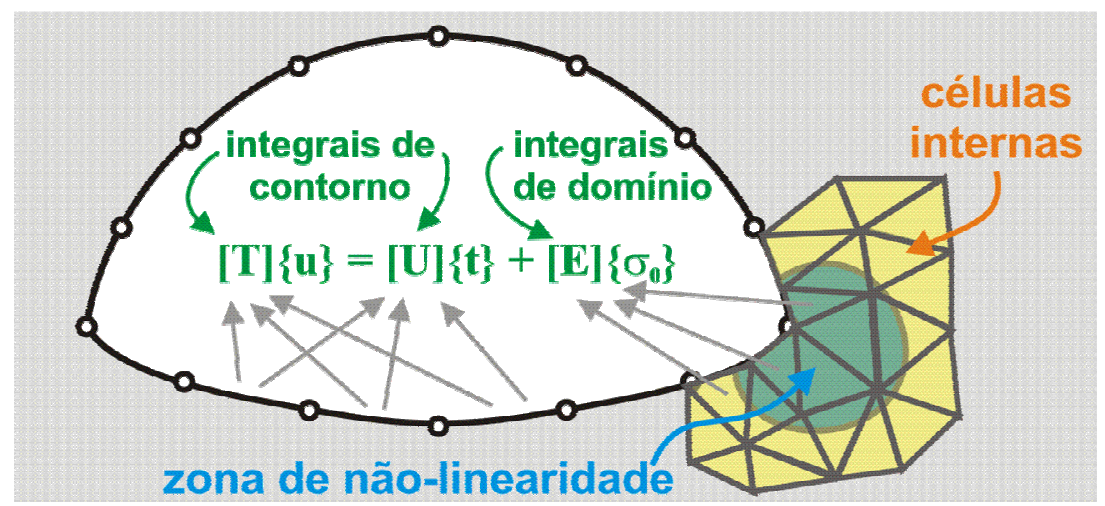

Figura 2.3 - Tratamento convencional para análises não-lineares no MEC com células internas.

Mesmo com o alto grau de sofisticação destes métodos, os resultados de análises computacionais ainda apresentam disparidade quando comparados com 0 comportamento real das estruturas. Além das limitações intrínsecas dos métodos numéricos, deve-se observar a questão do elevado esforço computacional necessário, principalmente em simulações da escavação seqüencial de túneis utilizando modelos tridimensionais. Neste caso, a simulação de um único caso de construção pode durar semanas, mesmo utilizando os computadores de alta capacidade de processamento atualmente disponíveis (NORONHA, 2007).

As limitações ainda existentes nos métodos numéricos, não os tornam desprezáveis. Pelo contrário, estes métodos destacam-se cada vez mais como ferramentas essenciais para a engenharia de túneis moderna, pois permitem prever e obter parâmetros-chave para guiar o projeto de túneis e o dimensionamento das estruturas de suporte a um custo muito menor que os métodos experimentais.

Nas últimas quatro décadas foram apresentados vários trabalhos na literatura sobre a modelagem numérica de túneis, sendo que a maioria deles considera o MEF como método numérico. Entre os trabalhos mais recentes destacam-se os trabalhos de Farias, Junior \& Assis (FARIAS; JUNIOR; ASSIS, 2004); França (FRANÇA, 2006); e Galli, Grimaldi e Leonardi (GALLI; GRIMALDI; LEONARDI, 2004).

No que diz respeito à análise de modelos de túneis com o MEC, há poucos trabalhos disponíveis na literatura. $\mathrm{Na}$ análise de modelos bidimensionais destacam-se os trabalhos de Beer (BEER, 1983); Venturini (VENTURINI, 1983); e Beer, Watson \& Swoboda (BEER; WATSON; SWOBODA, 1987). 
Beer apresentou um estudo sobre o acoplamento entre o MEC e o MEF em 1986, no intuito de combinar as melhores características dos dois métodos em análises de problemas geotécnicos. Porém, Golser (2001) mostrou que a vantagem do acoplamento não é tão significante quando comparada à análise apenas com o MEF. No que diz respeito às análises tridimensionais com plasticidade e o MEC, apenas nas últimas três décadas vêm sendo desenvolvidas pesquisas sobre o assunto. Dentre estas últimas análises destacam-se os trabalhos de Huber et al. (HUBER, et al. 1996) e Gao \& Davies (GAO; DAVIES, 2001).

A modelagem tridimensional da escavação de túneis com o NATM usando o MEC, vem sendo amplamente estudada na TU-Graz. Dünser (2001) apresentou diversos resultados de análise de modelos tridimensionais, considerando o avanço seqüencial do túnel. $O$ estudo das análises com efeito de plasticidade também vem sendo estudado na TU-Graz. O objetivo desta última pesquisa é a automatização do processo de geração das células internas, necessárias para considerar os efeitos de plasticidade.

A visualização de análises com o MEC para problemas de construção de túneis tem sido pouco discutida na literatura. Opriessnig e Beer (1998) da TU-Graz apresentaram alguns algoritmos gráficos específicos para o MEC. Porém, na maioria dos casos, os pré- e pós-processadores das análises com o MEC utilizam os mesmos algoritmos de visualização desenvolvidos para o MEF. Na tentativa de obter métodos mais adequados para o MEC, Noronha e Pereira (2003) apresentaram novos algoritmos específicos para a visualização com o MEC. Estes novos algoritmos combinam técnicas de computação gráfica e de análise não-linear, permitindo o uso de discretizações puramente em elementos de contorno e preservando as características básicas da simplicidade da modelagem com o MEC.

A modelagem da escavação seqüencial de túneis normalmente resulta em sistemas de grande escala, chegando a envolver milhares ou milhões de graus de liberdade (GOLSER, 2001). Nos últimos anos, diversos trabalhos têm sido propostos para acelerar a análise da escavação seqüencial. A maioria destas propostas faz uso de resolução iterativa dos sistemas de equações. Contudo, para modelos com um grande número de modificações na geometria, os ganhos obtidos pelos métodos 
iterativos são poucos, podendo tornar a análise inviável. No sentido de oferecer uma solução adequada para este problema, Noronha, Dünser e Beer (2007) desenvolveram um método para acelerar a escavação seqüencial. Este método deve ainda ser aprimorado e utilizado em modelos com mais de 10.000 graus de liberdade.

Enquanto as simulações do processo de escavação e do comportamento das estruturas de suporte de túneis sejam tópicos relativamente bem discutidos, as investigações sobre análises numéricas de maquinas tuneladoras (TBMs) ainda encontram-se em fase inicial. A escavação com TBMs envolve diversos efeitos mecânicos simultâneos que exigem modelos bastante elaborados. Nos últimos 15 anos, alguns trabalhos foram apresentados, entre eles os trabalhos de Barton (BARTON, 2000), Kasper (KASPER, 2004), Rostami; Ozdemir (ROSTAMI; OZDEMIR, 1996), Ozdemir; Nilsen (OZDEMIR; NILSEN, 1993), mas nenhum deles considerou uma modelagem completa de uma TBM.

\subsection{MÉtodo dos Elementos de CONTORNo}

O estudo da aplicação de técnicas de equações integrais como alternativa à resolução de equações diferenciais data desde o século XIX.

A equação integral que relacionou valores de contorno de deslocamentos e tensão foi estabelecida por Somigliana em 1886, a qual recebeu o nome de Identidade de Somigliana.

Fredholm deu o início em 1903 à aplicação das equações integrais para valores de problemas no contorno, usando equações integrais discretizadas em problemas de potencial harmônico, as quais fundamentaram as bases do MEC por aproximação indireta. A aproximação é definida como indireta por ter sido usada funções de densidades fictícias, ou seja, que não tinham sentido físico, mas puderam ser utilizadas para calcular quantidades físicas, como por exemplo, deslocamentos e tensões (GONÇALVES, 2006). 
$\mathrm{Na}$ formulação direta, as quantidades físicas reais do material são usadas como variáveis do problema, como deslocamentos e tensões, isto é, seus valores reais são usados desde o início, sem aproximações. O suporte principal para a formulação direta das equações de contorno do MEC foi a identidade de Somigliana.

Vários estudos em equações integrais para problemas de potencial e elasticidade começaram a surgir desde então através de livros e artigos de escritores russos, dos quais destacaram-se os trabalhos de Kellogg (KELLOGG, 1929), Muskhelisvili (MUSKHELISVILI, 1953), Mikhlin (MIKHLIN, 1957), Smirnov (SMIRNOV, 1964) e Kupradze (KUPRADZE, 1965).

Jaswon e Symm apresentaram em 1963 uma técnica aproximada de solução das equações integrais de contorno de Fredholm. Esta técnica consistia em discretizar o contorno em uma série de pequenos elementos lineares. Em seguida, as equações integrais de contorno de um problema potencial governado pela equação de Laplace eram aplicadas a um número particular de nós. A função potencial foi considerada constante sobre cada elemento. A técnica de integração usada foi a regra de Simpson, exceto para as integrais singulares, que foram tratadas analiticamente. Um sistema de equações lineares foi obtido e, assim, as incógnitas do problema foram determinadas. Os referidos autores propuseram uma formulação mais geral, através da aplicação da terceira identidade de Green, com potenciais e suas derivadas desconhecidas de contorno (BREBBIA; DOMINGUES, 1992).

Rizzo (1967) realizou a primeira publicação sobre a técnica de aproximação direta do MEC, usando deslocamento e força de superfície em uma equação integral aplicada sobre o contorno, que explorou a analogia entre a teoria do potencial e a teoria da elasticidade clássica e projetou a aproximação numérica para solucionar o problema. Ele utilizou elementos lineares para discretizar o contorno, onde as funções, agora de deslocamentos e forças de superfície, eram consideradas constantes sobre cada elemento. A técnica de integração usada foi a regra de Simpson para integrais não singulares. Cruse (1969) expandiu o trabalho de Rizzo (1967), para problemas tridimensionais, onde ele discretizou a superfície em elementos triangulares com os valores de deslocamentos e forças de superfície, considerados constantes sobre cada elemento. 
Lachat propôs em 1975 a utilização de polinômios de grau mais alto com funções de densidade que puderam trazer melhores resultados. Tal proposta foi implementada nos trabalhos de Lachat \& Watson (LACHAT; WATSON, 1975 e LACHAT; WATSON, 1976). Mais tarde outros trabalhos, como o de Cruse \& Wilson (CRUSE; WILSON, 1978), passaram a usar elementos isoparamétricos quadráticos, onde tanto a geometria do contorno como as funções densidade eram aproximadas por funções quadráticas.

Hansen (1976) apresentou a análise de placas infinitas com furos e contorno não carregado através do método direto. Ele utiliza duas equações integrais, uma correspondente à expressão do deslocamento e outra correspondente à sua derivada em relação a uma direção qualquer.

Cruse (1977) apresentou uma representação bidimensional de tensão, semelhante à identidade de Somigliana e a denominou de identidade de Somigliana para tensões.

Durante a década de 60 , as soluções apresentadas para as equações integrais de contorno eram do conhecimento, quase que exclusivo, dos cientistas matemáticos e físicos. Com isso, poucos trabalhos foram aplicados a problemas reais de engenharia. Hess e Smith em 1967 desenvolveram um trabalho, que na época foi considerado como o início de um novo método para soluções de problemas gerais de engenharia (BREBBIA; DOMINGUES, 1992). Porém, somente por volta dos anos 80 , os nomes das equações integrais de contorno e método das equações integrais passaram a serem chamadas por Método dos Elementos de Contorno (MEC) a partir dos trabalhos de Brebbia (BREBBIA, 1978) e Banerjee \& Butterfield (BANERJEE; BUTTERFIELD, 1981).

Brebbia (1978) fez uma generalização do MEC, apresentando uma formulação onde as relações de integrais podiam ser obtidas a partir da técnica dos resíduos ponderados. Com isso, tornou-se mais fácil relacionar e combinar o MEC com outros métodos numéricos, como MEF, por exemplo.

O MEC é aplicado para obter soluções de diversos problemas, inclusive para elementos estruturais tipo placas, onde estes têm sido tratados com boa eficiência. 
O estudo intensivo das placas com o MEC ocorreu em 1979 com os trabalhos de Stern e Tottenhan. Costa e Brebbia empregaram em 1984 o método direto na formulação desenvolvida para resolver problemas de placas tais como: flexão, vibração e flambagem (SIMÕES, 2001).

Palermo Jr. (1989) apresentou um trabalho sobre a analise elástica de placas, onde houve uma conexão nas formulações do Método dos Elementos de Contorno entre a teoria clássica e a de Mindlin.

O estudo de placas segundo a teoria clássica, levando em consideração a não linearidade geométrica foi apresentado no trabalho de Simões (SIMÕES, 2001). Neste trabalho foram feitas análises para diferentes condições de contorno, inclusive na obtenção das freqüências naturais das placas utilizando a teoria das vibrações livres.

Vários trabalhos no campo da mecânica da fratura com aplicação do Método dos Elementos de Contorno foram apresentados.

Cruse e Van Buren demonstraram uma análise de trinca por modelo de trinca elíptica em 1969. Porém, esta análise apresentou erros. Blandford et al apresentou um método aplicável para presença de duas superfícies de trincas coplanares em 1981 (FIGUEIREDO E ALMEIDA, 2003).

Portela, Aliabadi e Rooke desenvolveram o Método dos Elementos de Contorno Dual para problemas de corpos de trincas bidimensionais em 1992. No caso de corpos com trincas tridimensionais, destaca-se o trabalho de Mi \& Aliabadi, também em 1992 (GONÇALVES, 2006).

Watson apresentou um estudo da utilização direta do Método dos Elementos de Contorno aplicado a problemas de fissuras no estado plano de deformação em 1995 (FIGUEIREDO E ALMEIDA, 2003).

A aplicação do MEC na engenharia de túneis foi apresentada anteriormente no item 2.1 . 
Todos estes trabalhos foram essenciais para fundamentar e demonstrar que 0 Método dos Elementos de Contorno é uma ferramenta numérica de aproximação de elevada precisão.

No Departamento de Estruturas e Geotécnica da Escola Politécnica da Universidade de São Paulo, pesquisas com o MEC vêm sendo desenvolvidas, sob orientação do Prof. Marcos Noronha, o que já resultou em alguns trabalhos, como:

A. M. B. Pereira, "Avanços na Visualização, Análise Não-Linear e Programação com o Método dos Elementos de Contorno", Dissertação de mestrado, EPUSP, São Paulo, Brasil, 2004.

A. S. Muller, "Um Novo Algoritmo para Análises Não-Lineares Utilizando o Método dos Elementos de Contorno", Dissertação de mestrado, EPUSP, São Paulo, Brasil, 2004.

C. P. G. Souza, "Análise de alta precisão em modelos tridimensionais de elementos de contorno utilizando técnicas avançadas de integração numérica", Dissertação de mestrado, EPUSP, São Paulo, Brasil, 2007.

N. Carbone, "Desenvolvimento de um novo algoritmo para análise viscoplástica com o método dos elementos de contorno", Dissertação de mestrado, EPUSP, São Paulo, Brasil, 2007. 


\section{FUNDAMENTAÇÃO TEÓRICA}

O objetivo principal deste capítulo é fornecer uma visão geral da base teórica utilizada para o desenvolvimento da pesquisa. Com isso, serão abordados nesta etapa do trabalho: Escavação de Túneis, Modelos Reológicos, Método dos Elementos de Contorno e Problemas de Multi-Regiões.

\subsection{Escavação de TÚNEIS}

A abertura de um túnel em um maciço previamente em equilíbrio, submetido a uma configuração inicial de tensões, pode ser compreendida como a remoção das tensões existentes no contorno da escavação realizada. Essa remoção implica em uma redistribuição das tensões no maciço, que busca uma nova configuração de equilíbrio. $O$ equilíbrio estabelecido pode ser alcançado sem a utilização de um sistema auxiliar de suporte, neste caso trata-se de um maciço classificado como autoportante. Do contrário, como ocorre na maioria dos casos, faz-se necessário o auxilio de um sistema de suporte, como por exemplo, a adoção de uma estrutura de concreto projetado no contorno da escavação.

A interação entre o maciço e a estrutura de suporte constitui um sistema hiperestático, cujo estado de tensão-deformação é de difícil determinação. As deformações permitidas ao maciço antes e após a colocação da estrutura de suporte implicam em redistribuições de tensões para zonas vizinhas não escavadas do maciço. Este fenômeno é conhecido como arqueamento de tensões. O carregamento atuante no suporte, os esforços nele mobilizados e os deslocamentos que nele ocorrem são interdependentes e correlacionados, não sendo apenas função das tensões iniciais e das características geométricas da abertura, mas também das propriedades mecânicas do maciço que envolve o túnel, do sistema de escavação adotado, da velocidade de avanço, o tipo e as características do suporte e o momento de sua colocação. 
O arqueamento de tensões citado anteriormente, ocorre quando há resistência ao cisalhamento do maciço envolvente à abertura realizada. Para visualizar melhor o arqueamento de tensões a Figura 3.1 apresenta os elementos A, B e C situados numa faixa de solo imediatamente acima da calota de um túnel, no contorno da escavação. Antes da realização da abertura, esses elementos situam-se exatamente no perímetro da escavação. Após a realização da abertura, o elemento $A$ desloca-se mais do que o elemento $B$, que, por sua vez, desloca-se mais do que o elemento $C$. Essa diferença de deslocamento induz tensões de cisalhamento entre os elementos. Se o maciço, devido ás suas propriedades geomecânicas, for incapaz de resistir ao cisalhamento, os elementos deslocam-se por igual, assim como todo contorno da escavação, e consequentemente o túnel entra em colapso.

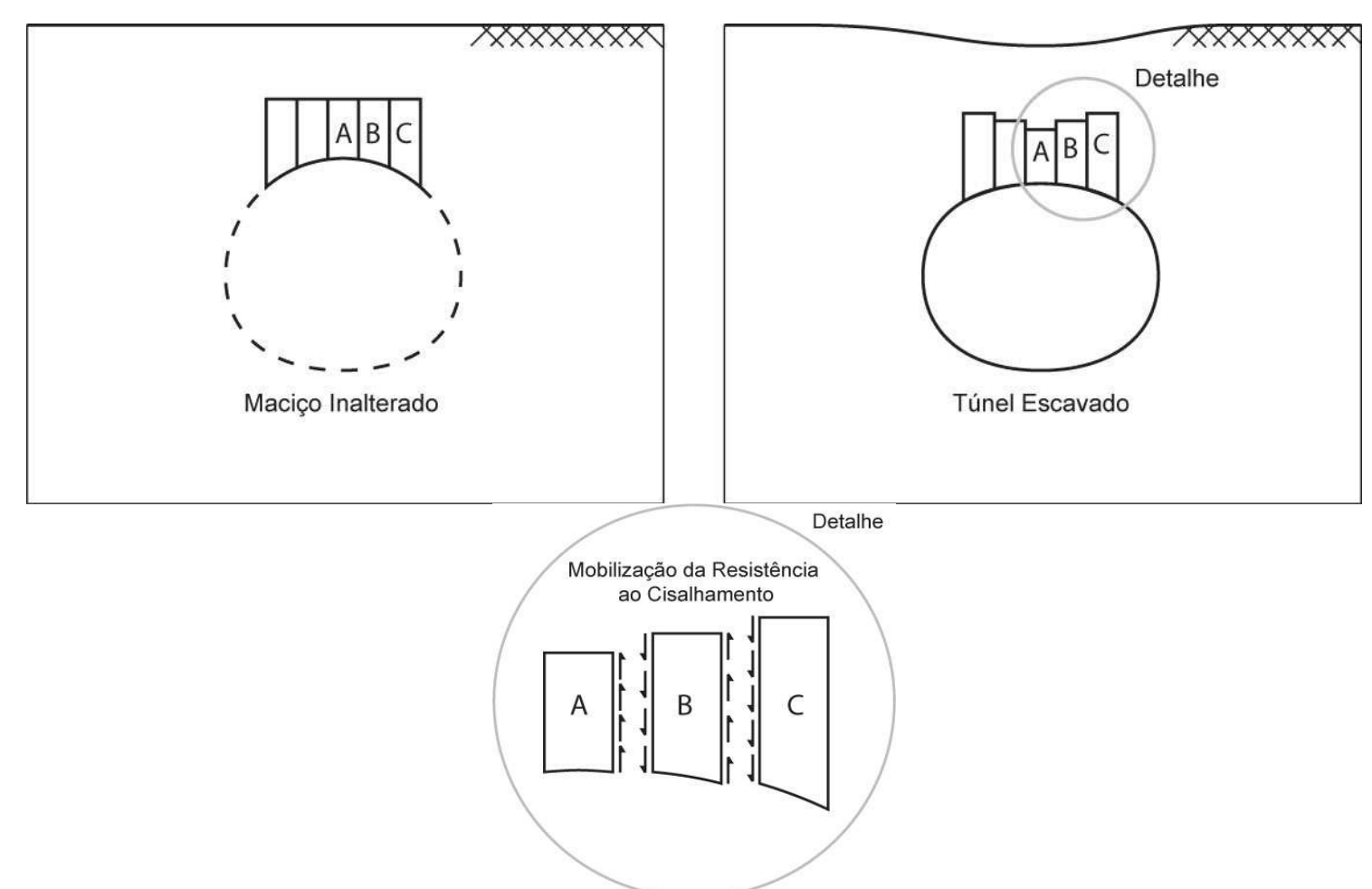

Figura 3.1 - Efeito arco: mobilização da resistência ao cisalhamento do maciço $0^{5}$.

Na maioria dos casos, antes da realização da abertura dos túneis, as direções das tensões principais coincidem com os eixos verticais e horizontais (Figura 3.2). As direções dos eixos principais de tensões indicam as direções dos planos onde não ocorrem tensões de cisalhamento, apenas tensões normais.

\footnotetext{
5 fonte: França, P. T, "Estudo do comportamento de túneis: Análise numérica tridimensional com modelo elasto-plástico", São Paulo, 2006.
} 
Portanto, pode-se concluir que, antes da escavação, em uma situação ideal, não existem tensões de cisalhamento nos planos verticais e horizontais do maciço. Como já citado anteriormente, após a execução da escavação, são mobilizadas tensões de cisalhamento nos arredores da abertura, inclusive nos planos verticais e horizontais, fazendo com que as direções das tensões principais na região afetada pela abertura sofram rotações, uma vez que os planos onde não ocorrem tensões de cisalhamento nessa região não coincidem mais com os planos verticais e horizontais (FRANÇA, 2006).

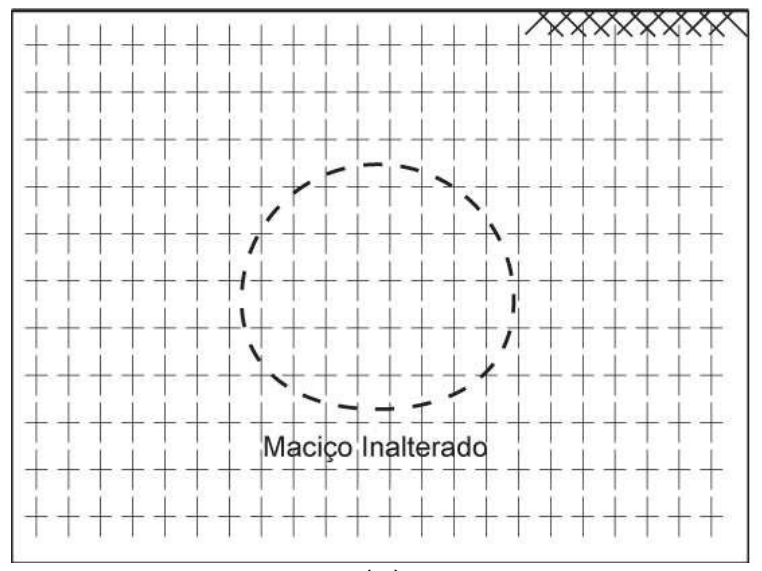

(a)

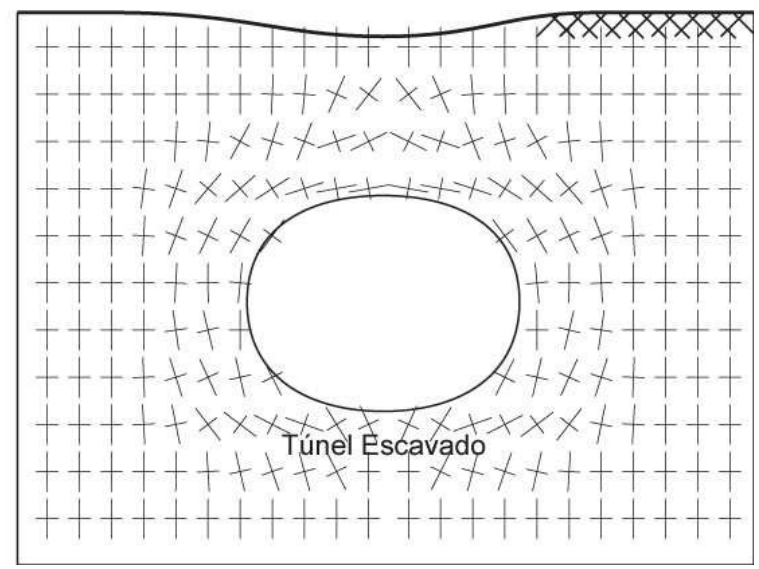

(b)

Figura 3.2 - Direção das tensões principais: (a) antes da escavação; (b) após a escavação ${ }^{6}$.

O avanço da escavação de um túnel provoca um movimento de todo o maciço para o interior da cavidade criada. Sendo assim, fica claro que adiante da frente de escavação já ocorre influência da abertura realizada.

Segundo Galli, Grimaldi \& Leonardi (2004), passada a frente de escavação, a distância onde ocorrerá o estabelecimento do equilíbrio e a condição do estado plano de deformação é função das características geomecânicas do maciço e do sistema de suporte adotado.

Quanto menor a resistência do maciço, maior é o desenvolvimento da zona plastificada e consequentemente maior a distância exigida para se atingir a condição de equilíbrio e de estado plano de deformação.

\footnotetext{
${ }^{6}$ fonte: França, P. T, "Estudo do comportamento de túneis: Análise numérica tridimensional com modelo elasto-plástico", São Paulo, 2006.
} 
Com relação ao sistema de suporte utilizado, quanto mais rígido ele for e quanto mais rápido ele for instalado, mais rápido se dará o estabelecimento da situação de equilíbrio, o que é bem intuitivo.

$\mathrm{Na}$ maioria dos casos práticos, o efeito da escavação é sentido até aproximadamente dois diâmetros adiante e dois diâmetros atrás da frente de escavação, conforme mostra a Figura 3.3 .

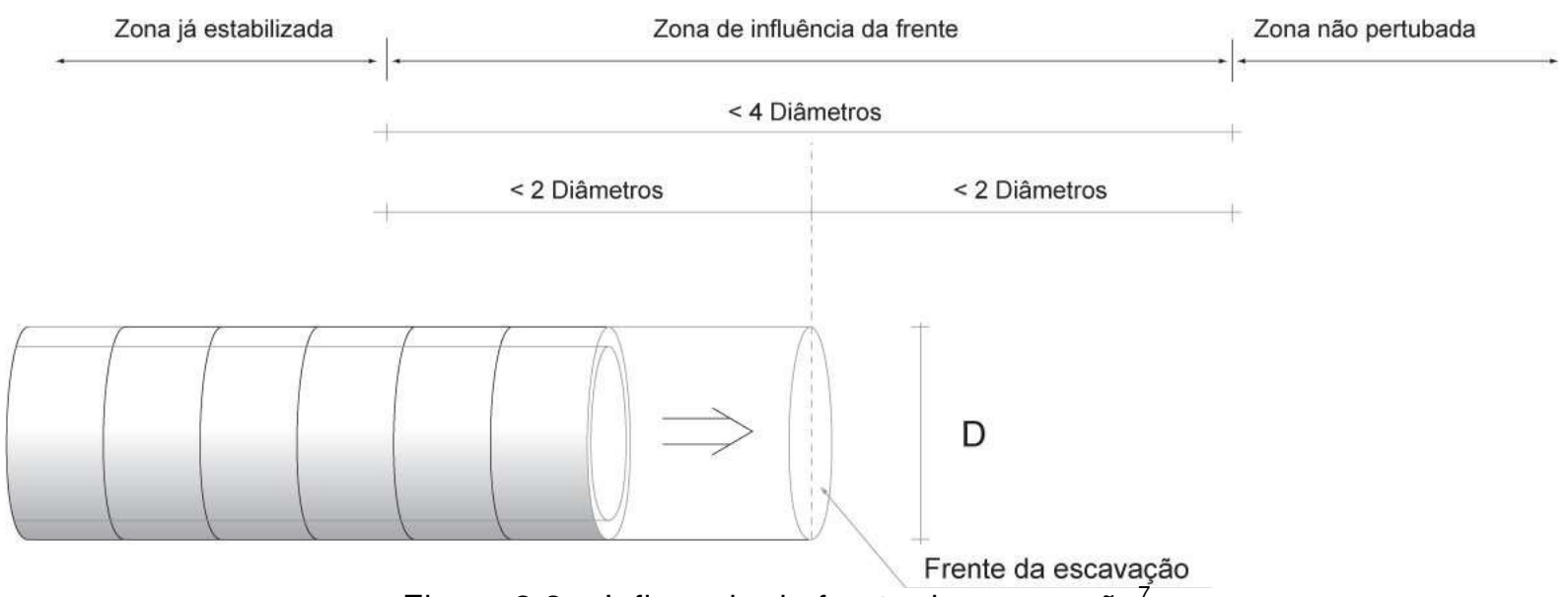

Figura 3.3 - Influencia da frente de escavação ${ }^{7}$.

\subsubsection{PRINCIPAIS Sistemas de EscaVAÇÃo de TÚNEIS}

Existem várias linhas distintas de sistemas de escavação de túneis, como a escavação a fogo e a escavação mecanizada, por exemplo. Atualmente destacamse como principais métodos de escavação de túneis, a escavação mecanizada com TBMs (Tunnel Boring Machines) e o NATM (New Austrian Tunnelling Method). A descrição do presente trabalho se resumirá nestes dois métodos.

Vários fatores influenciam na escolha do sistema de escavação de túneis, entre eles a características do maciço, o prazo para execução, o fator financeiro e os riscos ambientais.

\footnotetext{
7 fonte: França, P. T, "Estudo do comportamento de túneis: Análise numérica tridimensional com modelo elasto-plástico", São Paulo, 2006.
} 


\subsubsection{Máquinas Tuneladoras - TBMs (Tunnel Boring Machines)}

A execução de túneis com escavação mecânica tem sido cada vez mais constante, principalmente em obras de grandes dimensões, onde os métodos tradicionais com uso de explosivos ou escavadeiras tornam-se inviáveis ou pouco eficazes devido aos riscos de acidentes e aos impactos ambientais. Escavar túneis em centros urbanos exige um desafio ainda maior, principalmente porque os impactos causados durante a perfuração devem ser minimizados para que não haja danos em estruturas já existentes. Em casos como este, a escavação com máquinas tuneladoras (TBMs) tem se mostrado muito eficiente (SAMPAIO; OLIVEIRA; NORONHA, 2008).

TBMs têm sido empregadas com sucesso em túneis feitos em diversas condições de terreno em todo o mundo. A sua eficiência depende do seu projeto e das características e propriedades do maciço. Análises e estudos prévios devem ser feitos para que a escavação aconteça de modo a atender às diversas condições geológicas. Em geral, os maciços, cujas resistências da rocha intacta não ultrapassam $30 \mathrm{MPa}$, podem ser escavados por escarificação mecânica. A Figura 3.4 ilustra uma máquina tunelarora, que de forma simplificada pode ser comparada a uma máquina perfuratriz de grande diâmetro.

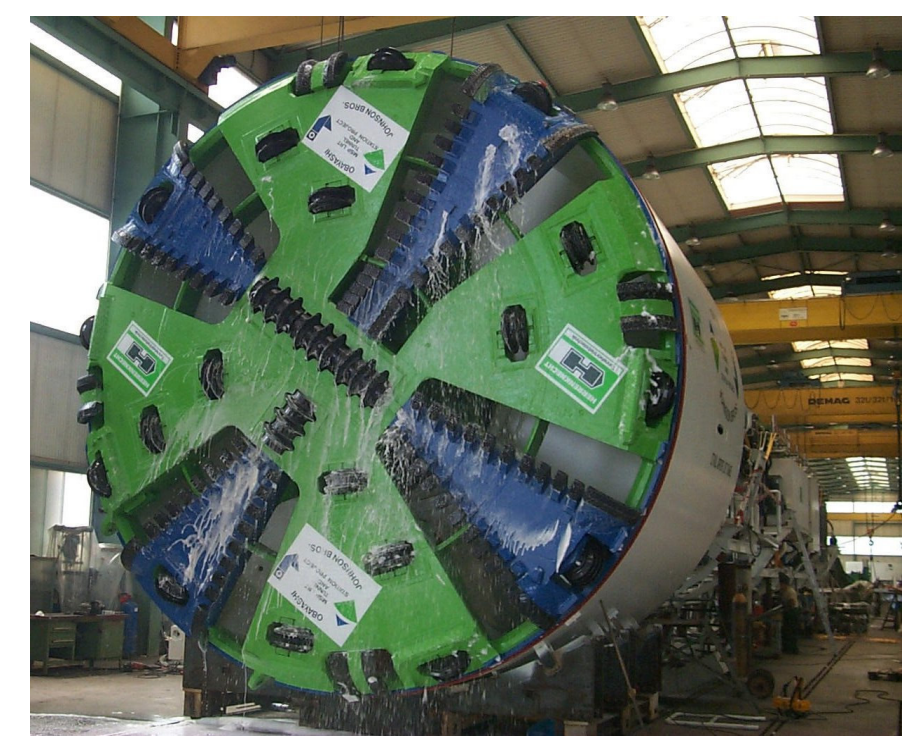

Figura 3.4 - Máquinas Tuneladoras - Tunnel Boring Machines ${ }^{8}$.

\footnotetext{
8 fonte: Www.gomezinternational.com/, acessado em: 30/08/2008.
} 
A escavação de túneis em rocha com TBMs causa distúrbios mecânicos nas imediações das zonas de interação máquina-rocha, como o efeito da Mecânica do Contato, por exemplo. O entendimento dos problemas de contato associados ao suporte e avanço destas máquinas é essencial para as etapas de dimensionamento e verificação de projetos de túneis.

O método construtivo da escavação de túneis com TBMs consiste, de forma bem resumida, na escavação mecânica através de máquinas dotada de cabeça giratória, acionada por motores elétricos. Na parte posterior da máquina são executados o revestimento em concreto projetado, ou então colocados tubos de concreto prémoldados, que são cravados sucessivamente no solo pelo conjunto de macacos hidráulicos.

\subsubsection{NATM (New Austrian Tunnelling Method)}

O NATM consiste na escavação seqüencial do maciço, utilizando concreto projetado como suporte, associado a outros elementos como cambotas metálicas, chumbadores e fibras no concreto. Estes elementos são determinados em função da capacidade autoportante do maciço.

A utilização do concreto projetado com acelerador de pega como elemento de suporte foi feita quando se imaginou que somente um material suficientemente plástico no momento da aplicação seria capaz de preencher as cavidades mais irregulares, que pudesse ser aplicado imediatamente após a escavação, e que oferecesse uma elevada rigidez e resistência em pouco tempo. O concreto projetado atua por forte aderência ao terreno, imobilizando os seus elementos formadores (blocos) e obrigando o maciço a suportar o carregamento em integração com o suporte (GOMES, 2006).

Quando o NATM é escolhido como método construtivo para escavação de um túnel, torna-se necessário observar os princípios que regem este sistema, portanto, é importante salientar que o principal suporte de um túnel é o maciço que o circunda. Deve-se mobilizar ao máximo a capacidade portante do maciço circunvizinho à abertura, formando um anel de estabilização em conjunto com o suporte. 
As deformações do maciço e do suporte devem ser rigorosamente observadas e controladas, evitando-se assim um processo de deterioração e relaxamento do maciço. O suporte que interage com o maciço deve ser aplicado no tempo correto, ou seja, respeitando as características geomecânicas do maciço, e a rigidez do mesmo deve ser compatível com o maciço, de maneira a restringir dentro de limites seguros as deformações. Na Figura 3.5 apresenta-se a seqüência construtiva típica em NATM.
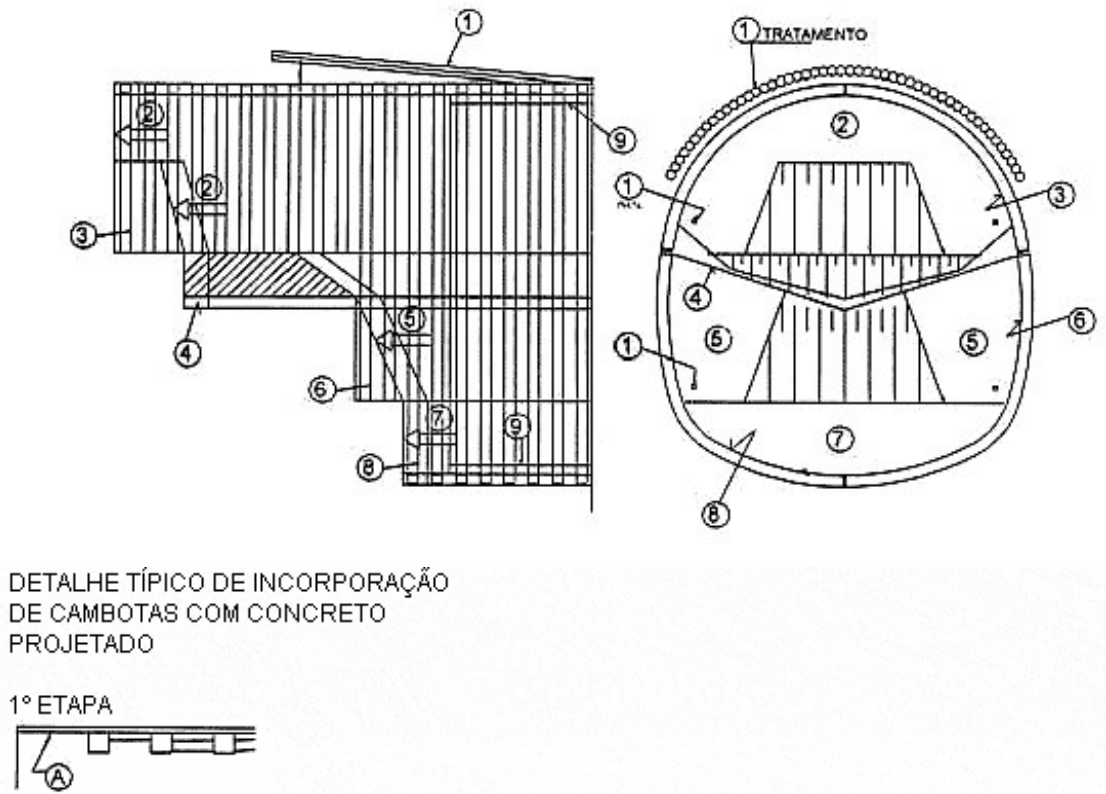

A - APLICAÇÃO DE UMA CAMADA DE CONCRETO

PROJETADO SOBRE A SUPERFÍCIE ESCAVADA

SEQUENNCIA EXECUTIVA

1 EXECUTAR TRATAMENTOS E DHP'S

2- ESCAVAR AVANÇO NA $1 / 2$ SESSÃO

3- INSTALAÇÃ́O CAMBOTA + CONCRETO PROJETADO DA $1 / 2$

4- EXECUTAR O ARCO INVERTIDO PROVISÓRIO

5- ESCAVAR O REBAIXO EM NICHOS LATERAIS

6- INSTALAR CAMBOTA + CONCRETO PROJETADO DO REBAIXO

7- ESCAVAR O ARCO INVERTIDO DEFINITIVO

8- FECHAR A CAMBOTA + CONCRETO PROJETADO DO ARCO

9- EXECUTAR REVESTIMENTO FINAL

C - EXECUÇÄO PARCIAL DA $2^{\circ}$ CAMADA DE CONCRETO PROJETADO

D - COMPLEMENTAÇÃO DA $2^{\circ}$ CAMADA DE CONCRETO PROJETADO NO PASSO ANTERIOR

Figura 3.5 - Seqüência construtiva típica de um túnel pelo método construtivo NATM ${ }^{9}$.

\footnotetext{
9 fonte: http://www.metro.sp.gov.br/, acessado em: 30/08/2008.
} 


\subsection{MOdelos ReolóGicos}

A Teoria dos Materiais engloba o estudo de modelos microscópicos e macroscópicos. Os modelos microscópicos são muito importantes para o entendimento dos processos mecânicos assim como no desenvolvimento de novos materiais, sejam eles homogêneos ou compostos. Os modelos macroscópicos descrevem o comportamento mecânico dos materiais sem a preocupação de explicar a sua origem físico-química (PIMENTA, 2002). Neste trabalho, está-se interessado preponderantemente neste aspecto da teoria.

Vários trabalhos de pesquisa avançam na construção de relações constitutivas mais aprimoradas, devido à complexidade do comportamento real da maioria dos materiais utilizados nas estruturas e da necessidade de se obter melhores representações destes materiais. Entretanto, caracterizar e equacionar o comportamento dos materiais de forma exata é uma tarefa difícil de ser alcançada. Dessa forma, torna-se necessário a adoção de modelos simplificados que proporcionem soluções suficientemente próximas do comportamento real das estruturas.

Embora exista uma grande variedade de modelos disponíveis, neste trabalho os modelos reológicos serão limitados aos descritos neste capítulo, visto que eles representam satisfatoriamente o comportamento dos materiais utilizados na prática.

As formulações que serão apresentadas têm como base os trabalhos: (CARBONE, 2007), (MÜLLER, 2004), (PIMENTA, 2002) e (VENTURINI, 1983).

\subsubsection{MODELOS BÁSICOS}

Materiais diferentes, submetidos às mesmas condições, apresentam comportamentos diferentes. Do ponto de vista matemático, as Equações 
Constitutivas são relações entre grandezas físicas que procuram introduzir em um modelo mecânico as propriedades dos materiais (PIMENTA, 2002).

Os modelos básicos em geral são facilmente compreendidos devido ao fato dos mesmos serem definidos por relações matemáticas simples. A combinação destes modelos forma representações mais complexas e interessantes que retratam de forma mais realista o comportamento de um material. A Figura 3.6 mostra os três modelos básicos: elástico, plástico e viscoso.

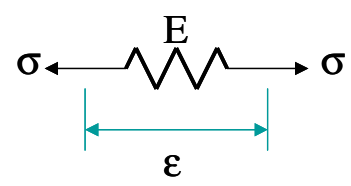

a)

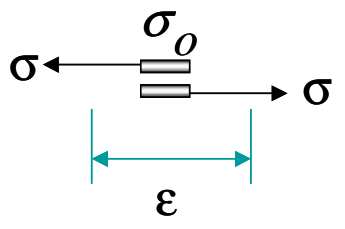

b)

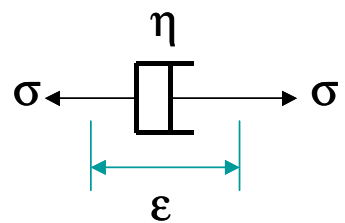

c)

Figura 3.6 - Modelos básicos unidimensionais: (a) Elástico, (b) Plástico, (c) Viscoso.

O modelo elástico, representado por uma mola (Figura 3.6a), é caracterizado pelo aparecimento de deformações elásticas instantâneas devido à aplicação de uma solicitação estática. Este modelo é adequado para materiais cujo comportamento não varia com o tempo e que em situações de descarregamento não apresentem deformações residuais. Na elasticidade linear a relação constitutiva é expressa pela lei de Hooke. Assim tem-se que:

$$
\sigma_{\mathrm{ij}}=C_{i j}^{l m} \varepsilon_{l m}
$$

onde $\sigma_{i j}$ são as tensões, $\varepsilon_{l m}$ as deformações e $C_{i j}^{l m}$ é a matriz constitutiva elástica.

O modelo plástico (Figura 3.6b), também conhecido como modelo plástico de SaintVenant é representado por um sólido que desliza com atrito sobre uma superfície, a partir do instante que a tensão aplicada ultrapassa o valor $\sigma_{0}$ (tensão de plastificação). O valor de $\sigma_{0}$ representa o valor absoluto da tensão necessária para provocar o deslocamento do sólido do modelo e é denominado resistência. 
A verificação da ocorrência do fenômeno de plastificação pode ser feita através de uma função da tensão $F\left(\sigma_{i j}\right)$, denominada de critério de resistência. Quando $F\left(\sigma_{i j}\right)<0$, diz-se que o material está num estado rígido e quando $F\left(\sigma_{i j}\right)=0$, diz-se que ele está num estado plástico apresentando deformações irreversíveis e imediatas.

O modelo viscoso (Figura 3.6c) é também conhecido por modelo viscoso de Newton, o qual é representado por um amortecedor. Este modelo fica caracterizado pelo comportamento dependente do tempo, ou seja, mesmo que as solicitações sejam constantes, as deformações dependerão do tempo. Neste caso, tem-se que:

$$
\sigma_{\mathrm{ij}}=\eta_{i j}^{l m} \dot{\varepsilon}_{l m},
$$

onde $\eta_{i j}^{l m}$ é a matriz viscosa escrita em função de parâmetros do material viscoso, os quais são determinados experimentalmente, e $\dot{\varepsilon}_{l m}$ é a velocidade de deformação.

\subsubsection{MOdELO ELASTOPLÁStico de PRANDTL-REUSS}

Este modelo é obtido pela associação em série de um modelo elástico com um modelo plástico, conforme a Figura 3.7 ilustra. Uma associação em série significa que os dois elementos estão submetidos à mesma tensão e que a deformação total é a soma das deformações dos elementos (PIMENTA, 2002).

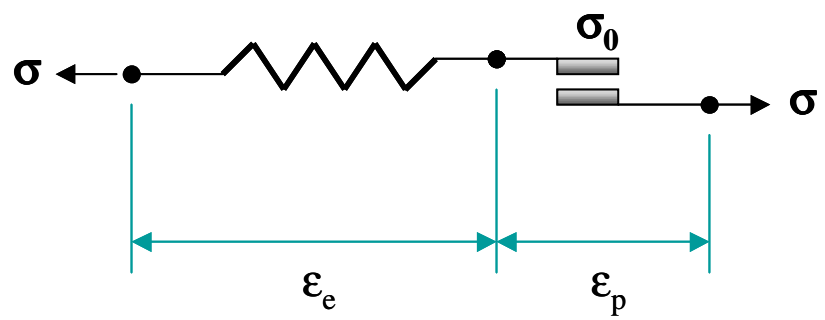

Figura 3.7 - Modelo Elastoplástico Perfeito. 
A deformação total é a soma das deformações dos elementos. Logo, tem-se:

$$
\varepsilon_{l m}=\varepsilon_{l m}^{e}+\varepsilon_{l m}^{p}
$$

onde $\varepsilon_{l m}, \varepsilon_{l m}^{e}$ e $\varepsilon_{l m}^{p}$ são respectivamente deformações totais, elásticas e plásticas.

Por sua vez, as tensões são dadas por:

$$
\sigma_{i j}=C_{i j}^{l m} \varepsilon_{l m}^{e}=C_{i j}^{l m}\left(\varepsilon_{l m}-\varepsilon_{l m}^{p}\right)=C_{i j}^{l m} \varepsilon_{l m}-\sigma_{i j}^{p}
$$

Normalmente realiza-se a caracterização do comportamento elastoplástico através da função de plastificação $F$. Quando $F<0$, diz-se que o material está num estado elástico. Quando $F=0$, diz-se que ele está num estado elastoplástico. O modelo elastoplástico é invíscido e apresenta deformações permanentes imediatas sempre que as tensões atingirem a resistência $\sigma_{0}$. Para a obtenção da formulação elastoplástica do MEC para o modelo em questão, a relação (3.4) deve ser imposta no desenvolvimento da equação integral do MEC.

\subsubsection{MOdELO VISCOELÁSTICO DE KELVIN-VOIGT}

O modelo de Kelvin-Voigt (Figura 3.8) associa em paralelo um modelo elástico e um viscoso. Por uma associação em paralelo entende-se que ambos os modelos estarão submetidos à mesma deformação e que a soma das tensões em cada modelo é igual a tensão $\left(\sigma_{i j}\right)$ aplicada à associação.

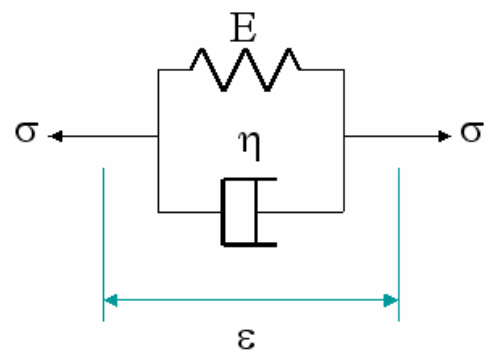

Figura 3.8 - Modelo Viscoelástico de Kelvin-Voigt. 
Portanto, temos que as deformações totais, elásticas e viscosas são iguais. Já as tensões são definidas pela soma das tensões viscosas (no amortecedor) e das tensões elásticas (na mola), então:

$$
\begin{gathered}
\varepsilon_{l m}=\varepsilon_{l m}^{e}=\varepsilon_{l m}^{v} \mathrm{e} \\
\sigma_{i j}=\sigma_{i j}^{e}+\sigma_{i j}^{v} .
\end{gathered}
$$

A tensão elástica $\sigma_{i j}^{e}$ e a tensão viscosa $\sigma_{i j}^{v}$ podem ser definidas como:

$$
\begin{gathered}
\sigma_{i j}^{e}=C_{i j}^{l m} \varepsilon_{l m} \mathrm{e} \\
\sigma_{i j}^{v}=\eta_{i j}^{l m} \dot{\varepsilon}_{l m} .
\end{gathered}
$$

Para materiais isotrópicos, a matriz constitutiva elástica $C_{i j}^{l m}$ e a matriz viscosa $\eta_{i j}^{l m}$ podem ser definidas pelas expressões abaixo:

$$
\begin{aligned}
& C_{i j}^{l m}=\lambda \delta_{i j} \delta_{l m}+\mu\left(\delta_{i l} \delta_{j m}+\delta_{i m} \delta_{j l}\right) \mathrm{e} \\
& \eta_{i j}^{l m}=\theta_{\lambda} \lambda \delta_{i j} \delta_{l m}+\theta_{\mu} \mu\left(\delta_{i l} \delta_{j m}+\delta_{i m} \delta_{j l}\right),
\end{aligned}
$$

onde $\theta_{\lambda}$ e $\theta_{\mu}$ são coeficientes representativos da viscosidade do material. Já os termos $\lambda$ e $\mu$ são as constantes de Lamé, dadas por:

$$
\begin{aligned}
& \lambda=\frac{v E}{(1+v)(1-2 v)} \mathrm{e} \\
& \mu=G=\frac{E}{2(1+v)} .
\end{aligned}
$$

Os termos $v, E$ e $G$ são, respectivamente, coeficiente de Poisson, módulos de elasticidade longitudinal e transversal. 
Na maioria dos problemas práticos a matriz viscosa pode ser apresentada por um único parâmetro viscoso $\gamma$. Com isso temos que:

$$
\eta_{i j}^{l m}=\gamma\left[\lambda \delta_{i j} \delta_{l m}+\mu\left(\delta_{i l} \delta_{j m}+\delta_{i m} \delta_{j l}\right)\right]=\gamma C_{i j}^{l m}
$$

Logo,

$$
\sigma_{i j}=C_{i j}^{l m} \varepsilon_{l m}+\gamma C_{i j}^{l m} \dot{\varepsilon}_{l m}
$$

Como será apresentado no item 3.3.2, para a obtenção da formulação viscoelástica do MEC específica para o modelo de Kelvin-Voigt, a relação (3.14) deve ser imposta no desenvolvimento da equação integral do MEC.

\subsubsection{MODELO VISCOELÁSTICO DE TRÊS PARÂMETROS}

Este modelo associa em série um modelo elástico e um modelo de Kelvin-Voigt, conforme mostra a Figura 3.9. O modelo de três parâmetros também é conhecido por Modelo de Boltzmann. Este modelo tem capacidade de simular deformações instantâneas.

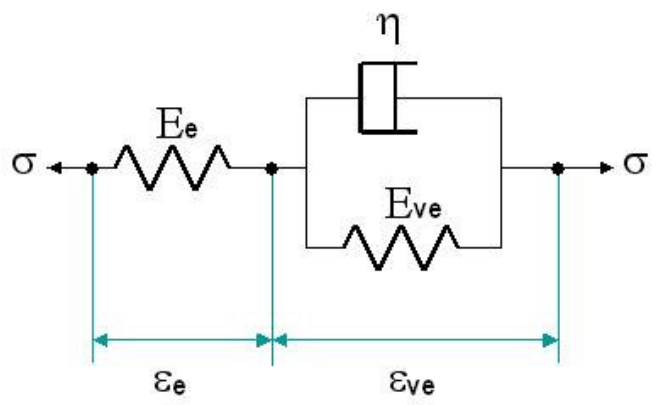

Figura 3.9 - Modelo Viscoelástico de Três Parâmetros.

A deformação total é dada por:

$$
\varepsilon_{l m}=\varepsilon_{l m}^{e}+\varepsilon_{l m}^{v e},
$$

onde $\varepsilon_{l m}$ representa as deformações totais, $\varepsilon_{l m}^{e}$ representa as deformações no modelo elástico e $\varepsilon_{l m}^{v e}$ representa as deformação no modelo de Kelvin-Voigt. 
Já a relação entre as tensões fica expressa por:

$$
\sigma_{i j}=\sigma_{i j}^{e}=\sigma_{i j}^{v e},
$$

onde $\sigma_{i j}$ representa as tensões totais, $\sigma_{i j}^{v e}$ representa as tensões viscoelásticas e $\sigma_{i j}^{e}$ representa as tensões elásticas.

Adota-se a hipótese de que o coeficiente de Poisson é igual em ambos os trechos. Com isso, podem-se definir as tensões elásticas e viscosas pelas seguintes expressões:

$$
\begin{gathered}
\sigma_{i j}^{e}=\bar{C}_{i j}^{l m} \mathcal{E}_{l m}^{e}=E_{e} C_{i j}^{l m} \mathcal{E}_{l m}^{e}, \\
\sigma_{i j}^{e l}=\hat{C}_{i j}^{l m} \varepsilon_{l m}^{v e}=E_{v e} C_{i j}^{l m} \varepsilon_{l m}^{v e} \mathrm{e} \\
\sigma_{i j}^{v}=\eta_{i j}^{l m} \dot{\varepsilon}_{l m}^{v e}=\gamma E_{v e} C_{i j}^{l m} \dot{\varepsilon}_{l m}^{v e},
\end{gathered}
$$

onde $\sigma^{e l}$ representa as tensões referentes à mola em paralelo com o amortecedor e $\bar{C}_{i j}^{l m}$ e $\hat{C}_{i j}^{l m}$ são as matrizes constitutivas escritas em função do módulo elástico $E_{e} \mathrm{e}$ $E_{v e}$, respectivamente. Assim, temos que:

$$
\sigma_{i j}=\sigma_{i j}^{v e}=\sigma_{i j}^{e l}+\sigma_{i j}^{v}=E_{v e} C_{i j}^{l m} \varepsilon_{l m}^{v e}+\gamma E_{v e} C_{i j}^{l m} \dot{\varepsilon}_{l m}^{v e}
$$

Derivando no tempo (3.15), tem-se:

$$
\dot{\varepsilon}_{l m}=\dot{\varepsilon}_{l m}^{e}+\dot{\varepsilon}_{l m}^{v e} .
$$

Logo, com algumas manipulações algébricas tem-se:

$$
\sigma_{i j}=\frac{E_{e} E_{v e}}{E_{e}+E_{v e}} C_{i j}^{l m}\left(\varepsilon_{l m}+\gamma \dot{\varepsilon}_{l m}\right)-\frac{\gamma E_{v e}}{E_{e}+E_{v e}} \dot{\sigma}_{i j}
$$

sendo $\dot{\sigma}_{i j}$ a taxa de variação da tensão total ou velocidade de tensão total. 


\subsubsection{MODELO VISCOPLÁSTICO (SEM COMPORTAMENTO INSTANTÂNEO)}

Este modelo é representado pelo arranjo em paralelo de um modelo de PrandtlReuss, com um modelo viscoso simples, como mostra a Figura 3.10.

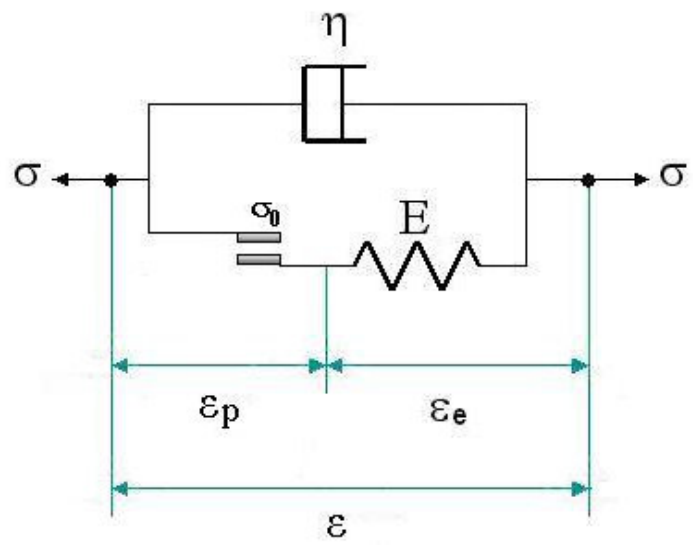

Figura 3.10 - Modelo Viscoplástico (sem comportamento instantâneo).

Assim, as deformações são dadas por:

$\varepsilon_{l m}=\varepsilon_{l m}^{v}=\varepsilon_{l m}^{e}+\varepsilon_{l m}^{p} \Rightarrow \varepsilon_{l m}^{e}=\varepsilon_{l m}-\varepsilon_{l m}^{p}$.

As tensões totais são expressas pela seguinte expressão:

$\sigma_{i j}=\sigma_{i j}^{v}+\sigma_{i j}^{e p}$,

onde $\sigma_{i j}^{v}$ são as tensões viscosas e $\sigma_{i j}^{e p}$ são as tensões elastoplásticas, definidas por:

$\sigma_{i j}^{v}=\eta_{i j}^{l m} \dot{\varepsilon}_{l m}^{v}=\gamma C_{i j}^{l m} \dot{\varepsilon}_{l m} \mathrm{e}$

$\sigma_{i j}^{e p}=C_{i j}^{l m} \varepsilon_{l m}^{e}$

Sendo assim, a relação para este modelo reológico é obtida substituindo as equações (3.7) e (3.8) na equação (3.6), logo: 
$\sigma_{i j}=\gamma C_{i j}^{l m} \dot{\varepsilon}_{l m}+C_{i j}^{l m} \mathcal{\varepsilon}_{l m}^{e}=\gamma C_{i j}^{l m} \dot{\varepsilon}_{l m}+C_{i j}^{l m}\left(\varepsilon_{l m}-\varepsilon_{l m}^{e}\right)=C_{i j}^{l m}\left(\varepsilon_{l m}-\gamma \dot{\varepsilon}_{l m}\right)-\sigma_{i j}^{p}$.

O termo $\sigma_{i j}^{p}$ origina-se dos problemas de tensão inicial expresso por:

$\sigma_{i j}^{p}=C_{i j}^{l m} \mathcal{E}_{l m}^{p}$

Para obtenção da formulação viscoplástica do MEC, com o modelo sem comportamento instantâneo, a equação (3.27) deve ser imposta no desenvolvimento da equação integral do MEC.

\subsubsection{MODELO VISCOPLÁSTICO (COM COMPORTAMENTO INSTANTÂNEO)}

O modelo viscoplástico com comportamento instantâneo, diferencia-se do modelo mostrado anteriormente, pela capacidade de simular deformações elásticas instantâneas. O modelo é representado pelo arranjo em série de um modelo elástico simples com um modelo viscoplástico mostrado no item anterior. A Figura 3.11 mostra o modelo viscoplástico com comportamento instantâneo.

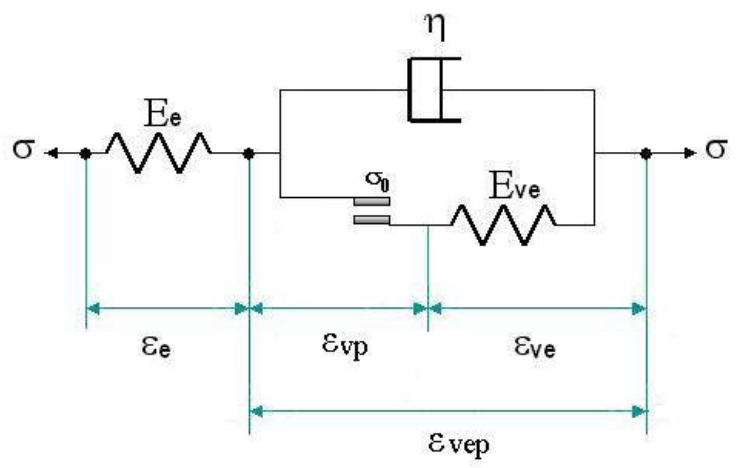

Figura 3.11 - Modelo Viscoplástico (com comportamento instantâneo).

Para este modelo as deformações são expressas por:

$\varepsilon_{i j}=\varepsilon_{i j}^{v e}+\varepsilon_{i j}^{e}+\varepsilon_{i j}^{v p} \Rightarrow \varepsilon_{i j}^{v e}=\varepsilon_{i j}-\varepsilon_{i j}^{v p}-\varepsilon_{i j}^{e}$. 
Por sua vez as tensões ficam expressas por:

$$
\sigma_{i j}=\sigma_{i j}^{v}+\sigma_{i j}^{e p}
$$

Considerando que o coeficiente de Poisson é igual em ambos os trechos do modelo, tem-se que:

$$
\begin{gathered}
\sigma_{i j}^{e p}=\bar{C}_{i j}^{l m} \mathcal{E}_{l m}^{v e}=E_{v e} C_{i j}^{l m} \mathcal{E}_{l m}^{v e}, \\
\sigma_{i j}^{e}=\hat{C}_{i j}^{l m} \mathcal{E}_{l m}^{e}=E_{e} C_{i j}^{l m} \mathcal{E}_{l m}^{e} \mathrm{e} \\
\sigma_{i j}^{v}=\eta_{i j}^{l m} \dot{\mathcal{E}}_{l m}^{v e p}=\gamma E_{v e} C_{i j}^{l m} \dot{\varepsilon}_{l m}^{v e p},
\end{gathered}
$$

Assim, tem-se que:

$$
\sigma_{i j}=E_{v e} C_{i j}^{l m} \mathcal{\varepsilon}_{l m}^{v e}+\gamma E_{v e} C_{i j}^{l m} \dot{\varepsilon}_{l m}^{v e p}
$$

A relação entre a velocidade de deformação de ambos os trechos do modelo são expressas por:

$$
\dot{\varepsilon}_{l m}=\dot{\mathcal{\varepsilon}}_{l m}^{e}+\dot{\mathcal{\varepsilon}}_{l m}^{v e}+\dot{\varepsilon}_{l m}^{v p}=\dot{\varepsilon}_{l m}^{e}+\dot{\mathcal{\varepsilon}}_{l m}^{v e p}
$$

Com algumas manipulações algébricas, chegamos a:

$$
\sigma_{i j}=\frac{E_{e} E_{v e}}{E_{e}+E_{v e}} C_{i j}^{l m}\left(\varepsilon_{l m}+\gamma \dot{\varepsilon}_{l m}\right)-\frac{\gamma E_{v e}}{E_{e}+E_{v e}} \dot{\sigma}_{i j}-\frac{E_{e}}{E_{e}+E_{v e}} \sigma_{i j}^{v p}
$$

O termo $\sigma_{i j}^{v p}$ é oriundo de problemas de tensão inicial, sendo expresso por:

$$
\sigma_{i j}^{v p}=E_{v e} C_{i j}^{l m} \mathcal{E}_{l m}^{v p}
$$

Existem outros modelos constitutivos viscoelásticos e viscoplásticos que podem ser construídos pela associação de modelos básicos, porém neste trabalho só serão utilizados os modelos básicos apresentados. 


\subsection{MÉtodo dos Elementos de Contorno}

Neste momento será apresentada uma revisão das formulações convencionais elastostática, viscoelástica, elastoplástica e viscoplástica utilizando o MEC. As formulações apresentadas a seguir foram baseadas em diversos trabalhos (BREBIA; DOMINGUES, 1992), (BEER, 2001), (BREBBIA; TELLES; WROBEL, 1984), (VENTURINI, 1983), (PEREIRA, 2004), (DE SOUZA, 2007) e (CARBONE, 2007).

\subsubsection{FORMULAÇÃo ELASTOSTÁtICA}

O cerne de uma formulação em elementos de contorno é reduzir a dimensionalidade do problema, isto é, a dimensão da representação do problema é transformada da dimensão do domínio para dimensão do contorno. Tal redução tem como vantagem a diminuição do tamanho dos sistemas a serem resolvidos numericamente (PEREIRA, 2004).

Os desenvolvimentos a seguir consideram um caso particular de um corpo elástico tendo um domínio $\Omega$ delimitado por um contorno $\Gamma$ que está sujeito a forças de superfície $\bar{t}$ em $\Gamma_{t}$ e deslocamentos $\bar{u}$ em $\Gamma_{u}$, como apresentados na Figura 3.12a. As condições de contorno do problema são:

Essenciais $\Rightarrow u_{i}=\bar{u}_{i}$ em $\Gamma_{u} \mathrm{e}$

Naturais $\Rightarrow p_{i}=\sigma_{i j} n_{j}=\bar{p}$ em $\Gamma_{t}$, onde $\Gamma=\Gamma_{u}+\Gamma_{t}$.

O MEC basicamente efetua a análise de problemas através da discretização do contorno $\Gamma$ do modelo, através de nós e elementos, conforme mostrado na Figura 3.12b. Primeiramente são analisados os valores de forças de superfície e deslocamentos para os nós dos elementos discretizados no contorno. A partir destes valores, obtêm-se os resultados em qualquer ponto do contorno através da interpolação em cada um dos elementos. 
Uma característica importante do MEC é o uso de uma solução especial da equação governante do problema chamada de Solução Fundamental que em parte é responsável pela eliminação da representação do domínio. Para análise de tensões, essa solução é associada ao problema de uma carga concentrada aplicada em um ponto $\mathrm{P}$ de um meio infinito, como mostra a Figura 3.12c.

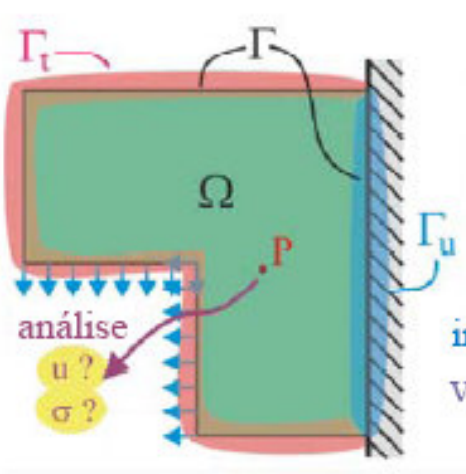

(a)

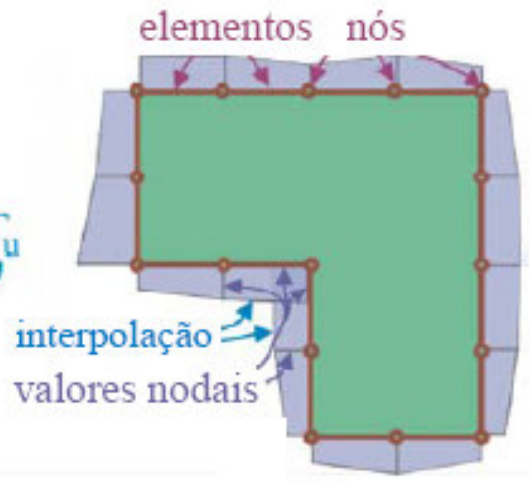

(b)

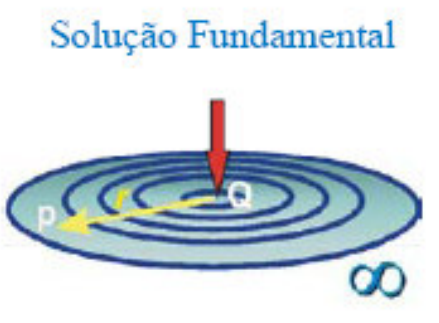

(c)

Figura 3.12 - (a) Modelo estrutural; (b) Discretização do modelo com elementos de contorno; (c) Solução fundamental.

Em geral, a formulação do MEC para problemas da elastostática pode ser desenvolvida por três métodos diferentes: o direto, o indireto e o semi-indireto. $O$ método direto utiliza parâmetros com significado físico, como deslocamentos e forças; nos outros métodos as formulações são feitas a partir de funções de densidade fictícias ou funções de tensões. A formulação elastostática do MEC pode ser alcançada por meio da técnica de resíduos ponderados empregada sobre a equação de equilíbrio descrita a seguir:

$\sigma_{i j, j}+b_{i}=0$.

A equação (3.40) representa as equações de equilíbrio da teoria da elasticidade linear. Para condensar o texto esta equação encontra-se em notação indicial, e os índices variam de 1 à 2 no caso bidimensional e de 1 à 3 no caso tridimensional. $O$ desenvolvimento apresentado neste trabalho considera apenas o caso da elasticidade bidimensional. Porém, para o caso tridimensional o procedimento é o mesmo. 
A equação de equilíbrio pode ser ponderada em todo o domínio pelos deslocamentos de uma solução fundamental $u^{*}{ }_{k i}$ : Logo:

$\int_{\Omega}\left(\sigma_{i j, j}+b_{i}\right) u_{k i}^{*} d \Omega=0$

Esta integral no domínio pode ser levada para o contorno ao serem efetuadas manipulações algébricas e pela aplicação do teorema de Betti. Considerando que a solução fundamental é uma função tipo delta de Dirac, chega-se então a:

$u_{k}(P)=\int_{\Gamma} u_{k i}^{*} p_{i} d \Gamma-\int_{\Gamma} p_{k i}^{*} u_{i} d \Gamma+\int_{\Omega} u_{k i}^{*} b_{i} d \Omega$.

A equação (3.42) é chamada de Identidade de Somigliana e fornece as componentes de deslocamento em qualquer ponto $P$ do domínio $\Omega$ do problema. Os termos $u_{k i}^{*}$ e $p_{k i}^{*}$ representam o deslocamento e a força de superfície na direção $k$ gerado por uma força unitária aplicada em $P$ na direção de $i$. As forças de volume $b_{i}$ são conhecidas.

Nas equações anteriores, todos os termos que apresentam um asterisco sobrescrito referem-se à solução fundamental da teoria da elasticidade determinadas por Kelvin, podendo ser encontradas em (BREBIA; DOMINGUES, 1992) entre outros. As expressões para a solução fundamental de deslocamentos $u_{k i}^{*}$ e forças de superfície $p_{k i}^{*}$ são dadas por:

$$
\begin{aligned}
& u_{k i}^{*}=\frac{1}{8 \pi \mu(1-v)}\left[(3-4 v) \ln \left(\frac{1}{r}\right) \delta_{k i}+r,,_{k} r,_{i}\right] \mathrm{e} \\
& p_{k i}^{*}=-\frac{1}{4 \pi(1-v) r}\left\{\frac{\partial r}{\partial n}\left[(1-2 v) \delta_{k i}+2 r,{ }_{k} r,{ }_{i}\right]+(1-2 v)\left(n_{k} r,_{i}-n_{i} r,_{k}\right)\right\},
\end{aligned}
$$

onde $\mu$ é o módulo de elasticidade transversal do material, $v$ é o coeficiente de Poisson e $r$ representa a distância entre o ponto $\mathrm{P}$ e um ponto onde os valores de $u_{k i}^{*}$ e $p_{k i}^{*}$ são observados. 
A solução fundamental apresentada em (3.43) para o caso bidimensional refere-se ao estado plano de deformação. Para resolver um problema do estado plano de tensão emprega-se o artifício de utilizar um coeficiente de Poisson fictício, dado por:

$v^{\prime}=\frac{v}{1+v}$.

Através da equação (3.42) e com os valores $u_{i}$ e $p_{i}$ conhecidos em todo o contorno, podemos calcular o deslocamento em qualquer ponto $P$ do domínio $\Omega$ do problema. Um problema de singularidade acontece quando precisamos calcular os valores de $u_{i}$ e $p_{i}$ no contorno. Isto acontece porque $r$ tende a zero nestes pontos. Todavia, com um tratamento adequado, consegue-se eliminar esta condição e a obtenção dos deslocamentos $u_{i}$ no contorno é alcançada através da seguinte equação:

$c_{k i} u_{i}(P)=\int_{\Gamma} u_{k i}^{*} p_{i} d \Gamma-\int_{\Gamma} p_{k i}^{*} u_{i} d \Gamma+\int_{\Omega} u_{k i}^{*} b_{i} d \Omega$

onde o coeficiente $c_{k i}$ depende da geometria do contorno na vizinhança do nó $P$.

Todo método numérico introduz aproximações na resolução de um problema. $O$ MEC aproxima a superfície do sólido por uma série de elementos de contorno, conforme a Figura 3.12 ilustra, onde os deslocamentos e as forças são representados em termos de uma série de valores nodais. Tal representação pode ser estendida para todo o contorno ao serem utilizadas funções de interpolação em cada elemento. No MEC, para um elemento de contorno arbitrário com um número $m$ de nós, considera-se que os deslocamentos $u_{i}$ e as forças de superfície $p_{i}$ são interpolados a partir de valores nodais $U_{i}^{l}$ e $P_{i}^{l}$ referentes ao nó $l$ do elemento da seguinte forma:

$u_{i}=\sum_{l=1}^{m} \phi^{l} U_{i}^{l} \mathrm{e}$
$p_{i}=\sum_{l=1}^{m} \phi^{l} P_{i}^{l}$,

onde $m$ é o numero de nós do elemento e $\phi^{l}$ são as funções de interpolação. 
Desprezando-se as forças de volume para facilitar a formulação, a equação (3.46) pode ser escrita algebricamente como:

$$
c_{k i} u_{i}(P)=\sum_{e=1}^{n_{e}} \sum_{l=1}^{m} \int_{\Gamma_{e}} u_{k i}^{*} \phi^{l} d \Gamma_{e} P_{i}^{l}-\sum_{e=1}^{n_{e}} \sum_{l=1}^{m} \int_{\Gamma_{e}} p_{k i}^{*} \phi^{l} d \Gamma_{e} U_{i}^{l}
$$

Para considerar o efeito de forças volumétricas é preciso tratar a integral de domínio a fim de eliminar a utilização de malhas de células internas. Existem várias técnicas que transformam tais integrais de domínio em integrais de contorno. Uma dessas técnicas requer o uso de um tensor especial conhecido como tensor de Galerkin, modificando o núcleo de deslocamento $u_{k i}^{*}$, que aplicado na integral de domínio as transforma em integrais de contorno equivalentes (VENTURINI, 1983).

Contudo, está técnica por mais que elimine a integral de domínio, ainda assim requer integrações adicionais no contorno do modelo. Banerjee e Pape (1987), com o intuito de eliminar qualquer integração adicional, desenvolveram uma técnica para solucionar problemas de forças de domínio por meio do desenvolvimento da solução de uma equação diferencial não-homogênea linear (PEREIRA, 2004).

A aplicação da equação (3.49) em todos os nós do contorno resulta no seguinte sistema:

$H u=G p$

onde $\boldsymbol{u}$ e $\boldsymbol{p}$ são os vetores de deslocamento e de forças de superfície, respectivamente. As matrizes $\boldsymbol{H}$ e $\boldsymbol{G}$ são matrizes densas e não-simétricas e ficam expressas por:

$$
\begin{aligned}
H_{k i}^{P} & \equiv \bar{c}_{k i}+\sum_{e=1}^{n_{e}} \sum_{l=1}^{m} \int_{\Gamma_{e}} p_{k i}^{*} \phi^{l} d \Gamma_{e} \mathrm{e} \\
G_{k i}^{P} & =\sum_{e=1}^{n_{e}} \sum_{l=1}^{m} \int_{\Gamma_{e}} u_{k i}^{*} \phi^{l} d \Gamma_{e} .
\end{aligned}
$$


Introduzindo as condições de contorno no sistema de equações (3.50) e passando para o lado esquerdo as incógnitas e para o lado direito os valores conhecidos, chega-se ao seguinte sistema de equações lineares:

$A X=F ，$

onde a matriz $\boldsymbol{A}$ é constituída por elementos das matrizes $\boldsymbol{H}$ e $\boldsymbol{G}, \boldsymbol{X}$ é o vetor de deslocamentos e forças de superfícies desconhecidos. $O$ vetor $\boldsymbol{F}$ é obtido dos deslocamentos e forças de superfícies conhecidos multiplicados por coeficientes das matrizes $\boldsymbol{H}$ e $\boldsymbol{G}$.

A solução do sistema linear (3.53) fornece os deslocamentos e forças de superfícies em todo o contorno do modelo. Para obter-se as componentes de deslocamentos em um ponto $P$ do domínio $\Omega$ do problema, faz-se 0 uso da Identidade de Somigliana, equação (3.42).

Outro ponto importante da análise é a obtenção do campo de tensões $\sigma_{i j}$ nos pontos internos do modelo a partir dos valores de deslocamentos e das forças de superfícies nos nós do contorno. A expressão que permite obter este resultado é a seguinte:

$\sigma_{i j}(P)=\sum_{j=1}^{n} \int_{\Gamma_{j}} D_{k i j} p_{k} d \Gamma_{j}-\sum_{j=1}^{n} \int_{\Gamma_{j}} S_{k i j} u_{k} d \Gamma_{j}$,

onde :

$$
\begin{gathered}
D_{k i j}=\frac{2 \mu \nu}{1-2 v} \delta_{i j} \frac{\partial u_{l k}^{*}}{\partial x_{l}}+\mu\left(\frac{\partial u_{i k}^{*}}{\partial x_{j}}+\frac{\partial u_{j k}^{*}}{\partial x_{i}}\right) \mathrm{e} \\
S_{k i j}=\frac{2 \mu v}{1-2 v} \delta_{i j} \frac{\partial p_{l k}^{*}}{\partial x_{l}}+\mu\left(\frac{\partial p_{i k}^{*}}{\partial x_{j}}+\frac{\partial p_{j k}^{*}}{\partial x_{i}}\right) .
\end{gathered}
$$




\subsubsection{FORMULAÇÃo VISCOELÁSTICA (REPRESENTAÇÃo NO CONTORNO)}

Esta abordagem garante uma das principais vantagens do MEC, pois é representada apenas em função de integrais de contorno. Para a determinação das equações integrais apropriadas, deve-se aplicar as equações constitutivas específicas para o modelo reológico que está sendo considerado. Neste trabalho foi considerado o modelo de Kelvin-Voigt, com isso, aplicando a equação (3.14) na equação a seguir:

$$
\int_{\Gamma} u_{k i}^{*} p_{i} d \Gamma-\int_{\Omega} \varepsilon_{k i j}^{*} \sigma_{i j} d \Omega=0
$$

temos:

$$
\int_{\Gamma} u_{k i}^{*} p_{i} d \Gamma-\int_{\Omega} \varepsilon_{k i j}^{*}\left(C_{i j}^{l m} \varepsilon_{l m}+\chi_{i j}^{l m} \dot{\varepsilon}_{l m}\right) d \Omega=0 \quad,
$$

onde equação (3.57) resultou de uma integração por parte da equação (3.41), e da desconsideração das forças de volume.

Sabendo-se que:

$$
\begin{aligned}
& \varepsilon_{k i j}^{*} C_{i j}^{l m} \varepsilon_{l m}=\sigma_{k l m}^{*} \varepsilon_{l m}=\sigma_{k l m}^{*} u_{l, m}=\sigma_{k i j}^{*} u_{i, j} \mathrm{e} \\
& \varepsilon_{k i j}^{*} \gamma_{i j}^{l m} \dot{\varepsilon}_{l m}=\gamma \sigma_{k l m}^{*} \dot{\varepsilon}_{l m}=\gamma \sigma_{k l m}^{*} \dot{u}_{l, m}=\gamma \sigma_{k i j}^{*} \dot{u}_{i, j},
\end{aligned}
$$

então a equação (3.58) pode ser rescrita como:

$$
\int_{\Gamma} u_{k i}^{*} p_{i} d \Gamma-\int_{\Omega} \sigma_{k j}^{*} u_{i, j} d \Omega-\gamma \int_{\Omega} \sigma_{k i j}^{*} \dot{u}_{i, j} d \Omega=0 \quad .
$$

Com algumas manipulações algébricas, temos:

$$
c_{k i} u_{i}(P)+\gamma c_{k i} \dot{u}_{i}(P)=\int_{\Gamma} u_{k i}^{*} p_{i} d \Gamma-\int_{\Gamma} p_{k i}^{*} u_{i} d \Gamma-\gamma \int_{\Gamma} p_{k i}^{*} \dot{u}_{i} d \Gamma
$$


A equação (3.62) fornece os valores das incógnitas no contorno do problema. Para a obtenção dos valores em qualquer ponto $P$ do domínio $\Omega$ do modelo, aplica-se a Identidade de Somigliana para o problema viscoelástico, portanto:

$u_{i}(P)+\gamma \dot{u}_{i}(P)=\int_{\Gamma} u_{k i}^{*} p_{i} d \Gamma-\int_{\Gamma} p_{k i}^{*} u_{i} d \Gamma-\gamma \int_{\Gamma} p_{k i}^{*} \dot{u}_{i} d \Gamma \quad$.

Para viabilizar a solução das equações integrais apresentadas anteriormente 0 contorno do modelo é discretizado com $n_{e}$ elementos de contorno. Logo, as variáveis do problema podem ser aproximadas, parametrizando-as com relações aos seus valores nodais e fazendo o uso de funções de interpolação, da mesma forma que foi feito na formulação elastostática, resultando em:

$$
\begin{aligned}
& p_{i}=\sum_{l=1}^{m} \phi^{l} P_{i}^{l}, \\
& u_{i}=\sum_{l=1}^{m} \phi^{l} U_{i}^{l} \mathrm{e} \\
& \dot{u}_{i}=\sum_{l=1}^{m} \phi^{l} \dot{U}_{i}^{l},
\end{aligned}
$$

onde $m$ é o numero de nós do elemento e $\phi^{l}$ são as funções de interpolação.

Substituindo as equações (3.64), (3.65) e (3.66) em (3.62) obtém-se:

$$
c_{k i} u_{i}(P)+\gamma c_{k i} \dot{u}_{i}(P)=\sum_{e=1}^{n_{e}} \sum_{l=1}^{m} \int_{\Gamma_{e}} u_{k i}^{*} \phi^{l} d \Gamma_{e} P_{i}^{l}-\sum_{e=1}^{n_{e}} \sum_{l=1}^{m} \int_{\Gamma_{e}} p_{k i}^{*} \phi^{l} d \Gamma_{e} U_{i}^{l}-\gamma \sum_{e=1}^{n_{e}} \sum_{l=1}^{m} \int_{\Gamma_{e}} p_{k i}^{*} \phi^{l} d \Gamma_{e} \dot{U}_{i}^{l}
$$

Para conhecermos os valores dos deslocamentos $U_{l}^{m}$ e das forças de superfícies $P_{l}^{m}$ nos $n$ nós do contorno do modelo, deve-se escrever o seguinte sistema de equação diferencial temporal:

$$
H U(t)+\gamma H \dot{U}(t)=G P(t)
$$

onde $t$ representa o tempo, $H$ e $G$ são as mesmas matrizes das Eqs (3.51) e (3.52). 
A solução de (3.68) exige uma técnica de integração temporal tal como Wilson- $\theta$, Newmark, ou Houbolt (CARBONE, 2007). Porém, segundo MESQUITA (2002), a aproximação linear dada por:

$\dot{U}_{s+1}=\frac{U_{s+1}-U_{s}}{\Delta t}$,

apresenta resultados aceitáveis para análises viscosas, sem o termo de aceleração. Reescrevendo a equação (3.68), temos:

$\bar{H} U_{s+1}=G P_{s+1}+F_{s}$,

sendo que:

$\bar{H}=\left(1+\frac{\gamma}{\Delta t}\right) H \mathrm{e}$

$F_{s}=\left(\frac{\gamma}{\Delta t}\right) H U_{s}$.

Introduzindo as condições de contorno no problema e passando para o lado esquerdo as incógnitas e para o lado direito os valores conhecidos, chega-se a um sistema similar ao da equação (3.53).

Outro ponto importante da análise é a obtenção do campo de tensões $\sigma_{i j}$ nos pontos internos do modelo a partir dos valores de deslocamentos e das forças de superfícies nos nós do contorno. A expressão que permite obter este resultado é a seguinte:

$\sigma_{i j}(P)=\sum_{j=1}^{n} \int_{\Gamma_{j}} D_{k i j} p_{k} d \Gamma_{j}-\sum_{j=1}^{n} \int_{\Gamma_{j}} S_{k i j} u_{k} d \Gamma_{j}-\gamma \sum_{j=1}^{n} \int_{\Gamma_{j}} S_{k i j} \dot{u}_{k} d \Gamma_{j}$,

onde $D$ e $S$ são determinados pelas equações (3.55) e (3.56). 


\subsection{Problemas de Multi-Regiões}

A formulação apresentada até aqui foi desenvolvida considerando um domínio $\Omega$ homogêneo, mas em determinados casos o domínio em estudo não se apresenta de forma homogênea e sim sob a forma de regiões constituídas de materiais diferentes. Um exemplo dessa situação é quando temos diferentes camadas de solos ou rochas presentes no modelo que está sendo analisado ou nos casos de escavação seqüencial de túneis onde o avanço da escavação deve ser modelado ou também quando analisamos o comportamento da interação maciço-suporte nas obras de túneis, entre outros. A Figura 3.13 ilustra um problema envolvendo multi-regiões na escavação de túneis em três estágios, onde a Região 1 representa o maciço que envolve o túnel.

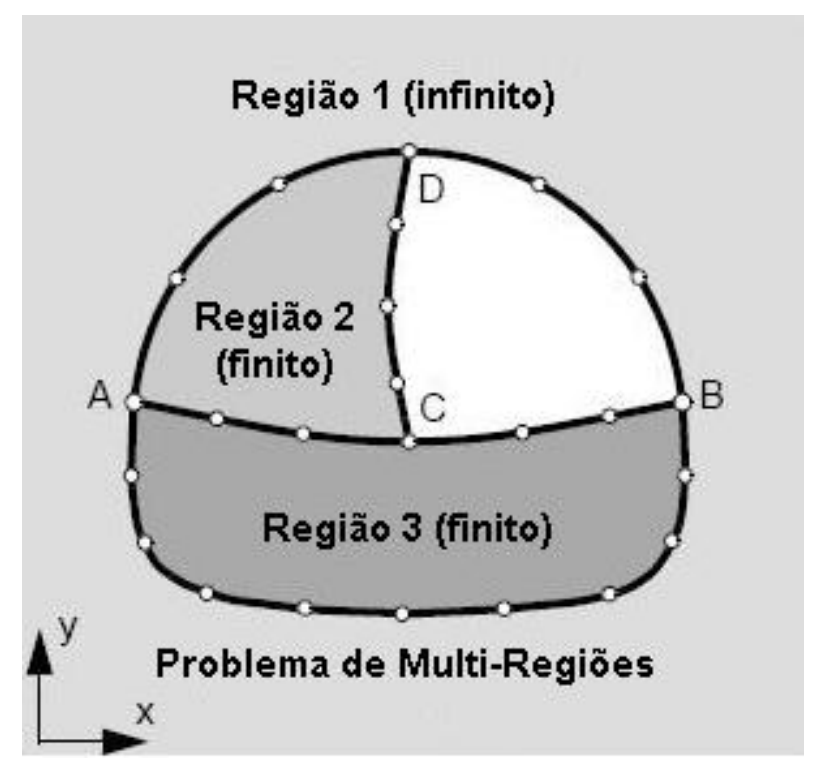

Figura 3.13 - Escavação de túneis em três estágios - Problema de multi-regiões.

No Método dos Elementos de Contorno o problema de multi-regiões pode ser simulado através do uso de sub-regiões, onde cada região tem seu contorno discretizado como se fosse independente uma da outra e aplicam-se condições de compatibilidade de deslocamento e equilíbrio de forças nos elementos da interface entre uma sub-região e outra para completar o sistema de equações do problema. 
Considere o problema apresentado na Figura 3.14 onde temos três regiões constituídas por diferentes materiais. Um domínio bidimensional foi representado por ser o foco deste trabalho, porém, o procedimento descrito abaixo se aplica a domínios tridimensionais também.

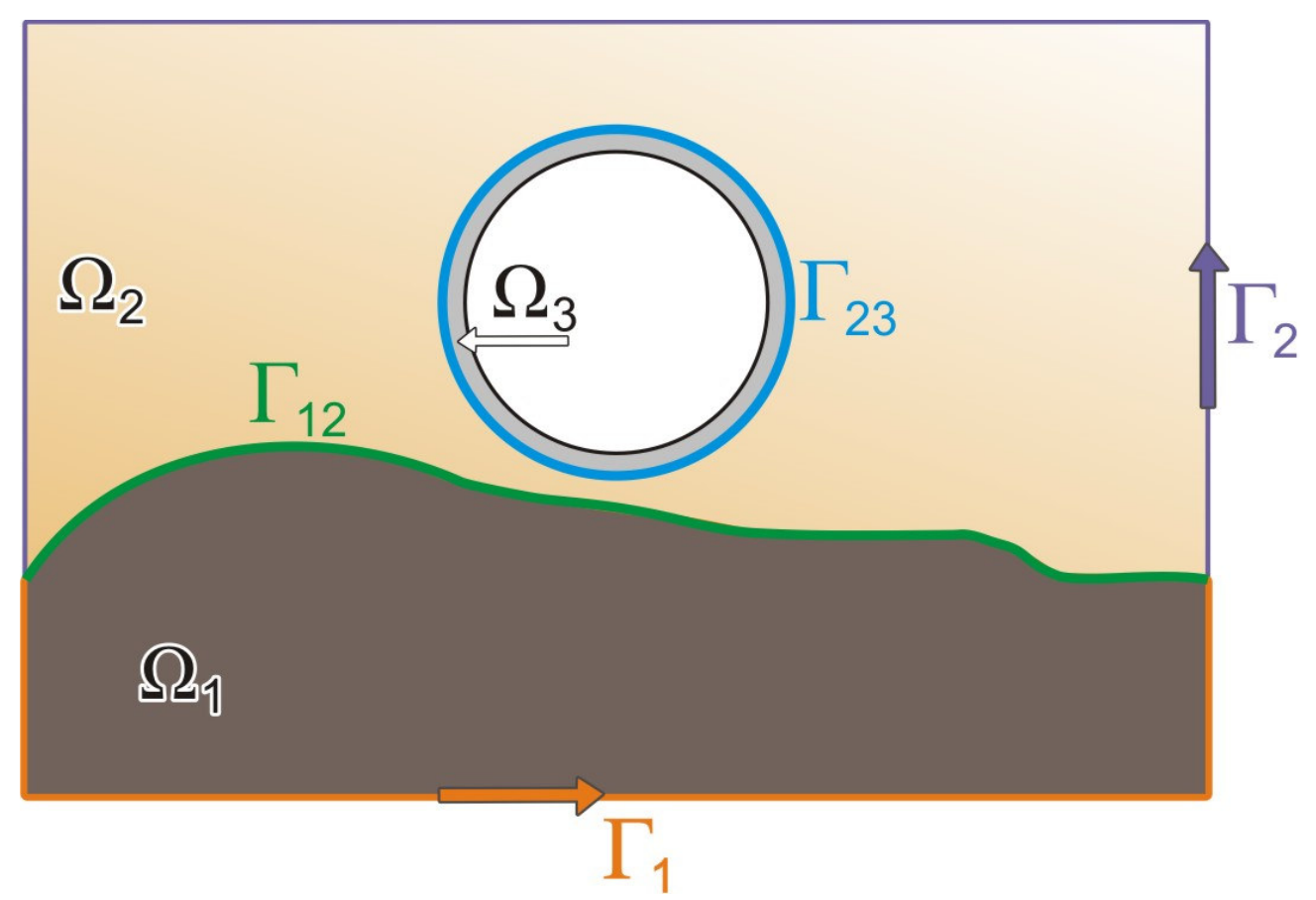

Figura 3.14 - Problema com domínio formado por várias regiões.

Os termos que aparecem na Figura 3.14 são explicados a seguir:

$\Gamma^{i} \rightarrow$ contorno da sub-região $\Omega^{i} ;$

$\Gamma^{i j} \rightarrow$ contorno pertencente a sub-região $\Omega^{i}$ e $\Omega^{j}$ (interface);

$u^{i}, p^{i} \rightarrow$ deslocamento e forças de superfície nos nós do contorno $\Gamma^{i}$ pertencente a sub-região $\Omega^{i}$;

$u^{i j}, p^{i j} \rightarrow$ deslocamento e forças de superfície nos nós do contorno $\Gamma^{i j}$ pertencente a sub-região $\Omega^{i}$ e $\Omega^{j}$;

$H^{i}, G^{i} \rightarrow$ partes das matrizes $H$ e $G$ obtidas para a sub-região $\Omega^{i}$ que multiplicam $u^{i}$ e $p^{i}$ respectivamente;

$H^{i j}, G^{i j} \rightarrow$ partes das matrizes $H$ e $G$ obtidas para a sub-região $\Omega^{i}$ que multiplicam $u^{i j}$ e $p^{i j}$ respectivamente. 
A Tabela 3.1 apresenta as equações do MEC para o problema em questão.

Tabela 3.1 - Equações do MEC para as três sub-regiões do problema

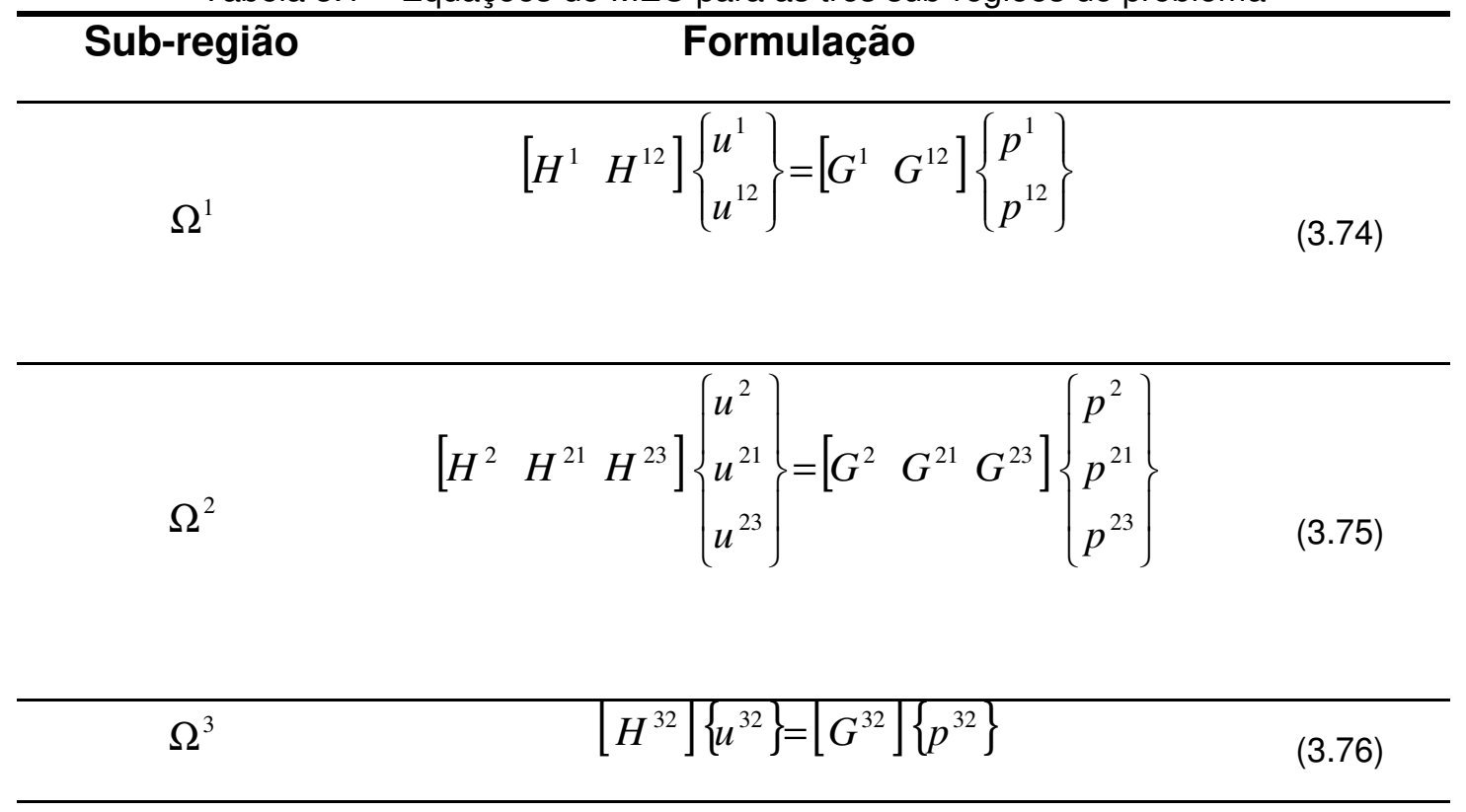

Aplicando-se as condições de compatibilidade de deslocamento apresentadas a seguir:

$u^{i j}=u^{j i}$,

e a de equilíbrio de forças, dada por:

$p^{i j}+p^{j i}=0$,

tem-se como resultado o sistema apresentado na equação (3.79), que ao se aplicar as condições de contorno ganha a configuração do sistema (3.53).

$\left[\begin{array}{cccccc}H^{1} & 0 & H^{12} & 0 & G^{12} & 0 \\ 0 & H^{2} & H^{21} & H^{23} & -G^{21} & -G^{23} \\ 0 & 0 & 0 & H^{32} & 0 & G^{32}\end{array}\right]\left\{\begin{array}{l}u^{1} \\ u^{2} \\ u^{12} \\ u^{23} \\ p^{12} \\ p^{23}\end{array}\right\}=\left[\begin{array}{cc}G^{1} & 0 \\ 0 & G^{2} \\ 0 & 0\end{array}\right]\left\{\begin{array}{l}p^{1} \\ p^{2}\end{array}\right\}$. 


\section{MODELAGEM COMPUTACIONAL DO SUPORTE DE TÚNEIS}

Além da consideração de meios infinitos e semi-infinitos os modelos de túneis são caracterizados pela modelagem de materiais com propriedades diferentes, que ocorrem intactos ou com diferentes níveis de fraturamento. Por se tratarem de estruturas mistas, simulações computacionais realísticas de obras de túneis envolvem uma combinação de materiais estruturais e geotécnicos como solo, rocha, concreto estrutural, concreto projetado (Figura 4.1a) e elementos estruturais metálicos (Figura 4.1b) (NORONHA, 2007).

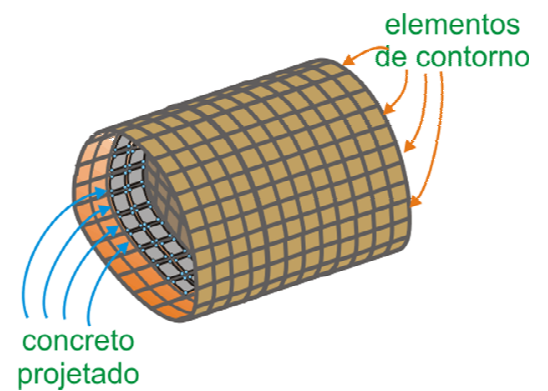

(a)

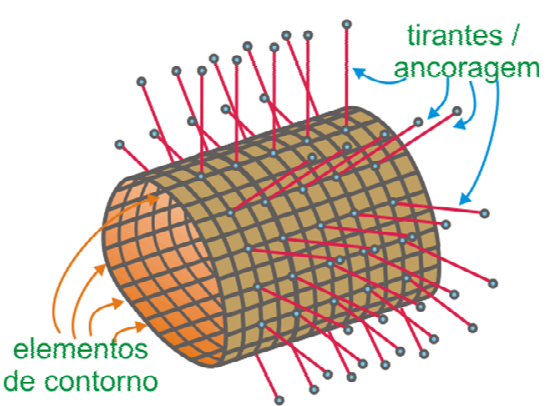

(b)

Figura 4.1 - Modelagem de túneis: (a) concreto projetado; (b) tirantes e barras de ancoragem.

A simulação numérica de túneis apresenta dificuldades no que diz respeito à precisão e ao grau de complexidade dos modelos. Simulações tridimensionais com um grau relativamente alto de representação podem envolver dezenas de milhões de graus de liberdade. Dependendo do método numérico utilizado, essa situação pode ser melhorada, mas ainda assim exige um elevado esforço computacional. Com isso, as análises tridimensionais ainda não são tão comuns nos projetos de escavações subterrâneas. Atualmente análises deste tipo são justificáveis somente em casos especiais.

Para contornar esse problema, uma opção seria utilizar outros tipos de análises menos dispendiosas. Neste trabalho será realizada modelagem bidimensional da estrutura de suporte de túneis com comportamento viscoelástico usando o MEC. Portanto, neste capítulo serão apresentados alguns tipos de análises bidimensionais e métodos de interação maciço-suporte e posteriormente a forma como a modelagem bidimensional do suporte de túneis foi tratada neste trabalho. 


\subsection{ANÁLISES BidimENSIONAIS}

Esta análise pode ser entendida como uma aproximação à situação tridimensional, onde é realizada uma seqüência de análises bidimensionais das seções transversais de maior interesse dentro do processo de construção de um túnel (GOMES, 2006). A seguir apresentaremos as características gerais dos três métodos mais utilizados de simulação bidimensional para a determinação de tensões e deformações finais do maciço e do revestimento.

\subsubsection{MÉTOdO dA PRESSÃo FICTÍCIA INTERNA}

Este método propõe três etapas distintas para a modelagem de escavação de um túnel, através da aplicação de uma pressão fictícia interna ao perímetro da escavação $\left(p_{f}\right)$. Num primeiro momento, considera-se o maciço como uma abertura não revestida com uma pressão interna $\left(p_{f}\right)$ igual à tensão in situ do terreno. Em seguida, antes de se instalar o suporte, a pressão interna $\left(p_{f}\right)$ é reduzida por um fator $\alpha$, que também é conhecido como fator de alívio, sendo que $0<\alpha<1$, e 0 maciço se movimenta radialmente para o interior do túnel, apresentando um deslocamento $u_{o}$. Como etapa final, logo após ter-se igualado o deslocamento da abertura não revestida, $u_{o}$, ao deslocamento obtido de leituras de instrumentação, então o suporte é instalado e a pressão fictícia interna $\left(p_{f}\right)$ é reduzida a zero (GOMES, 2006).

Vale lembrar que a pressão fictícia no modelo bidimensional somente mantém o mesmo grau de deformação e tensão das paredes do túnel em situação real, de modo que as deformações e as tensões que ocorrem dentro do maciço sejam diferentes. Contudo, este tipo de aproximação é considerado razoável sob o ponto de vista prático de engenharia (GOMES, 2006). A Figura 4.2 apresenta as etapas do método da pressão fictícia interna. 


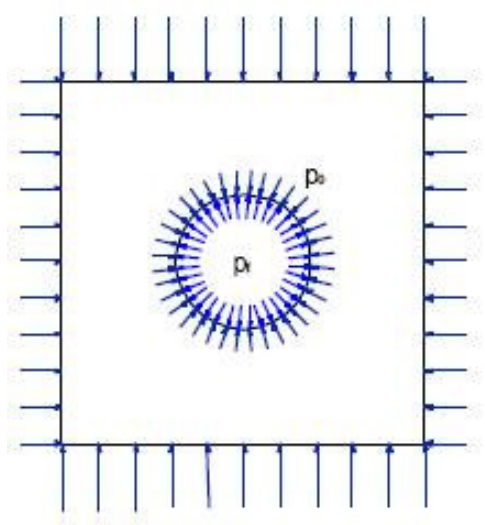

$\mathrm{p}_{\mathrm{t}}=\mathrm{p}_{\mathrm{o}}$

Determinação das tensões atuantes no perímetro escavado.

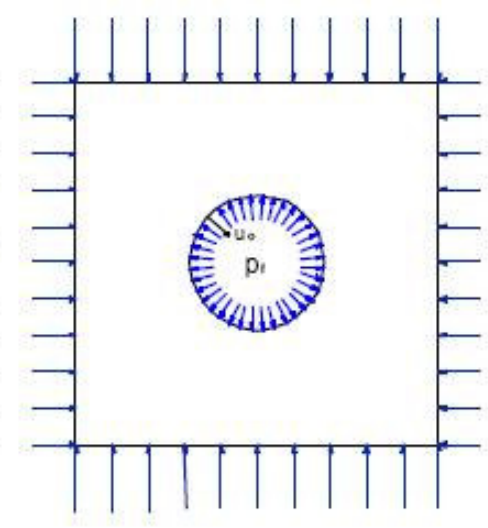

$\mathrm{p}_{\mathrm{r}}=\alpha . \mathrm{p}_{\circ}$

Escavação e aplicação da pressão fictícia no perímetro escavado.

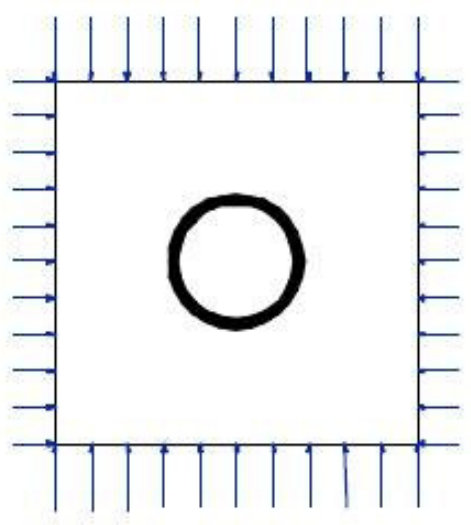

$\mathrm{p}_{\mathrm{t}}=$ zero.

Instalação do suporte e eliminação da pressão fictícia.

Figura 4.2 - Seqüência de passos requeridos pelo método da pressão fictícia ${ }^{10}$.

\subsubsection{MÉTODO dA REDUÇÃO de RIGIDEZ DO NÚCLEO}

Este método propõe uma seqüência de simulações planas, sendo que o maciço deve ser considerado intacto inicialmente. Antes do início da escavação do túnel e instalação do suporte, o módulo de elasticidade da região interna ao eventual perímetro do túnel (região do núcleo) é reduzido por um fator $\beta$ e o maciço se movimenta radialmente para o interior do túnel, apresentando um deslocamento $u_{o}$, no contorno da escavação. Após isto, ativa-se o suporte e concomitantemente escava-se o túnel, reduzindo-se progressivamente o valor do módulo de elasticidade de seu núcleo até zero (GOMES, 2006). A Figura 4.3 apresenta as etapas do método da redução de rigidez do núcleo.

Em situações em que se têm seqüências de escavação um pouco mais complexas com materiais de comportamento não-linear, o método da redução de rigidez do núcleo apresenta algumas discrepâncias com valores medidos em campo (SCHWEIGER; SCHULLER; PÖTTLER, 1997). Outra crítica relacionada a este método é o fato de não existir uma metodologia racional para se estimar o fator de redução de rigidez do maciço, $\beta$ (GOMES, 2006).

\footnotetext{
10 fonte: Gomes, R. A. M. P, "Análise tridimensional de túneis considerando o comportamento dependente do tempo na interação maciço-suporte”, São Carlos, 2006.
} 


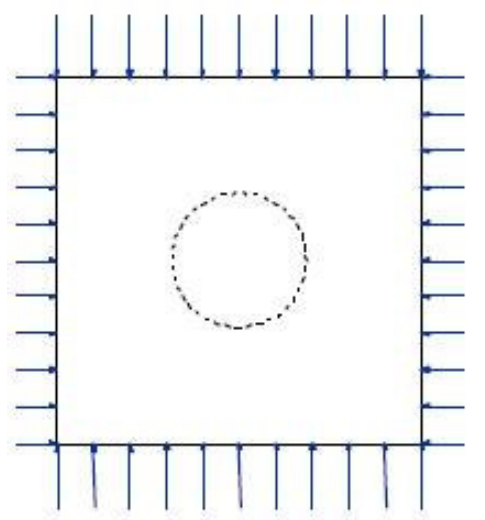

$\mathrm{E}_{\mathrm{n}}=\mathrm{E}_{\mathrm{m}}$

Determinação do estado de tensões atuantes no maciço não escavado.

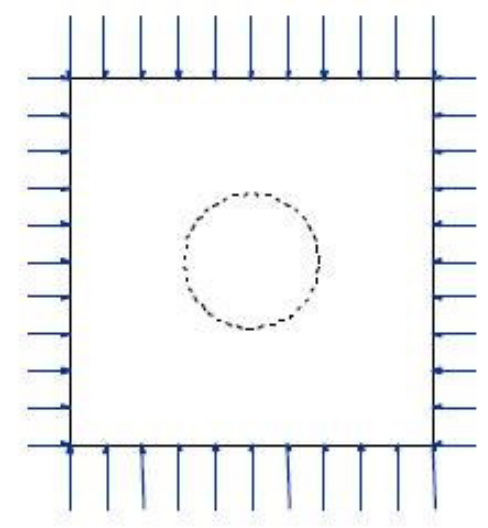

$$
E_{n}=\beta . E_{m}
$$

Redução da rigidez da região interior do perímetro a ser escavado.

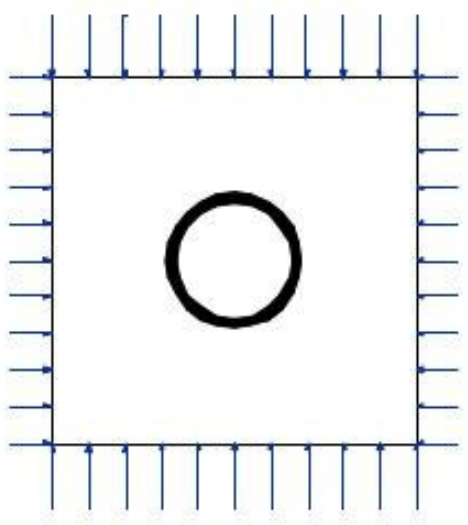

$$
\mathrm{E}_{\mathrm{n}}=\text { zero. }
$$

Instalação do suporte e eliminação da rigidez do núcleo.

Figura 4.3 - Seqüência de passos requeridos pelo método da redução de rigidez do núcleo ${ }^{11}$.

\subsubsection{MÉTOdO dA REDUÇÃo do CARREGAMENTO}

Este método propõe três etapas para modelagem de escavação de um túnel. Inicialmente, determinam-se as tensões existentes no contorno entre a região a ser escavada e o maciço para um estado de tensões in situ. Posteriormente, retira-se o carregamento in situ e o material da região interna ao eventual perímetro do túnel, aplica-se no contorno da escavação as tensões obtidas na primeira etapa, mas com sentido contrário à original e multiplicadas por um fator $\alpha$, até que se atinja o deslocamento desejado, $u_{o}$. Como terceira e última etapa, instala-se o suporte e aplicam-se as tensões obtidas na primeira fase com sentido contrário, mas agora multiplicada pelo fator de alívio, $(1-\alpha)$. O resultado final da simulação da escavação com a instalação do suporte é a soma dos resultados da simulação da primeira etapa com os da terceira (GOMES, 2006), como mostra a Figura 4.4.

Como este método utiliza-se do mesmo principio de aplicação de forças nodais para a simulação dos efeitos de suporte da frente de escavação, podemos considerá-lo como um método derivado do método da pressão fictícia interna, apesar de que o processo para obtenção dos resultados finais é diferente (GOMES, 2006).

\footnotetext{
11 fonte: Gomes, R. A. M. P, "Análise tridimensional de túneis considerando o comportamento dependente do tempo na interação maciço-suporte”, São Carlos, 2006.
} 


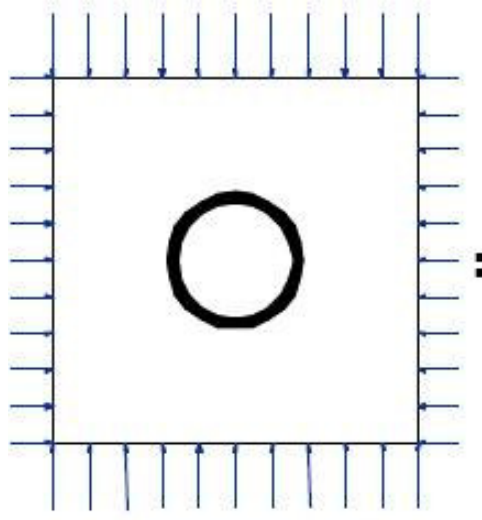

Estado final do processo de escavação e de instalação do suporte.

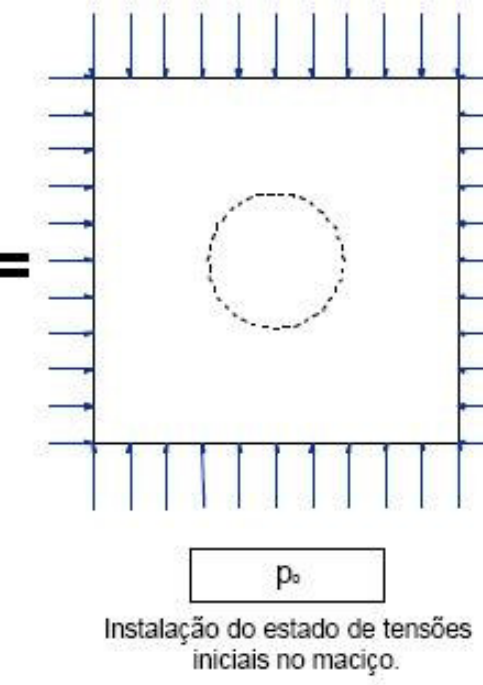
iniciais no maciço.

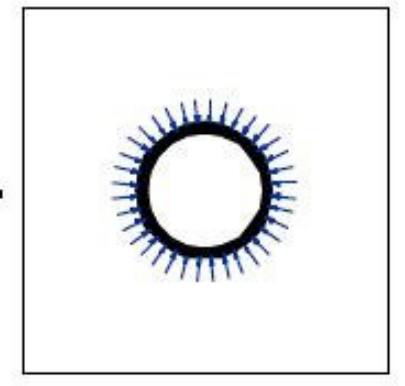

Instalação do suporte e aplicação do carregamento fictício sem as tensões iniciais do maciço.

$$
C_{1}=(1-\alpha) \cdot p_{0}
$$

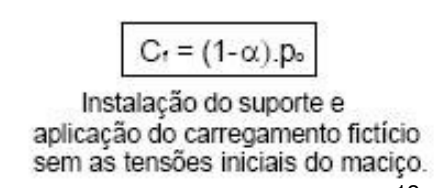

Figura 4.4 - Seqüência de passos requeridos pelo método da redução do carregamento ${ }^{12}$.

\subsection{MÉtodos de ANÁlise da INTERAÇÃo ENTRE O MACIÇO E O SUPORTE}

Este item discute de forma resumida alguns métodos de análises da interação entre o maciço e o suporte de túneis. Portanto, serão apresentados a seguir: Método de Convergência-Confinamento, Método proposto por Schwartz \& Einstein (1980), Método proposto por Pöttler (1990), Método proposto por Celestino (1992) e Método proposto por Chang (1994).

\subsubsection{MÉTOdo de CONVERGÊNCIA-CONFINAMENTO}

Nos projetos de túneis uma ferramenta auxiliar muito utilizada são as curvas características, que nada mais são do que a relação entre a pressão $P$ no entorno de uma abertura, e o deslocamento radial do maciço e do suporte, $u$. A Figura 4.5 apresenta alguns aspectos gerais de uma curva característica.

\footnotetext{
12 fonte: Gomes, R. A. M. P, "Análise tridimensional de túneis considerando o comportamento dependente do tempo na interação maciço-suporte”, São Carlos, 2006.
} 

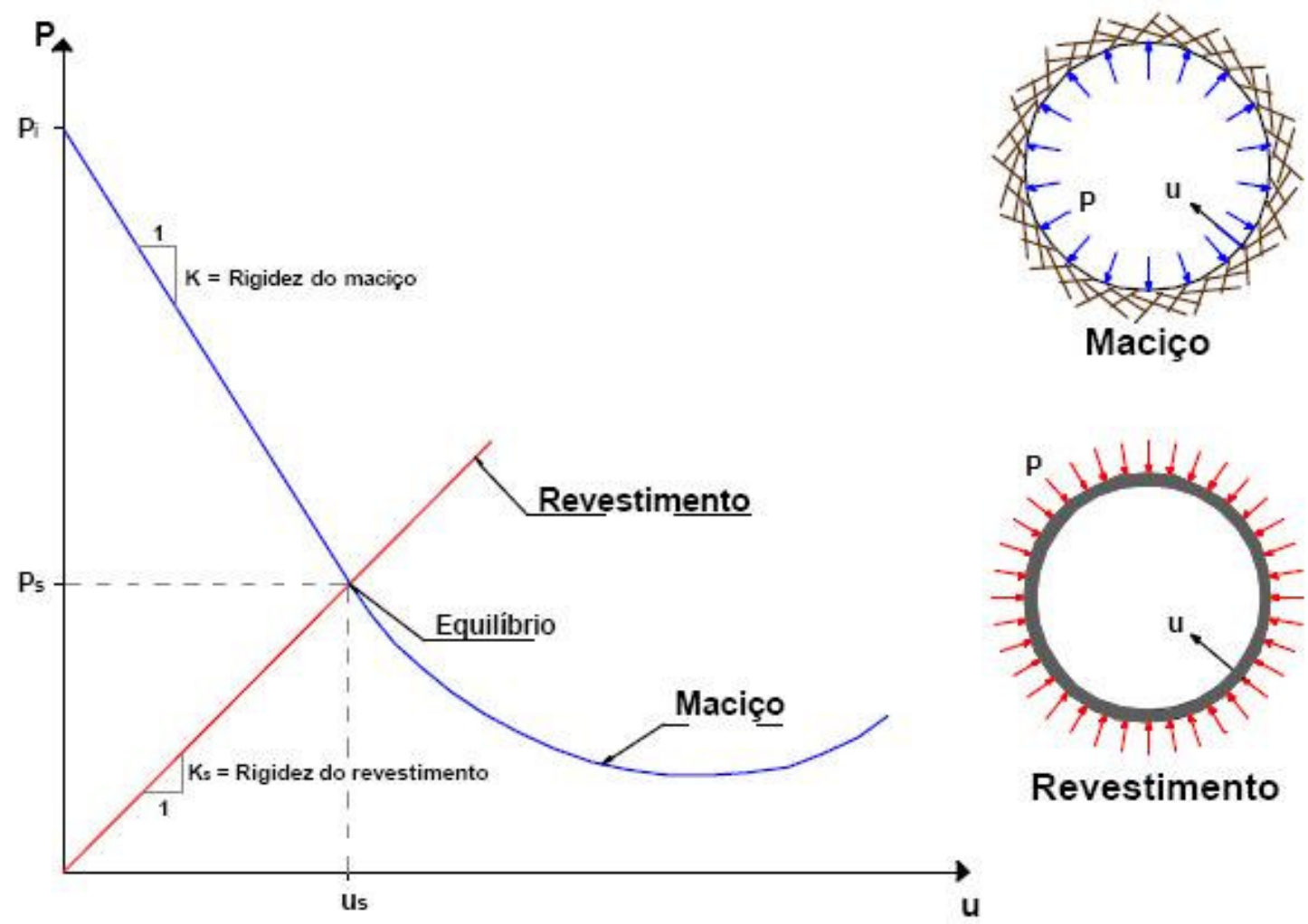

Figura 4.5 - Aspectos gerais de curvas características ${ }^{13}$.

A curva característica do maciço assume a existência de um maciço não perturbado por um túnel escavado sem suporte. Este possui inicialmente uma pressão interna, $P_{i}$, atuante em suas paredes com intensidade igual, mas de sentido contrário, às pressões existentes no maciço antes de sua escavação. A partir deste momento, a pressão $P_{i}$ é reduzida de forma a ocorrer o aparecimento dos deslocamentos radiais $u$, e a curva descrita por esta variação de $P$ versus $u$, é a curva característica do maciço (GOMES, 2006).

Seguindo o mesmo raciocínio, a curva característica do suporte é baseada nos deslocamentos que se desenvolvem à mesma proporção que a pressão externa ao suporte é gradualmente acrescida por influência do maciço. O ponto onde as curvas do maciço e do suporte se cruzam é chamado de ponto de equilíbrio da interação, onde $P_{s}$ será o carregamento final atuante no suporte e $u_{s}$ será o seu deslocamento radial final (GOMES, 2006).

\footnotetext{
13 fonte: Gomes, R. A. M. P, "Análise tridimensional de túneis considerando o comportamento dependente do tempo na interação maciço-suporte”, São Carlos, 2006.
} 
Várias situações particulares ao processo de escavação de túneis podem ser entendidas pela construção de curvas características e análises dos seus pontos de origem e equilíbrio, dentre essas situações podemos citar a influência direta dos processos de escavação e execução do suporte nos pontos de equilíbrio da interação maciço-suporte. A Figura 4.6 apresenta essas influências evidenciando a diferença em se considerar o suporte dependente ou não do tempo.

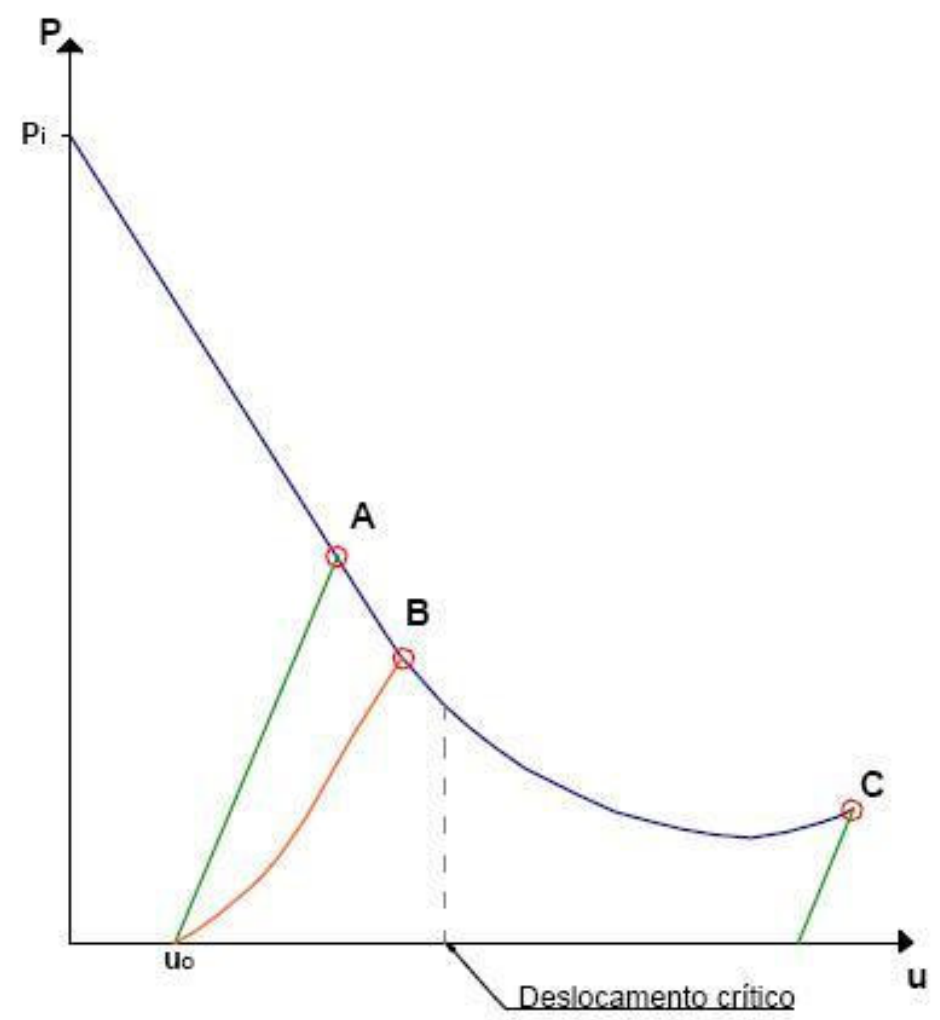

Figura 4.6 - Comparação entre diferentes características do suporte e seqüências de escavação do maciço ${ }^{14}$.

A reta que parte de $u_{0}$ e intercepta a curva do maciço no ponto A representa a curva característica para um suporte pré-moldado. No entanto, considerando um comportamento dependente do tempo para o suporte, observa-se que a curva característica para um suporte de concreto projetado também parte de $u_{0}$, conservadas as características geométrica do maciço e do suporte, mas a curva não é reta e intercepta a curva do maciço no ponto $B$, isto acontece devido ao fato do concreto não possuir rigidez constante ao longo do eixo do túnel, mas sim crescente de uma seção que se localiza próxima à face até outra distante (GOMES, 2006).

\footnotetext{
14 fonte: Gomes, R. A. M. P, "Análise tridimensional de túneis considerando o comportamento dependente do tempo na interação maciço-suporte”, São Carlos, 2006.
} 
Também podemos observar na Figura 4.6 as diferenças entre as seqüências de escavação. Nas situações anteriores foram escavadas pequenas quantidades de material do maciço que logo foram revestidas, só que o processo de escavação de túneis é caracterizado pela remoção de grande quantidade de material do maciço. Nessa situação encontra-se o ponto de equilíbrio em $C$, ponto que implica na desagregação do maciço (GOMES, 2006).

\subsubsection{MÉtodo PRoposto POR SCHWARTZ \& EINSTEIN (1980)}

Este método considera como principais responsáveis pelos esforços solicitantes em um suporte os seguintes fatores: a rigidez do suporte em relação ao maciço, a distância entre o último lance e a face (atraso na instalação do suporte) e a plastificação do maciço em volta da abertura (GOMES, 2006).

Neste método, o túnel é considerado único e de seção circular. Admite-se também que sua profundidade é tal que a influência da superfície e as variações nas tensões no maciço ao longo da altura podem ser desconsideradas. Geralmente, uma profundidade de 2 diâmetros é o suficiente para atender essas exigências.

O maciço neste método é tratado como um meio contínuo, homogêneo e isotrópico, ou seja, elimina a possibilidade de utilizá-lo em camadas saprolíticas ou em maciços com grandes falhas geológicas. Sua resistência pode ser simulada considerando o modelo elastoplástico perfeito (Figura 3.7), mas pode facilmente ser adaptada a qualquer tipo de critério de resistência. Outra característica do método é o fato de que o maciço e o suporte possuem comportamento independente do tempo e este último é considerado com comportamento elástico linear (Figura 3.6a).

O túnel é escavado em seção plena (sem parcializações), sem o auxílio de ar comprimido como medida de estabilização do teto e da frente de escavação e qualquer efeito de pressão de água nas cargas atuantes do suporte deverão ser tratados de maneira separada (GOMES, 2006). 


\subsubsection{MÉtodo PROPOSTO POR PötTLER (1990)}

Este método foi desenvolvido a partir de análises tridimensionais, que modelaram a execução de um túnel considerando o maciço com comportamento elástico com sistema de estabilização viscoelástico, de onde foram obtidos alguns parâmetros auxiliares para realização de modelagens bidimensionais. Sendo assim, ao invés de modelagens tridimensionais demoradas que consideram o avanço da frente de escavação passo a passo, este método permite a utilização de um modelo numérico bidimensional simples e de com boa precisão. Neste caso, o método de redução de carregamento do item 4.1.3 é utilizado como uma forma de se considerar os efeitos de transferência de carregamento do maciço para o suporte.

O método considera que durante a escavação de um túnel o suporte possui comportamento dependente do tempo. Com isso, determina-se a máxima tensão de compressão no suporte e o fator de segurança destes durante o processo de escavação. Com o propósito de considerar as propriedades dependentes do tempo do suporte neste modelo bidimensional, um módulo de elasticidade hipotético para concreto projetado foi determinado, este módulo é menor do que o seu módulo de elasticidade aos 28 dias.

O método apresenta algumas falhas quando o maciço apresenta um comportamento elastoplástico muito pronunciado, e quando as seqüências de escavação exigem muitas parcializações.

\subsubsection{MÉtodo Proposto por Celestino (1992)}

Este método apresenta um cálculo do tipo convergência-confinamento que leva em consideração os comportamentos dependentes do tempo para o maciço e suporte de concreto projetado, assim como, a consideração dos efeitos tridimensionais da 
frente de escavação, que ocasionam a transferência de carregamento do maciço para uma determinada seção transversal, quando a frente do túnel avança.

O método foi proposto após constatações negativas sobre os métodos usuais de dimensionamento de túneis, uma vez que estes consideram apenas configurações estabilizadas de deformações e tensões, situações que ocorrem apenas em seções distantes da frente de escavação, sendo que perto da face do túnel é onde ocorre a maioria dos acidentes em obras subterrâneas.

\subsubsection{MÉtodo Proposto por Chang (1994)}

Este método é baseado na determinação do carregamento atuante num segmento de suporte com revestimento de concreto projetado, que é considerado elástico com rigidez crescente com o tempo e seu fator de segurança. Isto é alcançado ao se introduzir uma relação entre a pressão atuante no suporte e a pressão fictícia devida ao efeito de suporte da frente de escavação, através de soluções analíticas da curva característica do maciço com as teorias da elasticidade e elastoplasticidade para problemas que admitam a consideração do estado plano de deformações.

De forma bastante resumida podemos dizer que o método segue os seguintes passos:

- Inicialmente assume-se ou determina-se a velocidade de avanço da escavação;

- Encontra-se a pressão fictícia devido ao efeito de suporte da face em função da posição da seção de análise em relação à frente de escavação;

- Determinam-se os incrementos de pressão no suporte, e a pressão total é obtida pelo acúmulo destes incrementos;

- O fator de segurança do suporte é então calculado pela comparação entre a tensão de compressão do suporte gerada pela pressão atuante e resistência à compressão do concreto projetado, a cada lance do processo de escavação. 


\subsection{Modelagem Bidimensional do SuPORTE de Túneis COM O MEC}

Apresenta-se neste item a forma com que a modelagem do suporte de túneis será tratada neste trabalho. A Figura 4.7 ilustra algumas das características básicas do problema.

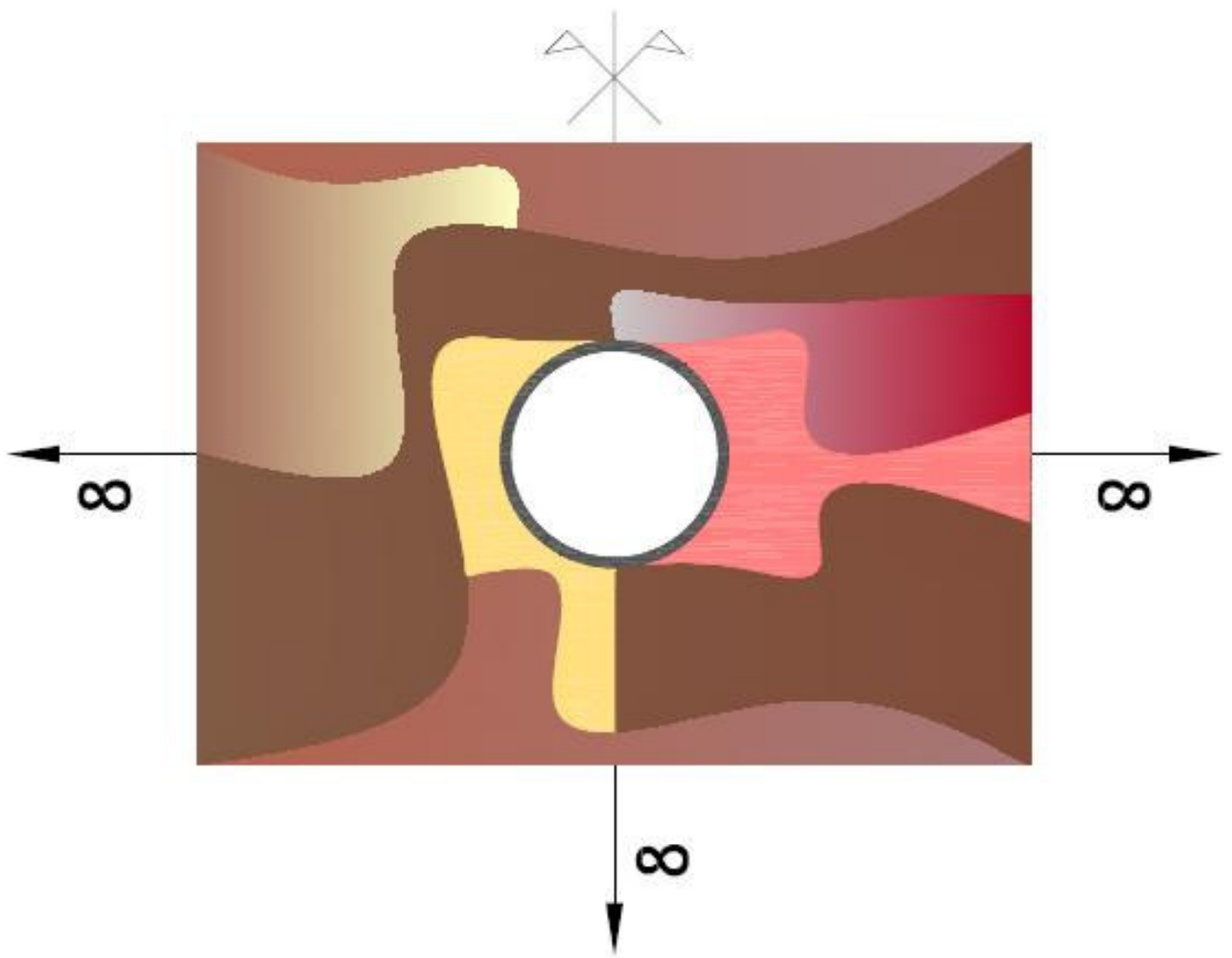

Figura 4.7 - Representação do modelo físico de túneis.

Além da consideração de meios infinitos e semi-infinitos os modelos de túneis são caracterizados pela modelagem de materiais com propriedades diferentes, uma vez que em volta da abertura do túnel temos o solo, que é um meio complexo e heterogêneo (Figura 4.7), ou a rocha, que é o material originário, em contato com materiais estruturais como concreto pré-moldado, concreto projetado (Figura 4.1a) e elementos estruturais metálicos (Figura 4.1b).

Diante do que foi exposto, o presente trabalho considerou para a resolução numérica do problema a análise bidimensional das seções transversais do modelo, conforme já justificado no início deste capítulo. Em seguida particularizou-se a estrutura de suporte do túnel para o concreto projetado. 
O concreto projetado pode ser definido como uma mistura de areia, brita, cimento Portland e aditivos aceleradores de pega bem homogeneizados. Esta mistura é impulsionada por uma máquina de projeção rumo à superfície a ser tratada. Este impulso é dado por meio de uma corrente de ar comprimido ou por uma bomba, que transporta a mistura em alta velocidade através de um tubo flexível, o mangote, até que a mistura atinja a superfície a ser estabilizada. Neste último momento, a mistura também sofre o efeito de compactação simultânea, reflexo da alta energia cinética dada aos agregados na saída do sistema.

Com o tipo da análise, do material e do comportamento do suporte definidos e partindo do princípio que o método numérico a ser utilizado na resolução do problema será o Método dos Elementos de Contorno (MEC), podemos definir o tipo de modelo básico adotado neste trabalho de acordo como ilustrado na Figura 4.8.

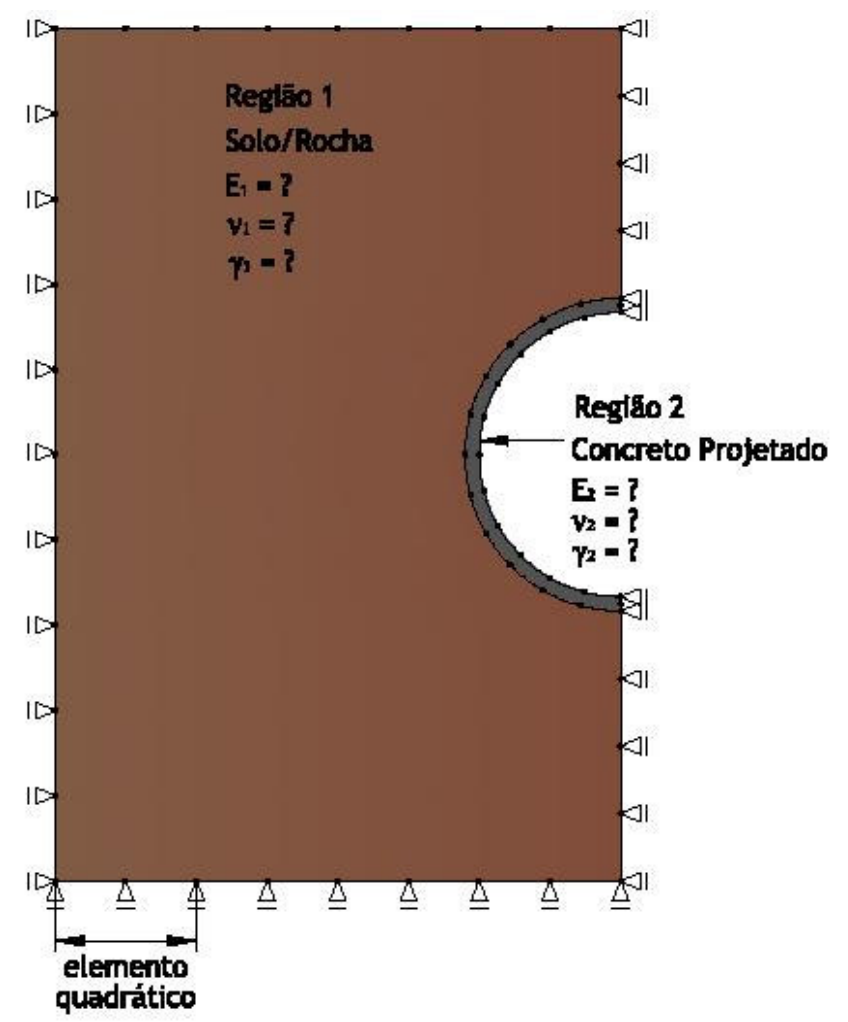

Figura 4.8 - Representação do modelo característico adotado no trabalho.

Como mostra a Figura 4.8, os modelos desta pesquisa tomarão partido da simetria do problema e serão caracterizados por duas regiões, a Região 1 representando o solo ou a rocha e a Região 2 representando o suporte em concreto projetado. 
As propriedades dos materiais utilizados na modelagem se resumiram ao módulo de elasticidade $(E)$, ao coeficiente do Poisson $(v)$ e ao parâmetro viscoso $(\gamma)$, sendo que cada Região terá suas próprias características, simulando assim a interação entre o maciço e o suporte.

Todo método numérico introduz aproximação na solução de um problema, levando por este motivo a soluções aproximadas. Nos modelos utilizados neste trabalho serão considerados elementos quadráticos, que se caracterizam por possuir três nós e fornecerem resultados com boa precisão nas análises como MEC.

Esta pesquisa está incorporada em um projeto maior (Figura 1.1), no qual há o desenvolvimento de um novo software para realizar simulações numéricas em engenharia de túneis. A plataforma computacional que está sendo desenvolvida procura incorporar os mais recentes algoritmos para análises lineares e nãolineares com o MEC. Esta plataforma também inclui os novos algoritmos de pré- e pós-processamento específicos para representações baseada puramente em discretizações de contorno, ao contrário do que é realizado em análises nãolineares, onde é necessário a discretização do domínio do modelo com células internas. Portanto, para todos os casos analisados neste trabalho será necessário apenas a discretização do contorno do modelo, assim como mostra a Figura 4.8.

Para que seja possível a análise baseada puramente em discretizações do contorno, torna-se necessário a utilização de artifícios para levar as integrais de domínio para o contorno. Neste sentido, os trabalhos realizados por Noronha e Pereira (2003), Pereira (2004), Müller (2004) e Carbone (2007) foram fundamentais para o desenvolvimento deste trabalho. De forma bastante resumida, Noronha e Pereira (2003) e Pereira (2004) apresentaram um algoritmo de visualização preciso com a discretização somente do contorno do modelo. Müller (2004) aplicou este novo algoritmo de visualização para solução de problemas elastoplásticos. Por fim Carbone (2007) utilizou o mesmo algoritmo de visualização só que para solução de problemas viscoplástico, sem a necessidade de discretização do contorno do modelo. 
Este trabalho consiste basicamente em usar e adaptar a plataforma existente para a modelagem do suporte em concreto projetado com comportamento viscoelástico. Para tanto, faz-se necessário o uso dos conceitos apresentados no item 3.4, para implementar multi-regiões na plataforma, já que apesar de todos o trabalhos citados, a plataforma foi desenvolvida considerando apenas um domínio homogêneo, o que impossibilita a modelagem de acordo com a Figura 4.8. A Figura 4.9 ilustra esta limitação da plataforma atual que não traz a implementação de multi-regiões.

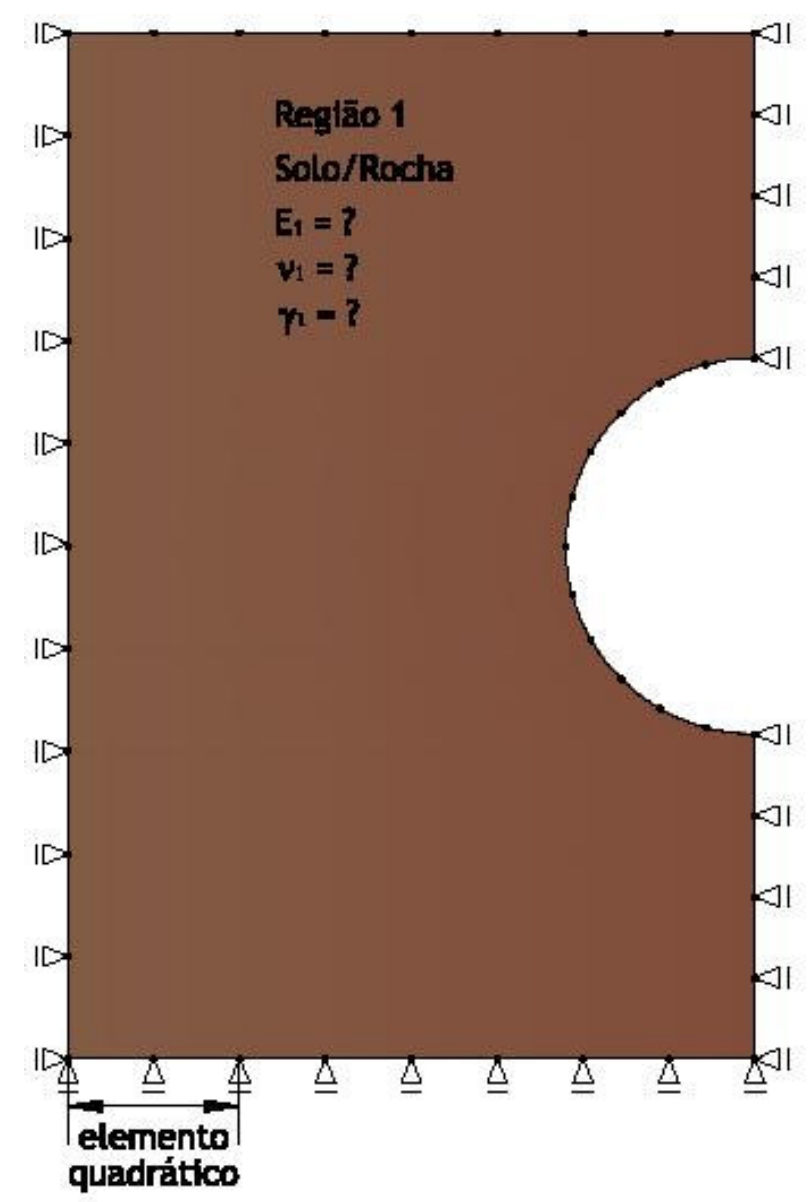

Figura 4.9 - Representação do modelo característico sem multi-regiões.

No MEC o problema de multi-regiões pode ser simulado através do uso de subregiões, onde cada região tem seu contorno discretizado como se fosse independente uma da outra e aplicam-se condições de compatibilidade de deslocamento e equilíbrio de forças nos elementos da interface entre uma subregião e outra para completar o sistema de equações do problema. 
O comportamento viscoelástico no modelo seria obtido inicialmente utilizando o algoritmo proposto por Carbone (2007). Este algoritmo (Figura 4.10) já estava implementado na plataforma, sendo necessários alguns ajustes para a consideração de multi-regiões.

ALGORITIMO PARA ANALUSE VISCOPLASTICA COM O MEC (REPRESENTAÇĀO NO CONTORNO)

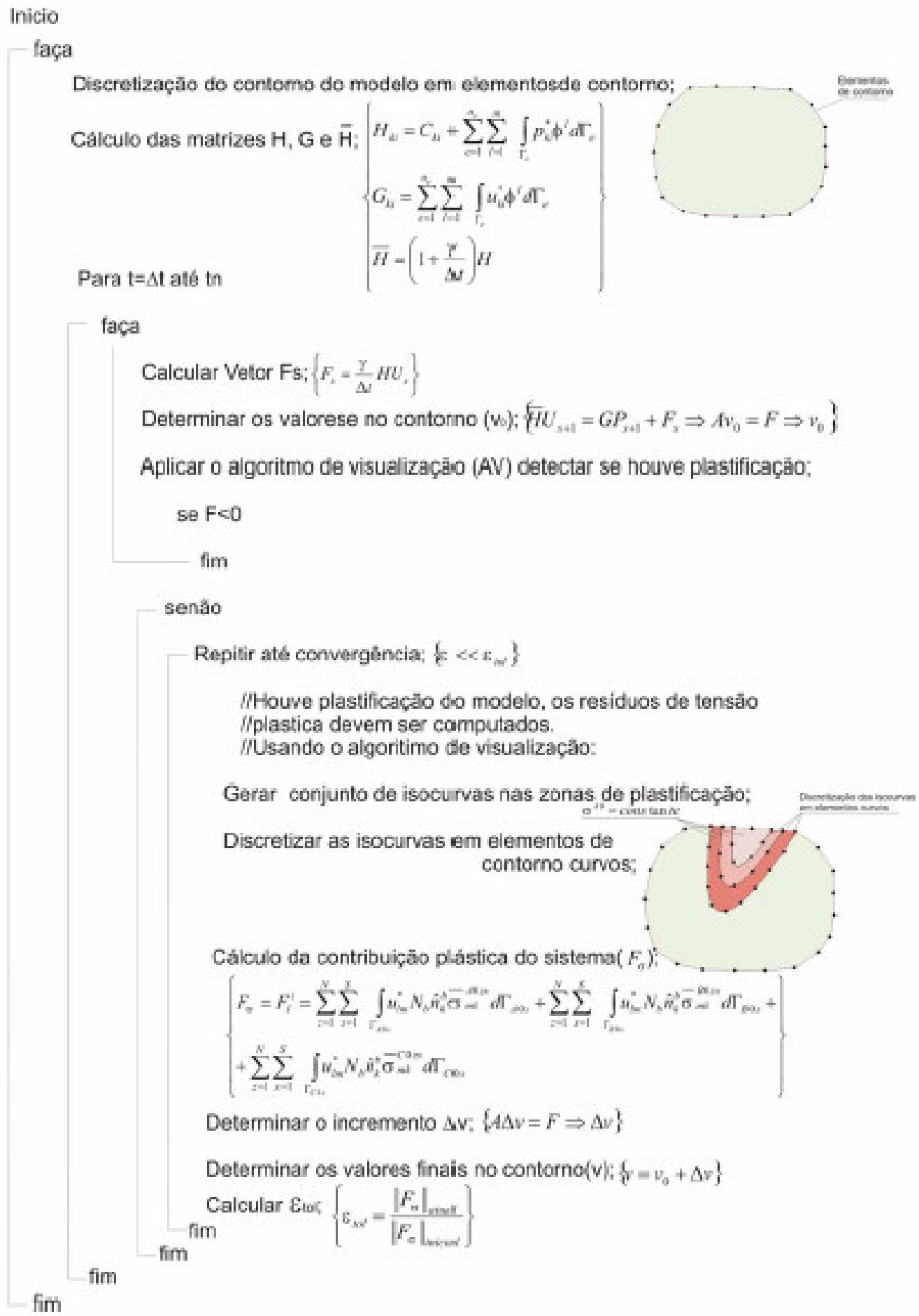

Figura 4.10 - Visão geral do algoritmo proposto por Carbone (2007). 
A questão da multi-regiões foi solucionada inicialmente para o caso de Elastostática. Após isto, o presente desenvolvimento realizou a implementação da viscosidade na plataforma, uma vez que a mudança se resumiu a alteração da equação (3.50) para (3.70) no código. Assim, obteve-se como resultado o algoritmo apresentado na Figura 4.11.

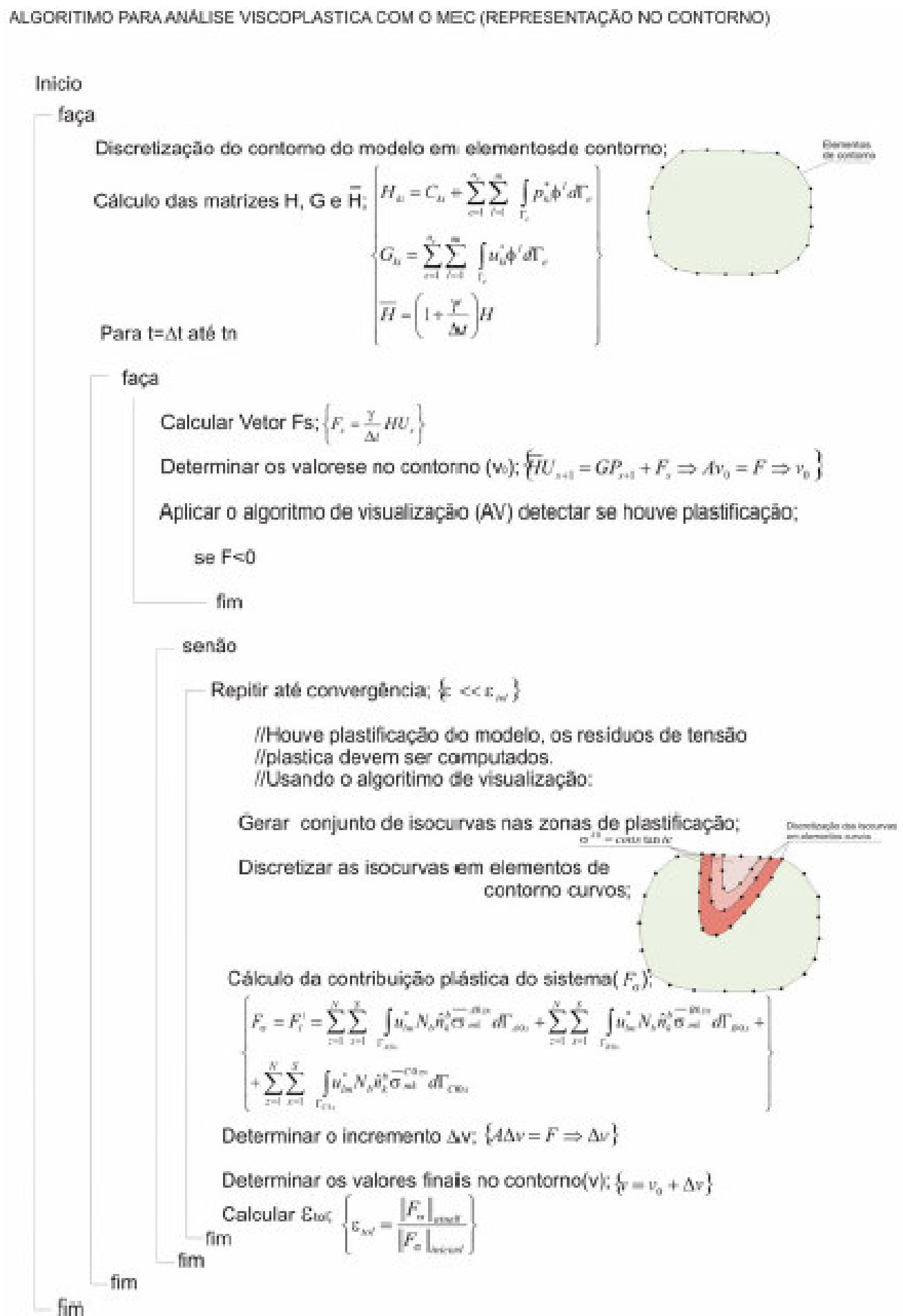

Figura 4.11 - Visão geral do algoritmo proposto. 


\section{EXEMPLOS NUMÉRICOS}

Neste capítulo apresentam-se exemplos numéricos com a finalidade de validar o algoritmo proposto, assim como realizar a modelagem bidimensional da estrutura de suporte de túneis com comportamento viscoelástico, usando o MEC. Para isso, os resultados obtidos pelo algoritmo proposto são confrontados com exemplos encontrados na literatura e análises com o MEF, através do software ADINA. O novo algoritmo viscoelástico considerando multi-regiões foi implementado e incorporado na plataforma computacional para análise numérica em engenharia de túneis utilizando o MEC, que encontra-se em desenvolvimento pelo grupo de pesquisa coordenado pelo Prof. Marcos Noronha. Os resultados dos exemplos apresentados neste capítulo para as análises viscoelásticas foram realizados com a referida plataforma.

\subsection{EXEMPLO 01: PeÇA tRACIONAdA}

Este é um exemplo clássico, amplamente utilizado para aferir modelos viscoelásticos. A sua solução analítica é muito simples e facilmente encontrada, portanto servindo como um "benchmark". Uma peça submetida a um carregamento distribuído de tração aplicado em sua face livre é analisada. Este exemplo será analisado em três situações distintas:

i. Peça tracionada apresentando um único domínio $\Omega$ no problema com comportamento viscoelástico;

ii. Peça tracionada com dois domínios $\Omega_{1}$ e $\Omega_{2}$ no problema, sendo que $\Omega_{1}$ e $\Omega_{2}$ apresentam as mesmas propriedades;

iii. Peça tracionada com dois domínios $\Omega_{1}$ e $\Omega_{2}$ no problema, sendo que $\Omega_{1}$ e $\Omega_{2}$ apresentam propriedades diferentes. 
A Figura 5.1 apresenta o modelo e a discretização em elementos de contorno, bem como as demais características da peça tracionada com um único domínio. Devido à sua simetria, apenas metade da estrutura foi discretizada.
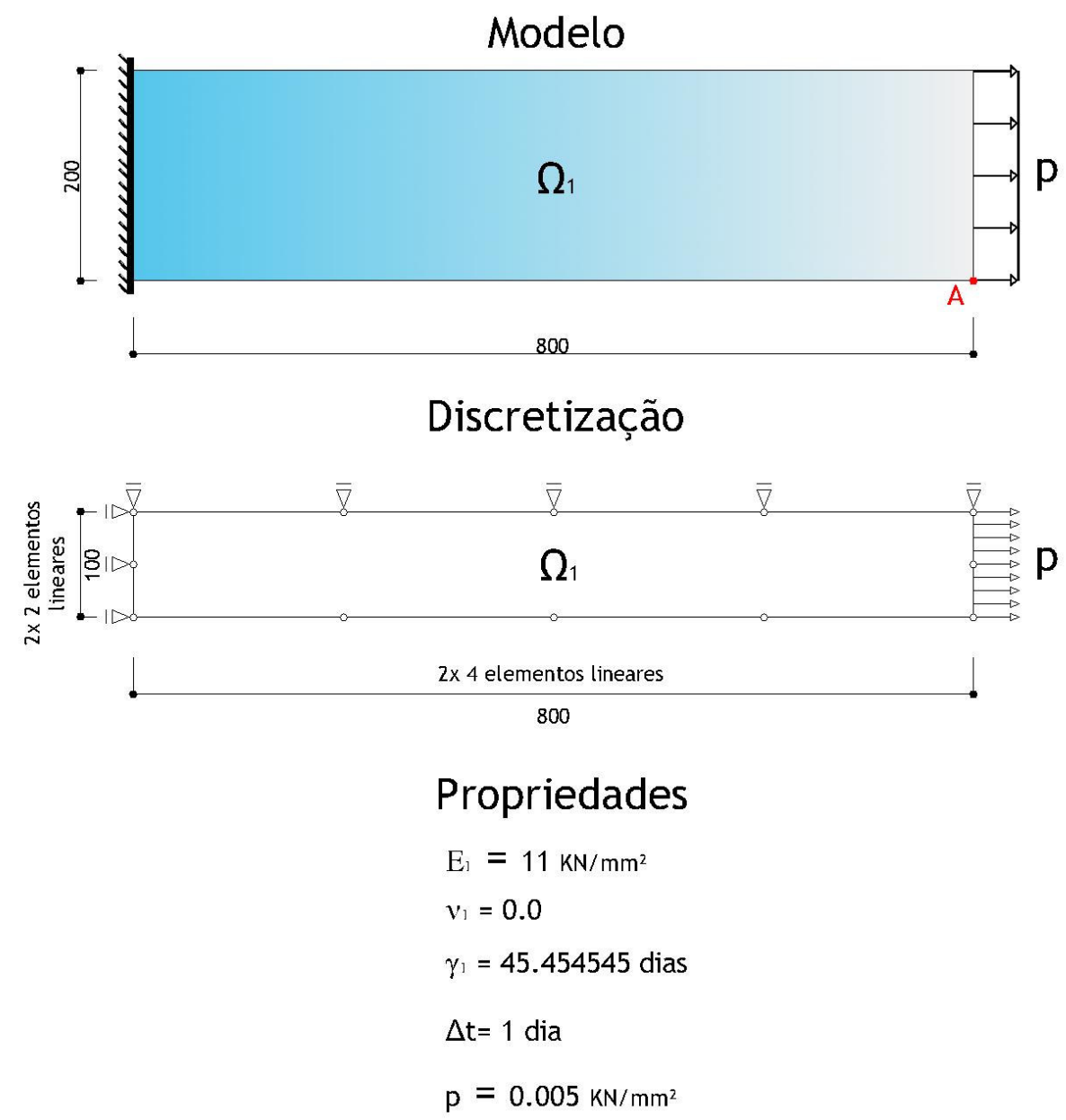

Figura 5.1 - Geometria, discretização e propriedades da estrutura para domínio único.

A resposta obtida com o algoritmo proposto é confrontada com a solução analítica do problema e com a resposta encontrada pelo método dos elementos finitos, através do software ADINA.

A Figura 5.2 apresenta o deslocamento longitudinal do ponto $A$ em função do tempo para a análise viscoelástica baseada no modelo de Kelvin-Voigt, considerando o problema como estado plano de tensão, lembrando que o $\Delta_{t}$ utilizado foi de um dia. 


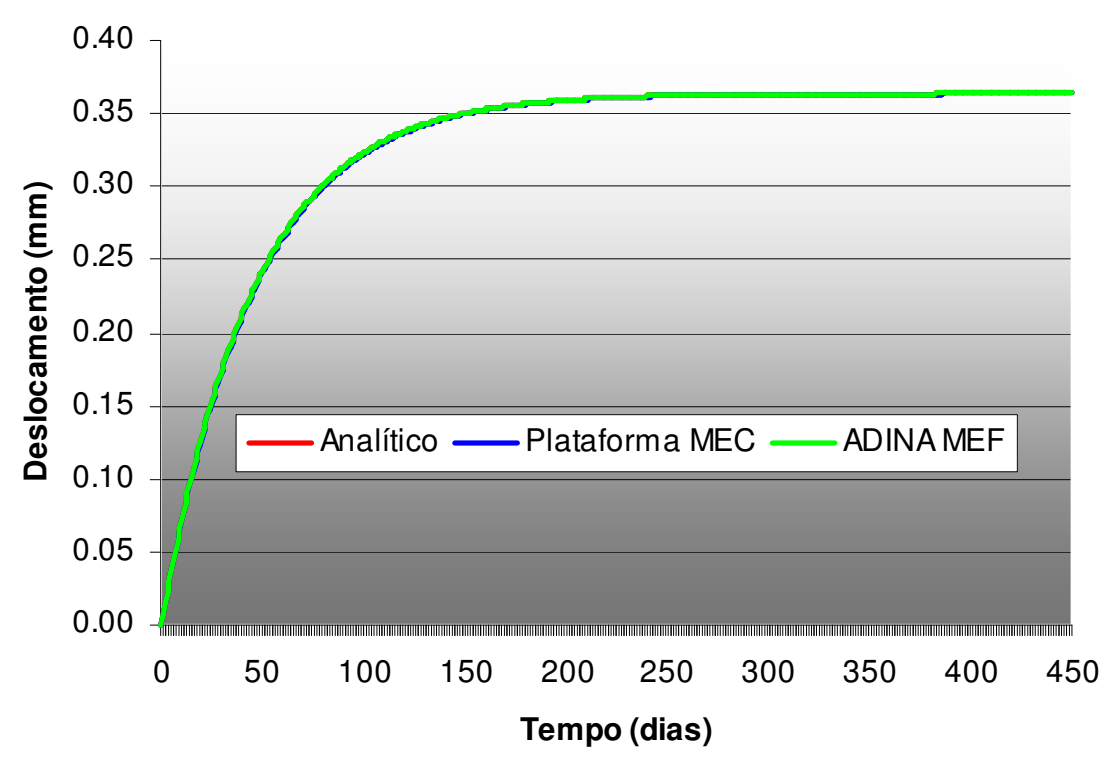

Figura 5.2 - Deslocamento longitudinal do ponto A (domínio único).

Nota-se uma perfeita concordância entre as três análises (solução analítica, Plataforma - MEC e ADINA - MEF), apresentando assim resultados estáveis e precisos, a Tabela 5.1 confronta o deslocamento longitudinal do ponto $\mathrm{A}$ para $\mathrm{t}=$ 450 dias.

Tabela 5.1 - Deslocamento longitudinal do ponto A para t = 450 dias (domínio único).

\begin{tabular}{ccc}
\hline Análise & Discretização & $\begin{array}{c}\text { Deslocamento } \\
(\mathbf{m m})\end{array}$ \\
\hline Analítica & - & 0.363618 \\
\hline Plataforma - MEC & $\begin{array}{c}\text { 12 elementos lineares }-12 \\
\text { nós }\end{array}$ & 0.363616 \\
\hline ADINA - MEF & $\begin{array}{c}128 \text { elementos } \\
\text { isoparamétricos de 9 nós - }\end{array}$ & 0.363618 \\
& 585 nós \\
\hline
\end{tabular}

A Figura 5.3 mostra a malha em elementos finitos realizada no software ADINA assim como $o$ deslocamento longitudinal do ponto $A$ para $t=450$ dias, ilustrando bem a diferença entre o MEC e o MEF no que diz respeito à discretização. 


\begin{tabular}{|c|c|c|c|c|c|c|c|c|c|c|c|c|c|c|c|c|c|c|c|c|c|c|c|c|c|c|c|c|c|c|c|}
\hline 18 & 20 & 22 & 24 & 26 & 28 & 30 & 32 & 64 & 63 & 62 & 67 & 60 & 59 & 58 & 57 & 96 & 95 & 94 & 93 & 92 & 91 & 90 & 89 & 128 & 127 & 125 & 125 & 124 & 123 & 122 & 721 \\
\hline 17 & 19 & 21 & 25 & 25 & 27 & 29 & 31 & 56 & 55 & 54 & 53 & 52 & 51 & 50 & 49 & 58 & 97 & 86 & 85 & 84 & 83 & 82 & 87 & 120 & 119 & 118 & 117 & 116 & 115 & 114 & 113 \\
\hline 2 & 4 & 6 & 8 & 10 & 12 & 14 & 16 & 48 & 47 & 46 & 45 & 44 & 43 & 42 & 41 & 80 & 79 & 78 & 77 & 76 & 75 & 74 & 73 & 112 & 111 & 110 & 109 & 108 & 107 & 106 & 105 \\
\hline 1 & 3 & 5 & 7 & 9 & 11 & 13 & 15 & 40 & 39 & 38 & 37 & 35 & 35 & 34 & 33 & 72 & 71 & 70 & 69 & 68 & 67 & 66 & 65 & 104 & 103 & 102 & 107 & 100 & 99 & 98 & 97 \\
\hline
\end{tabular}

A
$\mathbf{D}$
$\mathbf{I}$
$\mathbf{N}$
$\mathbf{A}$

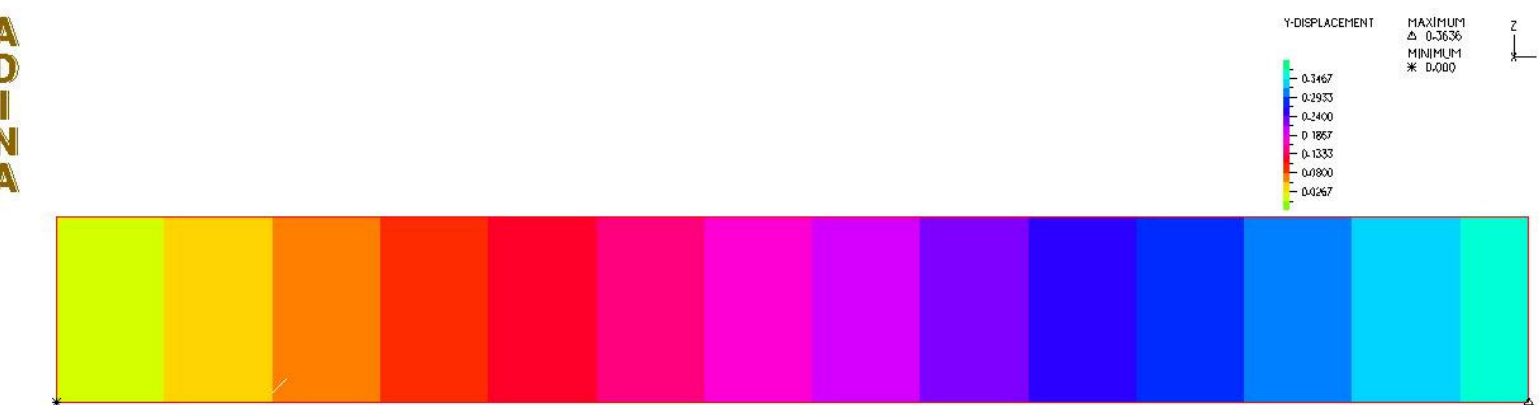

Figura 5.3 - Malha de elementos finitos e deslocamento longitudinal do ponto A para $\mathrm{t}=450$ dias (domínio único).

Vale salientar a representação bem mais simples e reduzida do modelo discretizado com o MEC (Figura 5.1) quando comparado com o modelo discretizado com o MEF (Figura 5.3).

Esta primeira simulação é importante para mostrar que a nova plataforma realiza simulações viscoelásticas com apenas um domínio e para validar a mesma para esse tipo de situação.

Agora vamos modelar a segunda situação onde temos dois domínios no problema, ambos com as mesmas propriedades. A Figura 5.4 apresenta o modelo e a discretização em elementos de contorno, bem como as demais características da peça tracionada com dois domínios. Devido à sua simetria, apenas metade da estrutura foi discretizada.

Assim como na situação anterior a resposta obtida com o algoritmo proposto é confrontada com a solução analítica do problema e com a resposta encontrada pelo método dos elementos finitos, através do software ADINA. 


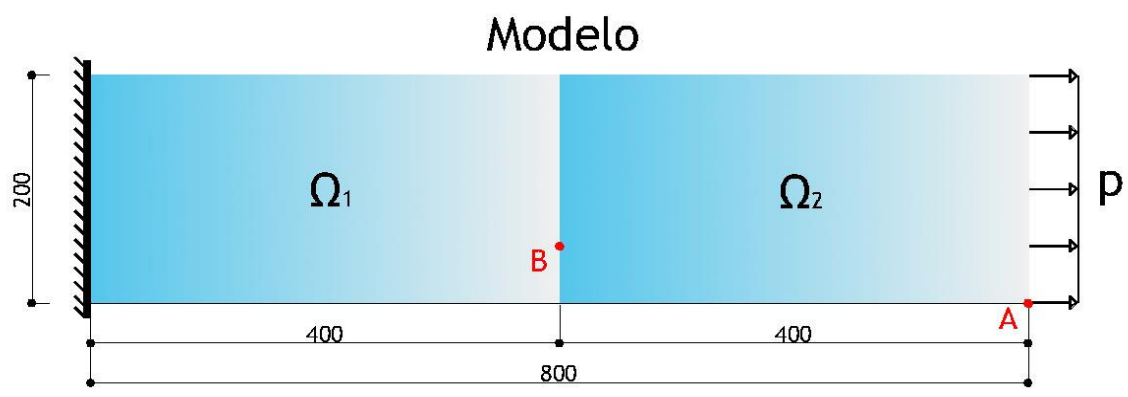

Discretização

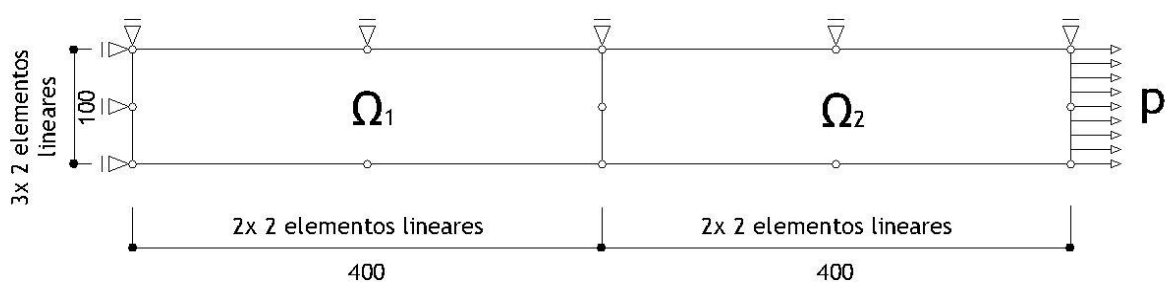

\section{Propriedades}

$$
\begin{aligned}
& \mathrm{E}_{1}=11 \mathrm{kN} / \mathrm{mm}^{2} \\
& v_{1}=0.0 \\
& \gamma_{1}=45.454545 \text { dias } \\
& \Delta \mathrm{t}=1 \mathrm{dia} \\
& \mathrm{p}=0.005 \mathrm{kN} / \mathrm{mm}^{2}
\end{aligned}
$$

$$
\begin{aligned}
& \mathrm{E}_{2}=11 \mathrm{kN} / \mathrm{mm}^{2} \\
& v_{2}=0.0 \\
& \gamma_{2}=45.454545 \text { dias }
\end{aligned}
$$

Figura 5.4 - Geometria, discretização e propriedades da estrutura para dois domínios iguais.

A Figura 5.5 apresenta o deslocamento longitudinal do ponto $A$ em função do tempo para a análise viscoelástica baseada no modelo de Kelvin-Voigt, considerando o problema como estado plano de tensão.

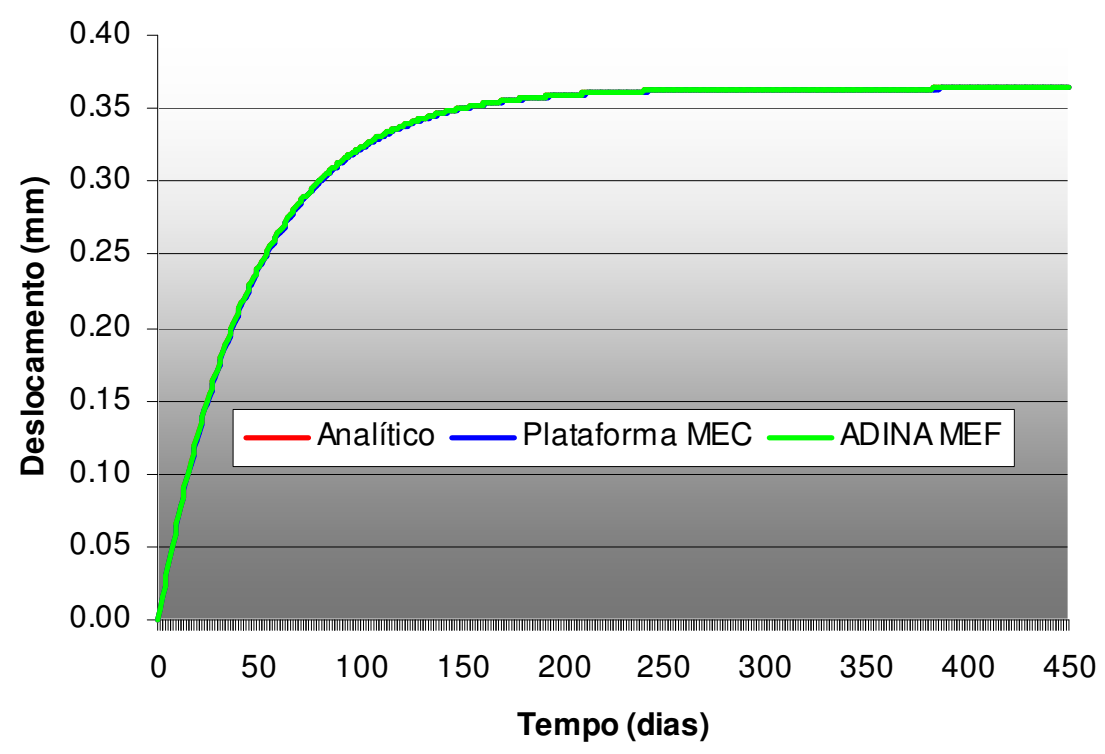

Figura 5.5 - Deslocamento longitudinal do ponto A (domínios iguais). 
Como já se esperava o resultado desta análise foi exatamente igual à situação anterior, onde tínhamos apenas um domínio, como nesta análise os domínios apresentam as mesmas propriedades não havia motivo para que o resultado fosse diferente.

Esta segunda simulação é importante para mostrar que a nova plataforma realiza simulações viscoelásticas com mais de um domínio e para validar a mesma para esse tipo de situação, além disso, é possível compará-lo com a situação anterior, onde tínhamos um único domínio.

A Figura 5.6 apresenta o deslocamento longitudinal do ponto B em função do tempo para a análise viscoelástica baseada no modelo de Kelvin-Voigt, considerando o problema como estado plano de tensão, lembrando que este ponto faz parte da interface das duas regiões.

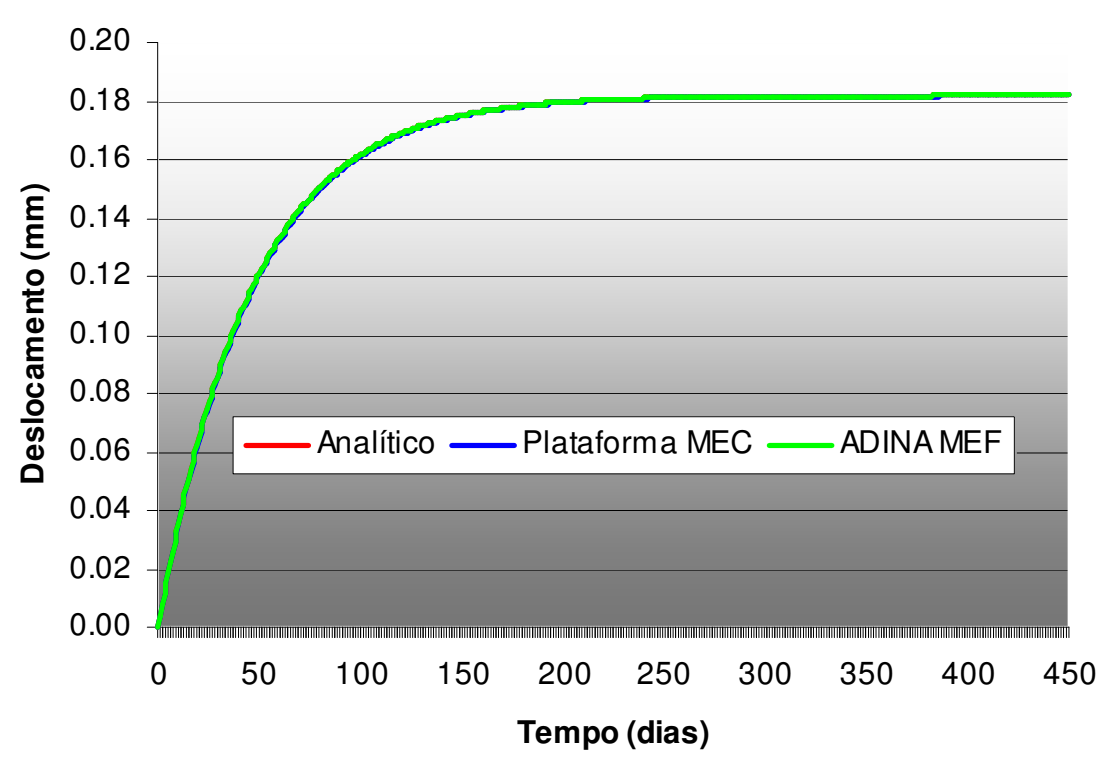

Figura 5.6 - Deslocamento longitudinal do ponto B (domínios iguais).

O comportamento da solução numérica está perfeitamente de acordo com aquele apresentado pela solução analítica. A Tabela 5.2 confronta o deslocamento longitudinal do ponto $B$ para $t=450$ dias e ratifica os bons resultados encontrados. 
Tabela 5.2 - Deslocamento longitudinal do ponto B para $t=450$ dias (domínios iguais).

Análise

Discretização

Deslocamento

$(\mathrm{mm})$

\begin{tabular}{|c|c|c|}
\hline Analítica & - & 0.181809 \\
\hline Plataforma - MEC & $\begin{array}{l}16 \text { elementos lineares }-16 \\
\text { nós }\end{array}$ & 0.181808 \\
\hline ADINA - MEF & $\begin{array}{c}128 \text { elementos } \\
\text { isoparamétricos de } 9 \text { nós - } \\
585 \text { nós }\end{array}$ & 0.181818 \\
\hline
\end{tabular}

Agora vamos modelar a terceira situação onde temos dois domínios no problema, mas agora com propriedades diferentes. A Figura 5.7 apresenta o modelo e a discretização em elementos de contorno, bem como as demais características da peça tracionada com domínios diferentes. Devido à sua simetria, apenas metade da estrutura foi discretizada.

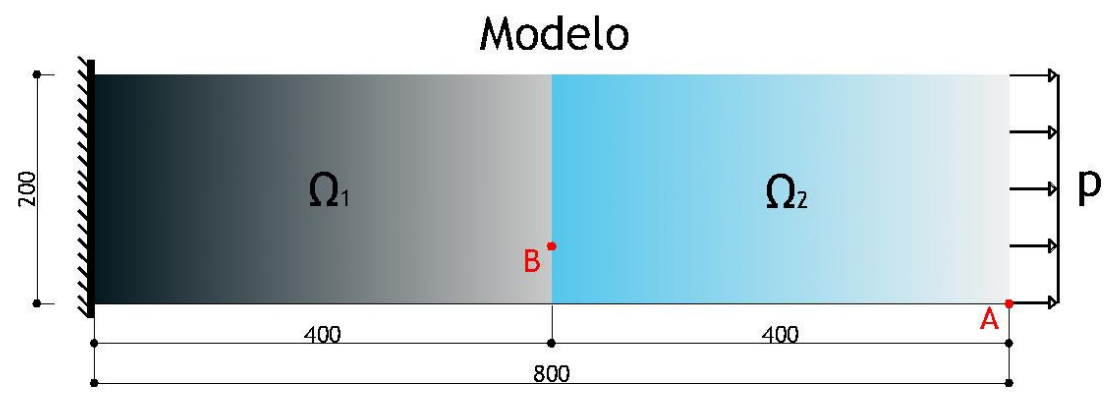

Discretização

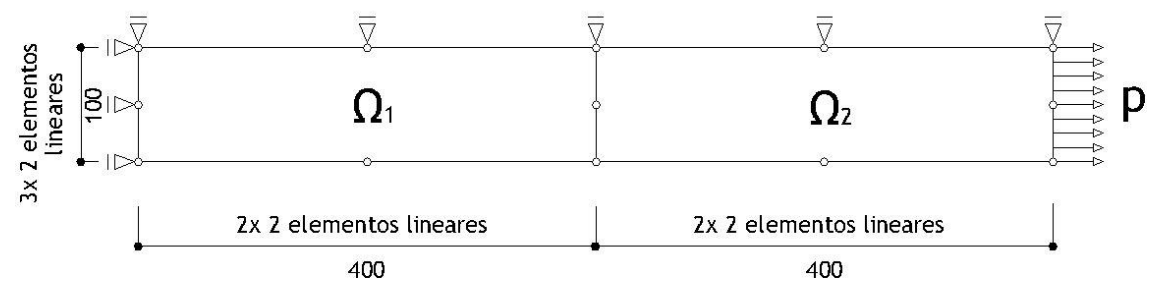

Propriedades

$$
\begin{aligned}
& E_{1}=70 \mathrm{kN} / \mathrm{mm}^{2} \\
& v_{1}=0.0 \\
& \gamma_{1}=250 \text { dias } \\
& \Delta t=1 \mathrm{dia} \\
& p=0.005 \mathrm{kN} / \mathrm{mm}^{2}
\end{aligned}
$$$$
\mathrm{E}_{2}=11 \mathrm{kN} / \mathrm{mm}^{2}
$$$$
v_{2}=0.0
$$$$
\gamma_{2}=45.454545 \text { dias }
$$

Figura 5.7 - Geometria, discretização e propriedades da estrutura para domínios diferente. 
A Figura 5.8 apresenta o deslocamento longitudinal do ponto $A$ em função do tempo para a análise viscoelástica baseada no modelo de Kelvin-Voigt, considerando o problema como estado plano de tensão e propriedades diferentes para os dois domínios.

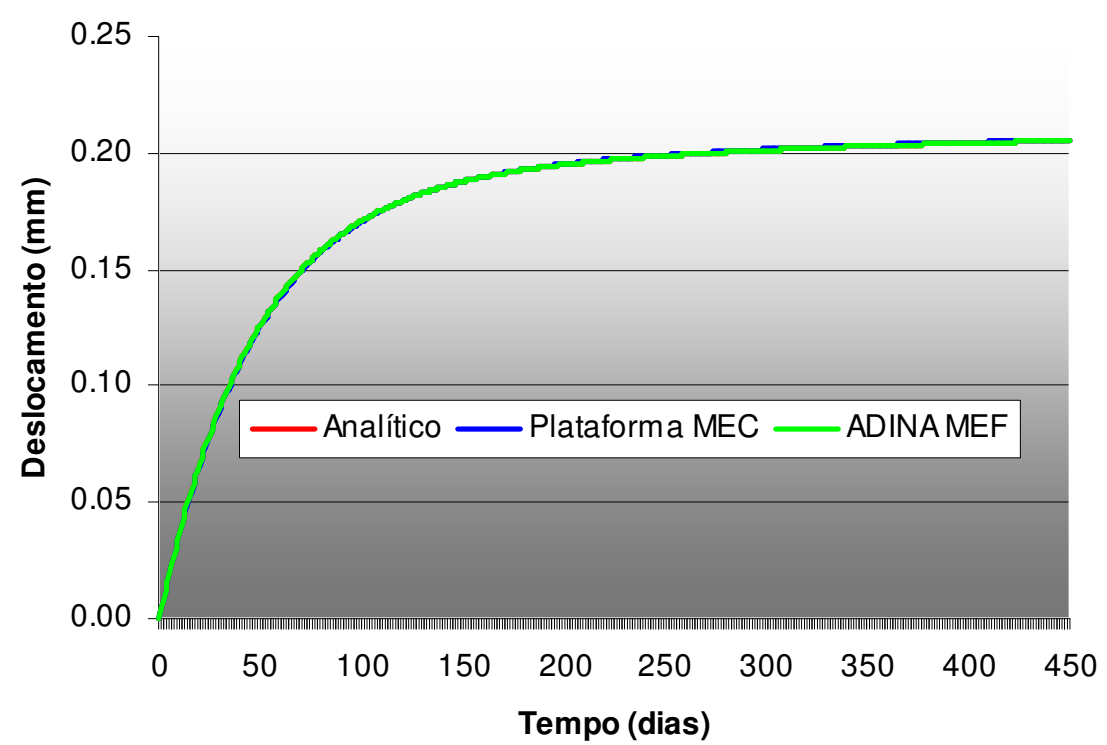

Figura 5.8 - Deslocamento longitudinal do ponto A para domínios diferentes.

Novamente nota-se uma perfeita concordância entre as três soluções (solução analítica, Plataforma - MEC e ADINA - MEF), apresentando assim resultados estáveis e precisos. A Tabela 5.3 e a Tabela 5.4 confrontam o deslocamento longitudinal do ponto $A$ e do ponto $B$ respectivamente para $t=450$ dias.

Tabela 5.3 - Deslocamento longitudinal do ponto A para t = 450 dias (domínios diferentes).

Análise

Discretização

Deslocamento (mm)

\begin{tabular}{ccc}
\hline Analítica & - & 0.205353 \\
\hline Plataforma - MEC & $\begin{array}{c}\text { 16 elementos lineares - 16 } \\
\text { nós }\end{array}$ & 0.205639 \\
\hline ADINA - MEF & $\begin{array}{c}\text { 128 elementos } \\
\text { isoparamétricos de 9 nós - } \\
585 \text { nós }\end{array}$ & 0.205353 \\
& & \\
\hline
\end{tabular}


Tabela 5.4 - Deslocamento longitudinal do ponto B para t = 450 dias (domínios diferentes).

Análise

Discretização

Deslocamento

$(\mathrm{mm})$

\begin{tabular}{ccc}
\hline Analítica & - & 0.023544 \\
\hline Plataforma - MEC & $\begin{array}{c}\text { 16 elementos lineares }-16 \\
\text { nós }\end{array}$ & 0.023832 \\
\hline ADINA - MEF & $\begin{array}{c}128 \text { elementos } \\
\text { isoparamétricos de } 9 \text { nós - } \\
585 \text { nós }\end{array}$ & 0.023544 \\
\hline
\end{tabular}

Devido às propriedades do $\Omega_{1}$ os deslocamentos diminuíram, o que já era esperado uma vez que o módulo de Elasticidade deste material aumentou. Esta terceira simulação é importante para a validação da plataforma viscoelástica com multiregiões. A Figura 5.9 apresenta as duas regiões na malha dos elementos finitos realizada no software ADINA assim como os deslocamentos longitudinais para $t=$ 450 dias.
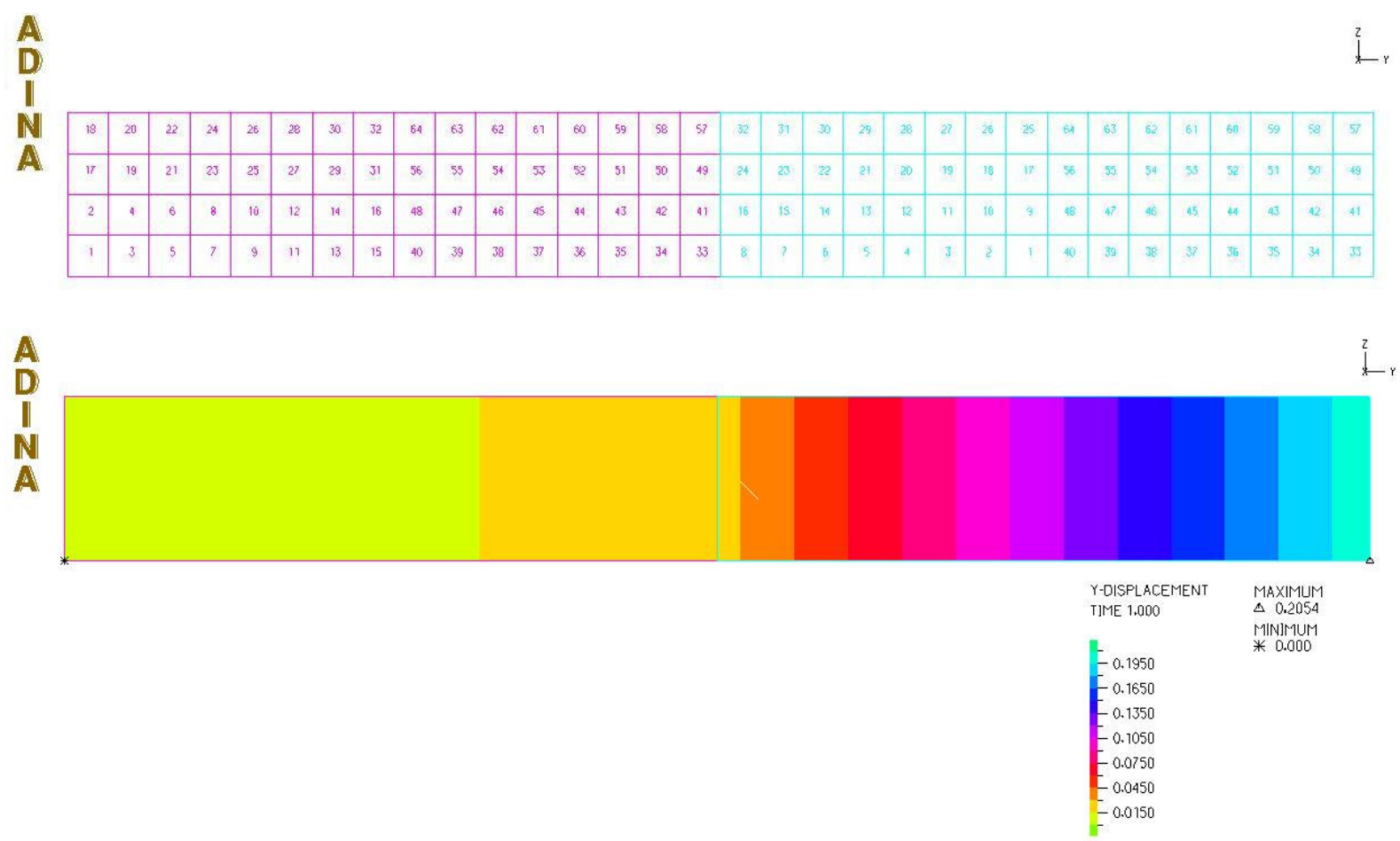

Figura 5.9 - Malha de elementos finitos das duas regiões e deslocamento longitudinal para $t=$ 450 dias. 


\subsection{EXEMPLO 02: CILINDRO SOB PRESSÃO INTERNA}

Um cilindro de parede espessa submetido a uma pressão interna $\boldsymbol{P}$ é analisado. Devido à sua dupla simetria apenas 1/4 da estrutura é discretizada. Este exemplo foi analisado nas mesmas situações do exemplo anterior, ou seja, para uma região, para duas regiões iguais e por último para duas regiões diferentes.

A Figura 5.10 apresenta o modelo e a discretização em elementos de contorno, bem como as demais características do cilindro sob pressão interna com um único domínio. Neste exemplo utilizou-se 14 elementos quadráticos implicando em 28 nós.
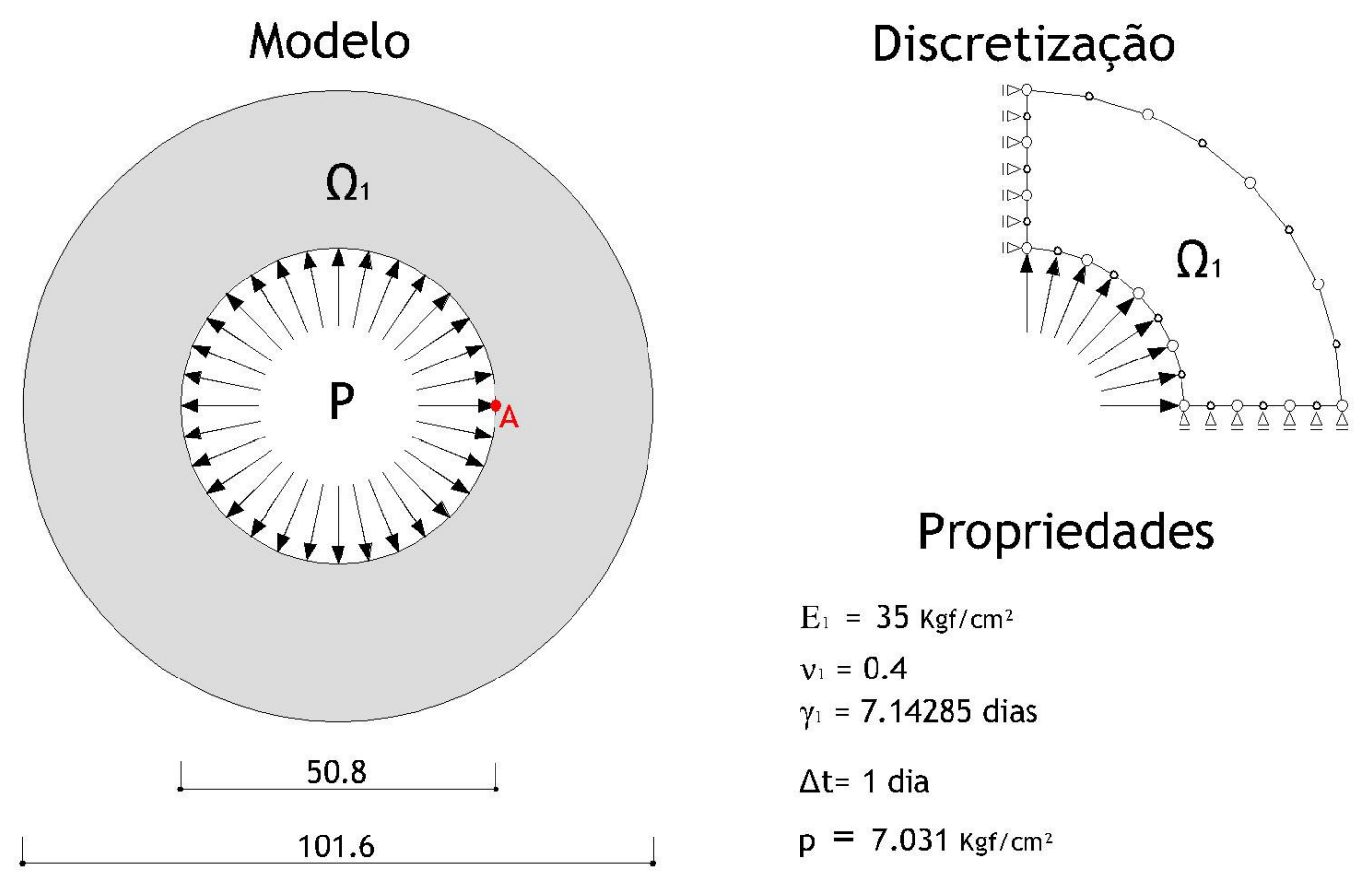

\section{Propriedades}

$\mathrm{E}_{1}=35 \mathrm{kgf} / \mathrm{cm}^{2}$

$v_{l}=0.4$

$\gamma_{1}=7.14285$ dias

$\Delta \mathrm{t}=1 \mathrm{dia}$

$\mathrm{p}=7.031 \mathrm{Kgf} / \mathrm{cm}^{2}$

Figura 5.10 - Geometria, discretização e propriedades do cilindro para domínio único.

Assim como no exemplo anterior, a resposta obtida com o algoritmo proposto é confrontada com a solução analítica do problema e com a resposta encontrada pelo método dos elementos finitos, através do software ADINA.

Os resultados do deslocamento radial, para o problema de estado plano de tensão da parede interna são apresentados na Figura 5.11, lembrando que a análise viscoelástica é baseada da no modelo de Kelvin-Voigt. 


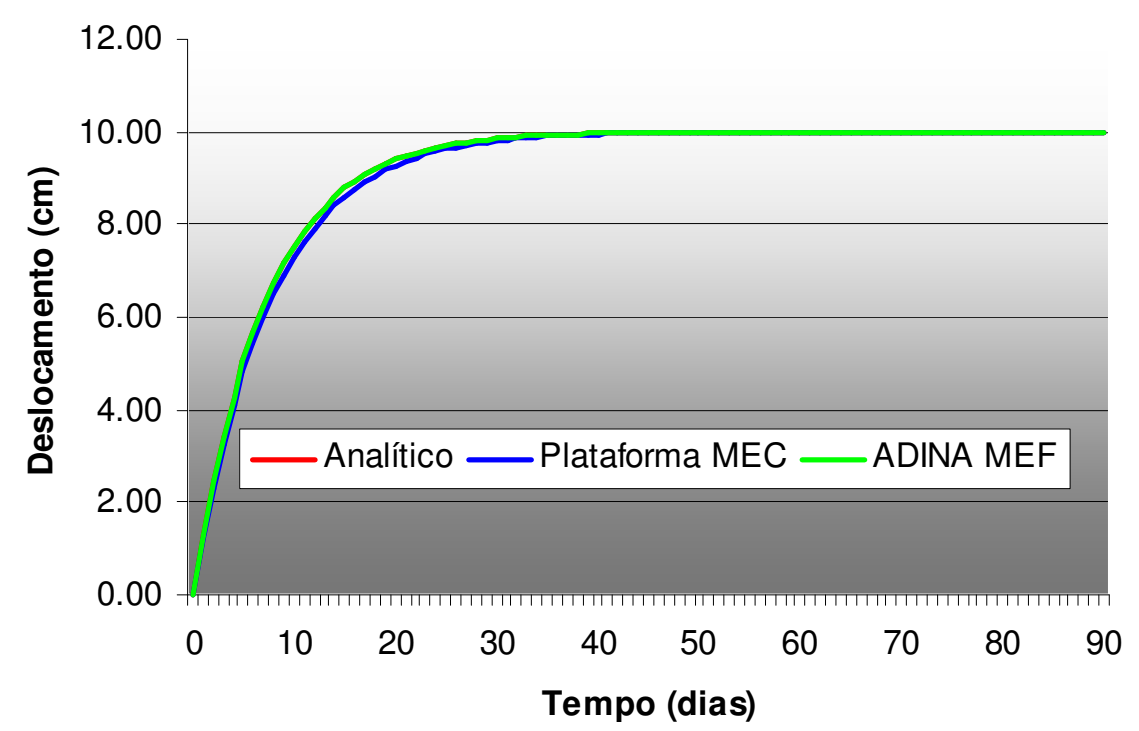

Figura 5.11 - Deslocamento radial da parede interna (domínio único).

Como pode ser observado, os resultados obtidos são bastante precisos. A Tabela 5.5 compara o deslocamento radial da parede interna para $\mathrm{t}=90$ dias.

Tabela 5.5 - Deslocamento radial da parede interna para t = 90 dias (domínio único).

\begin{tabular}{ccc} 
Análise & Discretização & $\begin{array}{c}\text { Deslocamento } \\
\text { (cm) }\end{array}$ \\
\hline Analítica & - & 10.000861 \\
\hline Plataforma - MEC & $\begin{array}{c}14 \text { elementos quadráticos - } \\
28 \text { nós }\end{array}$ & 10.000149 \\
\hline ADINA - MEF & $\begin{array}{c}96 \text { elementos } \\
\text { isoparamétricos de 9 nós - } \\
429 \text { nós }\end{array}$ & 10.004700 \\
\hline
\end{tabular}

A Figura 5.12 mostra a malha em elementos finitos realizada no software ADINA assim como o deslocamento radial da parede interna para $t=90$ dias, ilustrando bem a diferença entre o MEC e o MEF no que diz respeito à discretização. Novamente vale ressaltar a representação bem mais simples e reduzida do modelo discretizado com o MEC quando comparado com o modelo discretizado com o MEF. 
A
$\mathbf{D}$
$\mathbf{N}$
$\mathbf{N}$

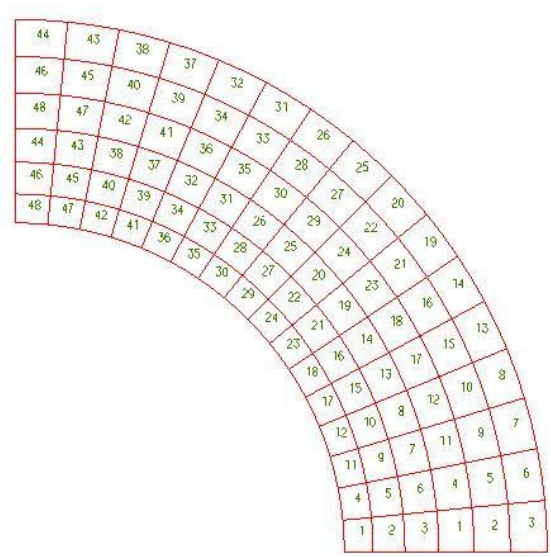

A
$\mathbf{D}$
$\mathbf{I}$
$\mathbf{N}$
$\mathrm{A}$

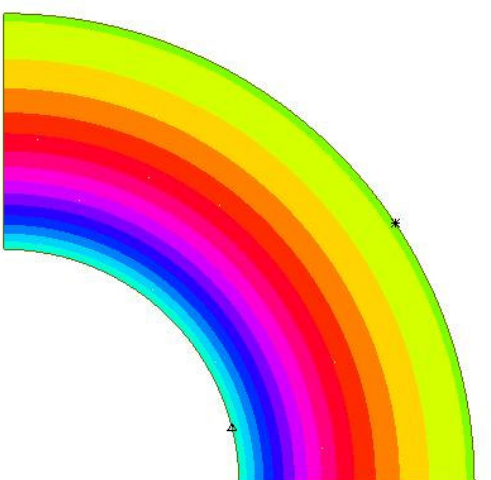

DISPLACEMENT MAXIMUM

$\triangle 10.00$
MINIMUM

米 6.455

Figura 5.12 - Malha de elementos finitos e deslocamento radial da parede interna para $t=90$ dias (domínio único).

A seguir, apresenta-se a modelagem da segunda situação onde temos dois domínios no problema, ambos com as mesmas propriedades. A Figura 5.13 apresenta o modelo e a discretização em elementos de contorno, bem como as demais características do cilindro sob pressão interna com dois domínios. Devido à sua dupla simetria apenas $1 / 4$ da estrutura foi discretizada.

Seguindo a mesma lógica adotada até aqui, a resposta obtida com o algoritmo proposto é confrontada com a solução analítica do problema e com a resposta encontrada pelo método dos elementos finitos, através do software ADINA.

Esta segunda simulação é importante para mostrar que a nova plataforma realiza simulações viscoelásticas com mais de um domínio e para validar a mesma para esse tipo de situação. Além disso, é possível compará-lo com a situação anterior, onde tínhamos um único domínio. 


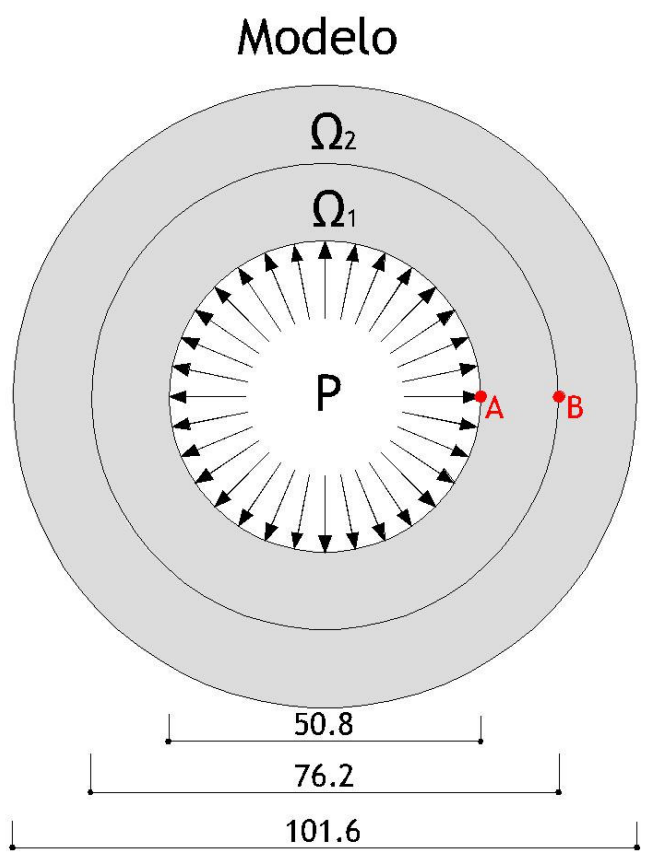

Discretização

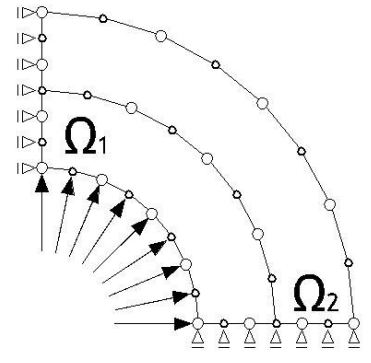

\section{Propriedades}

$$
\begin{array}{ll}
E_{1}=35 \mathrm{kgf} / \mathrm{cm}^{2} & E_{2}=35 \mathrm{kgf} / \mathrm{cm}^{2} \\
v_{1}=0.4 & v_{2}=0.4 \\
\gamma_{1}=7.14285 \text { dias } & \gamma_{2}=7.14285 \text { dias } \\
\Delta t=1 \text { dia } & \\
p=7.031 \mathrm{~kg} / \mathrm{cm}^{2} &
\end{array}
$$

Figura 5.13 - Geometria, discretização e propriedades do cilindro para domínios iguais.

Os resultados do deslocamento radial, para o problema de estado plano de tensão da parede interna são apresentados na Figura 5.14.

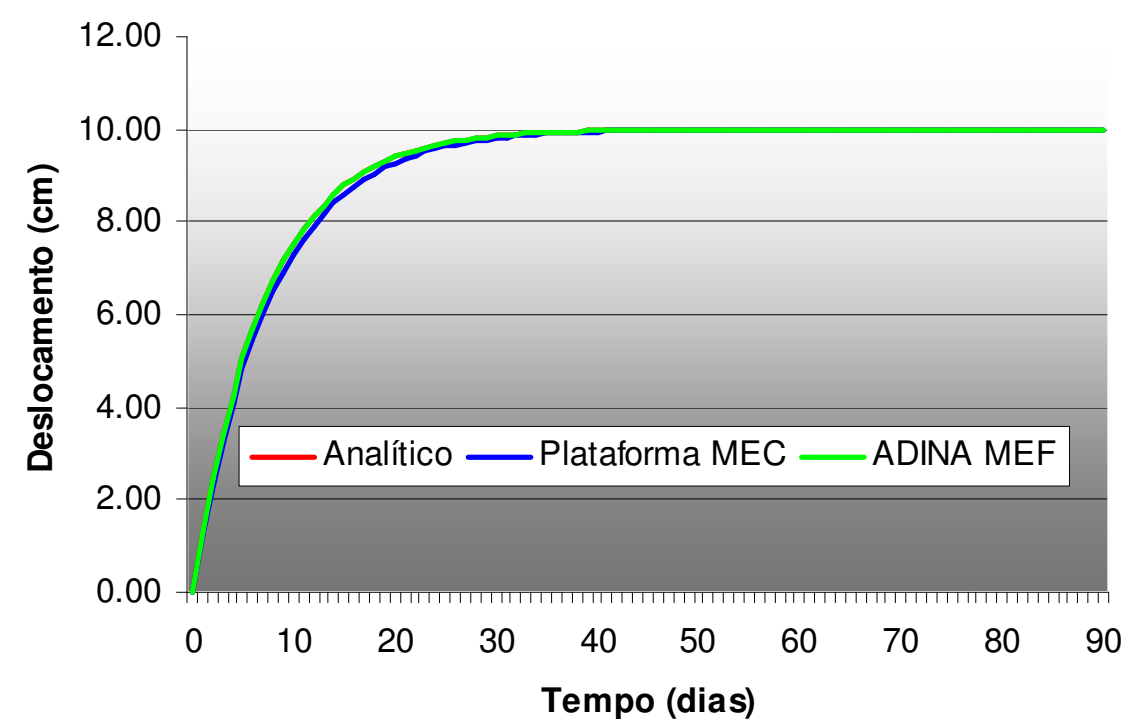

Figura 5.14 - Deslocamento radial da parede interna para dois domínios iguais.

Como já se previa, o resultado desta análise foi exatamente igual à situação anterior, onde tínhamos apenas um domínio. De fato, como nesta análise os domínios apresentam as mesmas propriedades não havia motivo para que o resultado fosse diferente. 
A Figura 5.15 apresenta o deslocamento radial na interface entre os dois domínios, onde localiza-se o ponto $\mathrm{B}$, em função do tempo para a análise viscoelástica baseada no modelo de Kelvin-Voigt, considerando o problema como estado plano de tensão, lembrando que este ponto faz parte da interface das duas regiões.

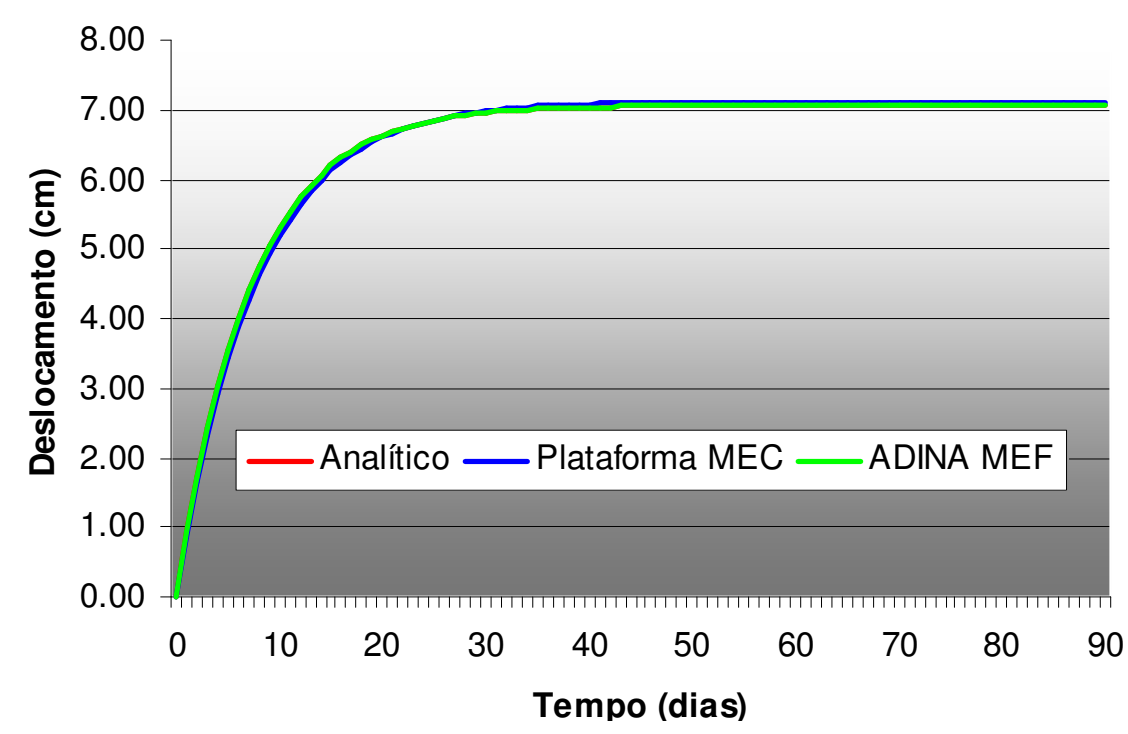

Figura 5.15 - Deslocamento radial do ponto B para dois domínios iguais.

O deslocamento radial na interface entre os dois domínios, onde localiza-se o ponto $\mathrm{B}$, é menor que o deslocamento radial na parede interna do vaso, o que já se esperava. A Tabela 5.6 confronta os resultados encontrados para o deslocamento radial na interface entre os dois domínios para $\mathrm{t}=90$ dias.

Tabela 5.6 - Deslocamento radial na interface entre os dois domínios para $\mathrm{t}=90$ dias.

\begin{tabular}{ccc} 
Análise & Discretização & $\begin{array}{c}\text { Deslocamento } \\
(\mathbf{c m})\end{array}$ \\
\hline Analítica & - & 7.064100 \\
\hline Plataforma - MEC & 18 elementos quadráticos - \\
& 36 nós & 7.120205 \\
\hline ADINA - MEF & $\begin{array}{c}96 \text { elementos } \\
\text { isoparamétricos de 9 nós - } \\
\end{array}$ & 4.070000 \\
\hline
\end{tabular}


Finalizando os exemplos de validações do algoritmo proposto, vamos modelar a terceira situação onde temos dois domínios no problema, agora com propriedades diferentes. A Figura 5.16 apresenta o modelo e a discretização em elementos de contorno, bem como as demais características do cilindro sob pressão interna com dois domínios diferentes. Devido à sua dupla simetria apenas $1 / 4$ da estrutura foi discretizada.
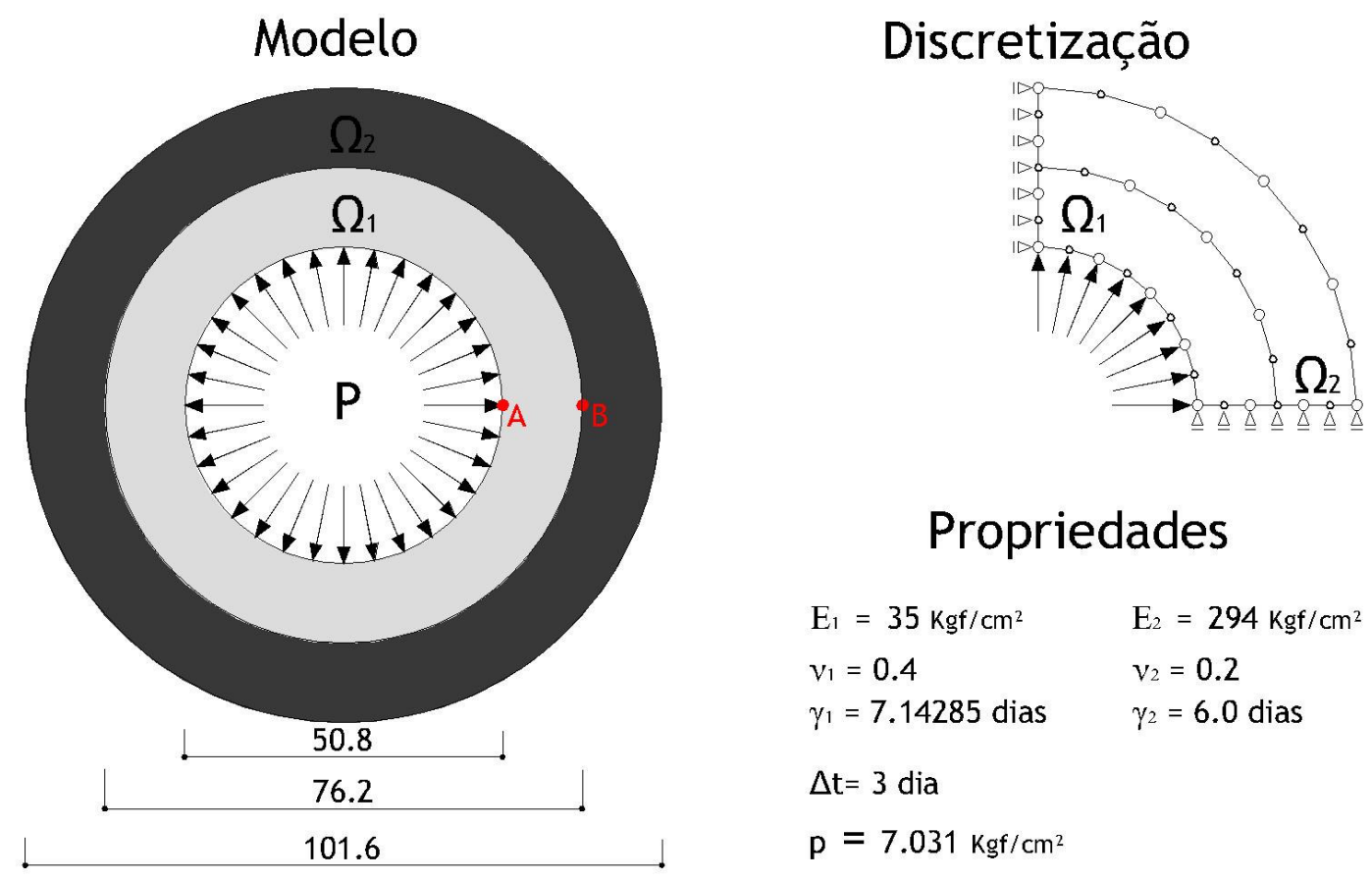

\section{Propriedades}

$\begin{array}{ll}\mathrm{E}_{1}=35 \mathrm{kgf} / \mathrm{cm}^{2} & \mathrm{E}_{2}=294 \mathrm{kgf} / \mathrm{cm}^{2} \\ \mathrm{v}_{1}=0.4 & \mathrm{v}_{2}=0.2 \\ \gamma_{1}=7.14285 \text { dias } & \gamma_{2}=6.0 \text { dias } \\ \Delta \mathrm{t}=3 \mathrm{dia} & \\ \mathrm{p}=7.031 \mathrm{kgf} / \mathrm{cm}^{2} & \end{array}$

Figura 5.16 - Geometria, discretização e propriedades do cilindro para domínios diferentes.

Diferente das situações anteriores a resposta obtida neste último exemplo é confrontada apenas com a solução pelo método dos elementos finitos, através do software ADINA. Outro parâmetro que mudou neste último exemplo de validação foi o $\Delta_{t}$ utilizado, sendo agora igual a três dias.

A Figura 5.17 apresenta o deslocamento radial da parede interna, onde se localiza o ponto $A$, em função do tempo para a análise viscoelástica baseada no modelo de Kelvin-Voigt, considerando o problema como estado plano de tensão e propriedades diferentes para os dois domínios. 


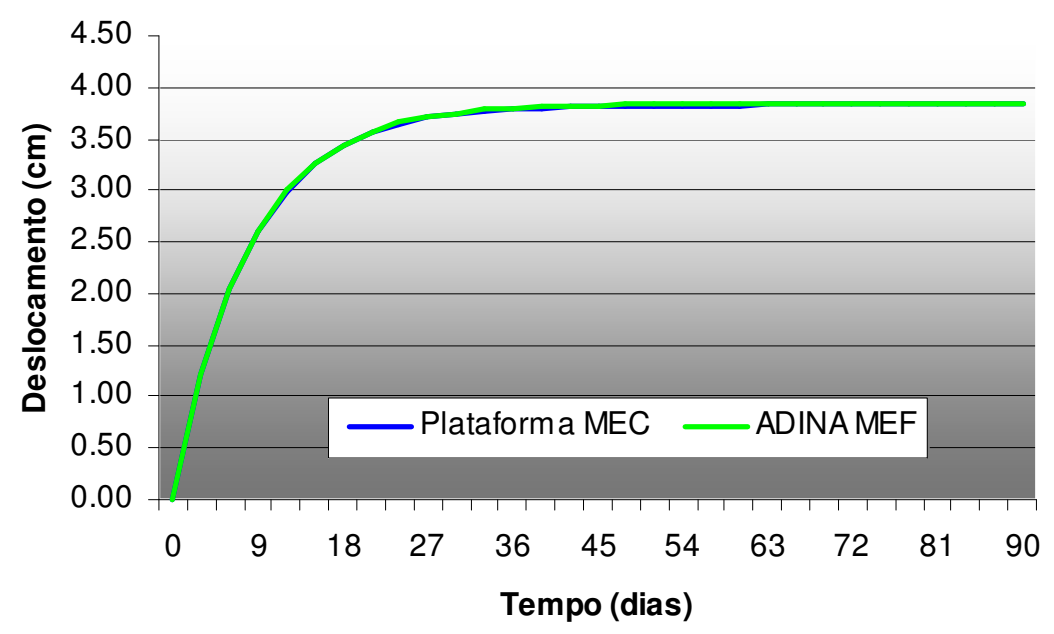

Figura 5.17 - Deslocamento radial da parede interna para dois domínios diferentes.

A Figura 5.17 ratifica os bons resultados encontrados até aqui. A Tabela 5.7 compara o deslocamento radial da parede interna para $\mathrm{t}=90$ dias.

Tabela 5.7 - Deslocamento radial da parede interna para $\mathrm{t}=90$ dias (domínios diferentes).

Análise

\begin{tabular}{ccc}
\hline Plataforma - MEC & $\begin{array}{c}\text { 18 elementos quadráticos - } \\
36 \text { nós }\end{array}$ & 3.832038 \\
\hline ADINA - MEF & $\begin{array}{c}96 \text { elementos } \\
\text { isoparamétricos de } 9 \text { nós - } \\
429 \text { nós }\end{array}$ & 3.8387026 \\
\hline
\end{tabular}
(cm)

Deslocamento

A Figura 5.18 apresenta o deslocamento radial na interface entre os dois domínios.

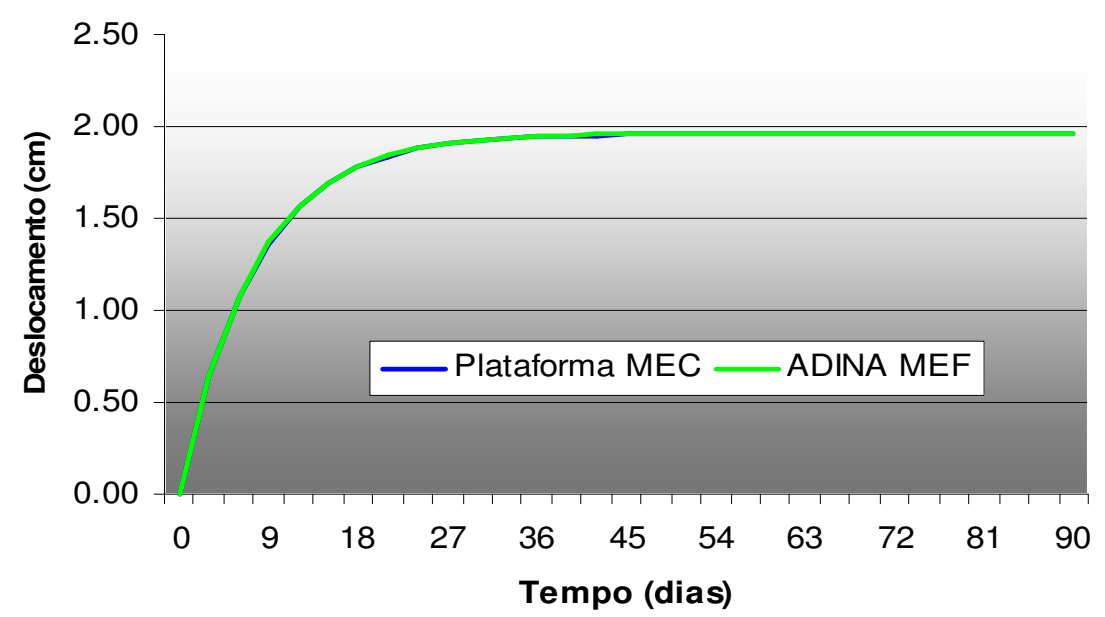

Figura 5.18 - Deslocamento radial da parede interna para dois domínios diferentes. 
A Tabela 5.8 compara o deslocamento radial na interface entre os dois domínios para $\mathrm{t}=90$ dias.

Tabela 5.8 - Deslocamento radial da parede interna para $\mathrm{t}=90$ dias.

\begin{tabular}{ccc}
\hline Análise & Discretização & $\begin{array}{c}\text { Deslocamento } \\
(\mathbf{c m})\end{array}$ \\
\hline Plataforma - MEC & $\begin{array}{c}18 \text { elementos quadráticos - } \\
36 \text { nós }\end{array}$ & 1.961563 \\
\hline ADINA - MEF & $\begin{array}{c}96 \text { elementos } \\
\text { isoparamétricos de } 9 \text { nós - }\end{array}$ & 1.965486 \\
& 429 nós \\
\hline
\end{tabular}

A Figura 5.19 mostra a malha em elementos finitos realizada no software ADINA assim como o deslocamento radial do vaso sob pressão interna para $t=90$ dias.

$\mathbf{A}$
$\mathbf{D}$
$\mathbf{I}$
$\mathbf{N}$
$\mathbf{A}$

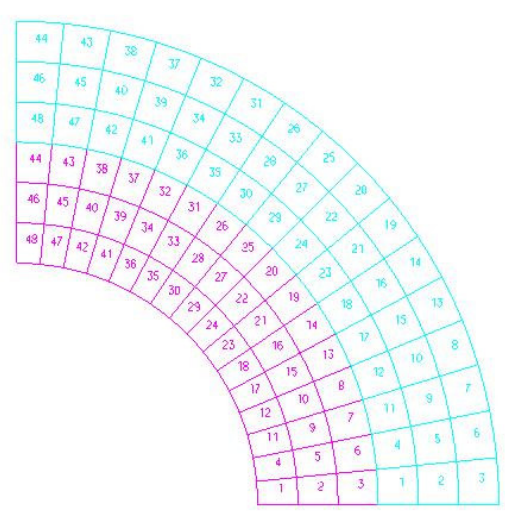

A
$\mathbf{D}$
$\mathbf{N}$
$\mathbf{N}$
$\mathbf{A}$
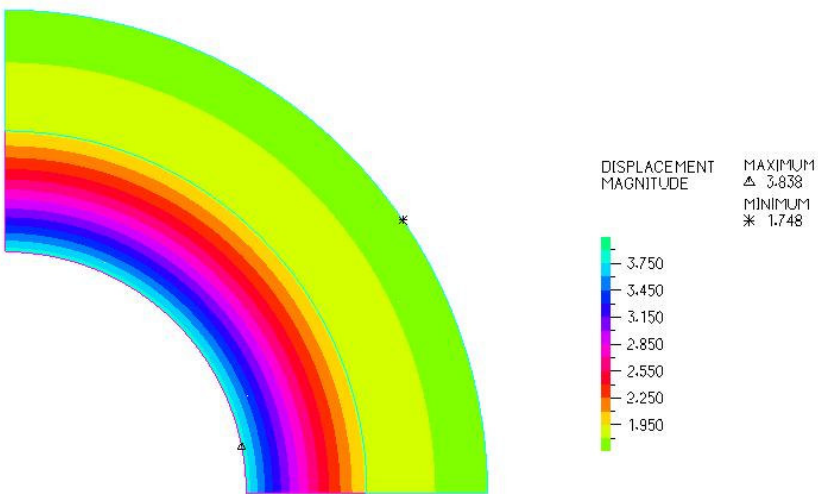

Figura 5.19 - Malha de elementos finitos e deslocamento radial da parede interna, $\mathrm{t}=90$ dias. 


\subsection{EXEMPLO 03: TÚNEL COM DUAS REGIÕES}

Os exemplos apresentados nas seções anteriores foram fundamentais para validar o algoritmo proposto, permitindo assim que fosse possível realizar a modelagem desejada nesta pesquisa. Neste sentido, apresenta-se agora a modelagem bidimensional da estrutura de suporte de túneis com comportamento viscoelástico usando o MEC.

O exemplo consiste em um túnel submetido a um carregamento na sua superfície simulando, por exemplo, uma edificação. O modelo é caracterizado por duas regiões, a primeira representando o solo/rocha e a segunda o concreto projetado, ambas com comportamento viscoelástico baseada no modelo de Kelvin-Voigt. A Figura 5.20 ilustra o problema, bem como sua discretização. Devido à sua simetria, apenas metade da estrutura foi discretizada.

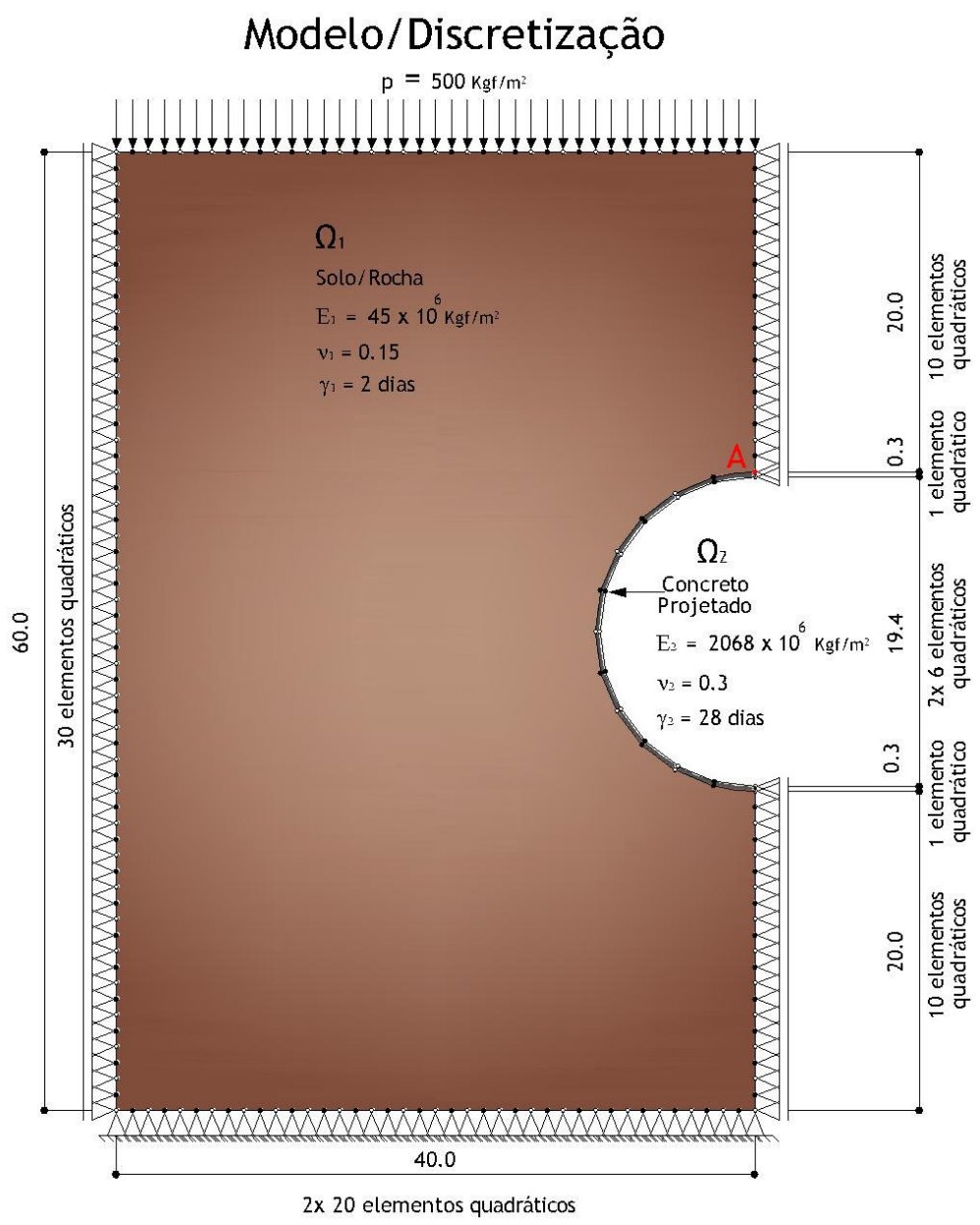

Figura 5.20 - Geometria, discretização e propriedades do túnel com dois domínios. 
As propriedades dos materiais utilizados na modelagem, módulo de elasticidade $(E)$, coeficiente do Poisson $(v)$ e parâmetro viscoso $(\gamma)$, foram extraídas de referências usuais que tratam da análise de túneis, como, por exemplo, (GOMES, 2006) e (MESQUITA, 2002). Os resultados para o deslocamento vertical do ponto A, que pertence a parede externa do túnel são apresentados na Figura 5.21, considerando o problema como estado plano de deformação e $\Delta_{t}=2$ dias .

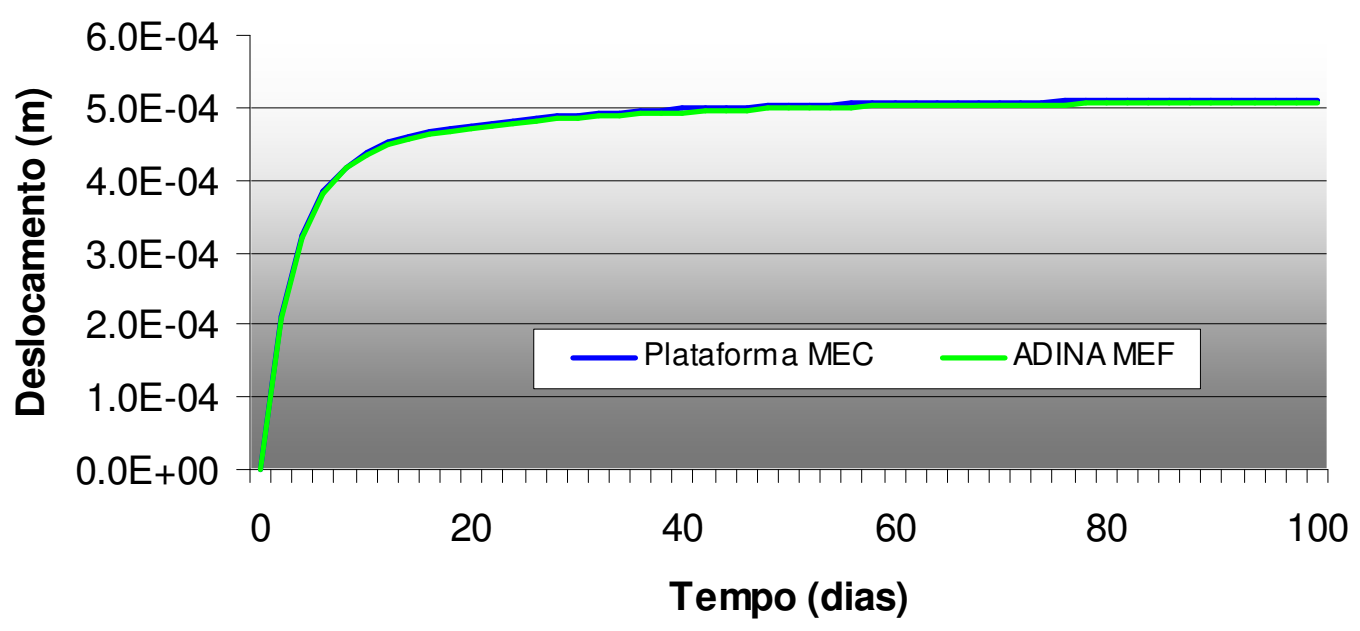

Figura 5.21 - Deslocamento vertical do ponto A.

A Tabela 5.9 compara o deslocamento vertical do ponto $A$ entre os dois métodos para $t=100$ dias.

Tabela 5.9 - Deslocamento vertical do ponto A para $\mathrm{t}=100$ dias.

\begin{tabular}{ccc}
\hline Análise & Discretização & $\begin{array}{c}\text { Deslocamento } \\
(\mathbf{m})\end{array}$ \\
\hline Plataforma - MEC & 110 elementos quadráticos & 0.000510 \\
& -220 nós & \\
\hline ADINA - MEF & 2392 elementos & 0.000506 \\
& isoparamétricos de 9 nós - & \\
\hline
\end{tabular}

A Figura 5.22 mostra a malha em elementos finitos realizada no software ADINA assim como o deslocamento vertical do modelo para $t=100$ dias. 
$\mathbf{A}$
$\mathbf{D}$
$\mathbb{N}$
$\mathbf{A}$
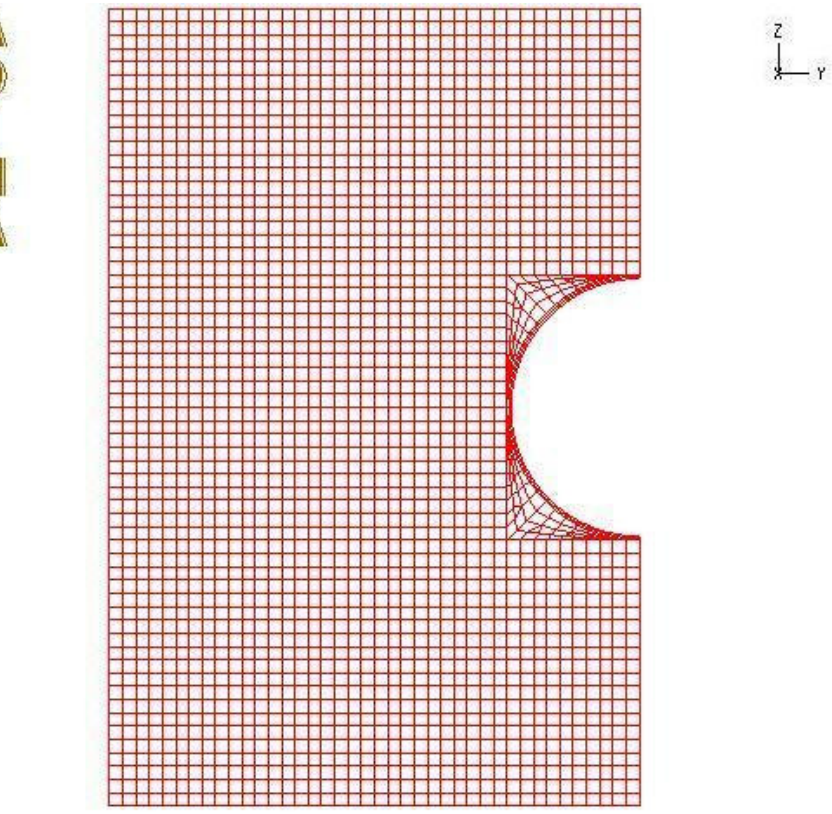

A
$\mathbf{D}$
$\mathbf{N}$
$\mathbf{N}$
$\mathbf{A}$
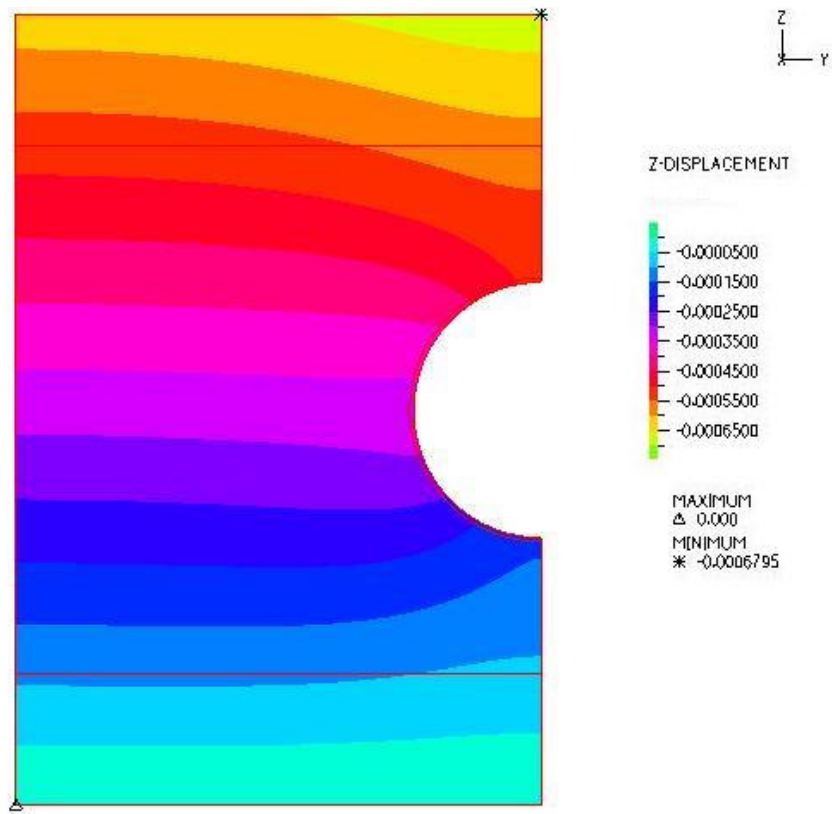

Z-DISPLACEMENT

$-0.0000500$

$-0.0001500$

$-0.0002500$

$-0.0003500$

$-0.0004500$

$-0.0006500$

MAXIMUM

$\rightarrow \rightarrow 0,0006795$

Figura 5.22 - Malha de elementos finitos e deslocamento vertical do modelo para $t=100$ dias.

O problema poderia ter sido analisado com uma densidade de malha bem menor, porém a malha foi escolhida de maneira que os nós no contorno do modelo coincidissem nos dois métodos numéricos, MEC e MEF.

Semelhante aos outros exemplos, nota-se uma perfeita concordância entre os resultados obtidos pelo algoritmo proposto e a solução numérica pelo MEF, através do software ADINA. 


\subsection{EXEMPLO 04: TÚNEL COM QUATRO REGIÕES}

O último exemplo apresentado neste capítulo consiste de um túnel muito semelhante ao do exemplo anterior. Porém, na tentativa de obter uma simulação computacional mais realística de obras de túneis, subdivide-se a região do solo/ rocha em três camadas diferentes, introduzindo um grau de heterogeneidade no modelo. O modelo é caracterizado por 4 regiões, as três primeiras representando o solo e a última região representando a estrutura de suporte em concreto projetado. Todas as regiões possuem comportamento viscoelástico baseada no modelo de Kelvin-Voigt. A Figura 5.23 ilustra o problema, bem como sua discretização. Devido à sua simetria apenas metade da estrutura foi discretizada.

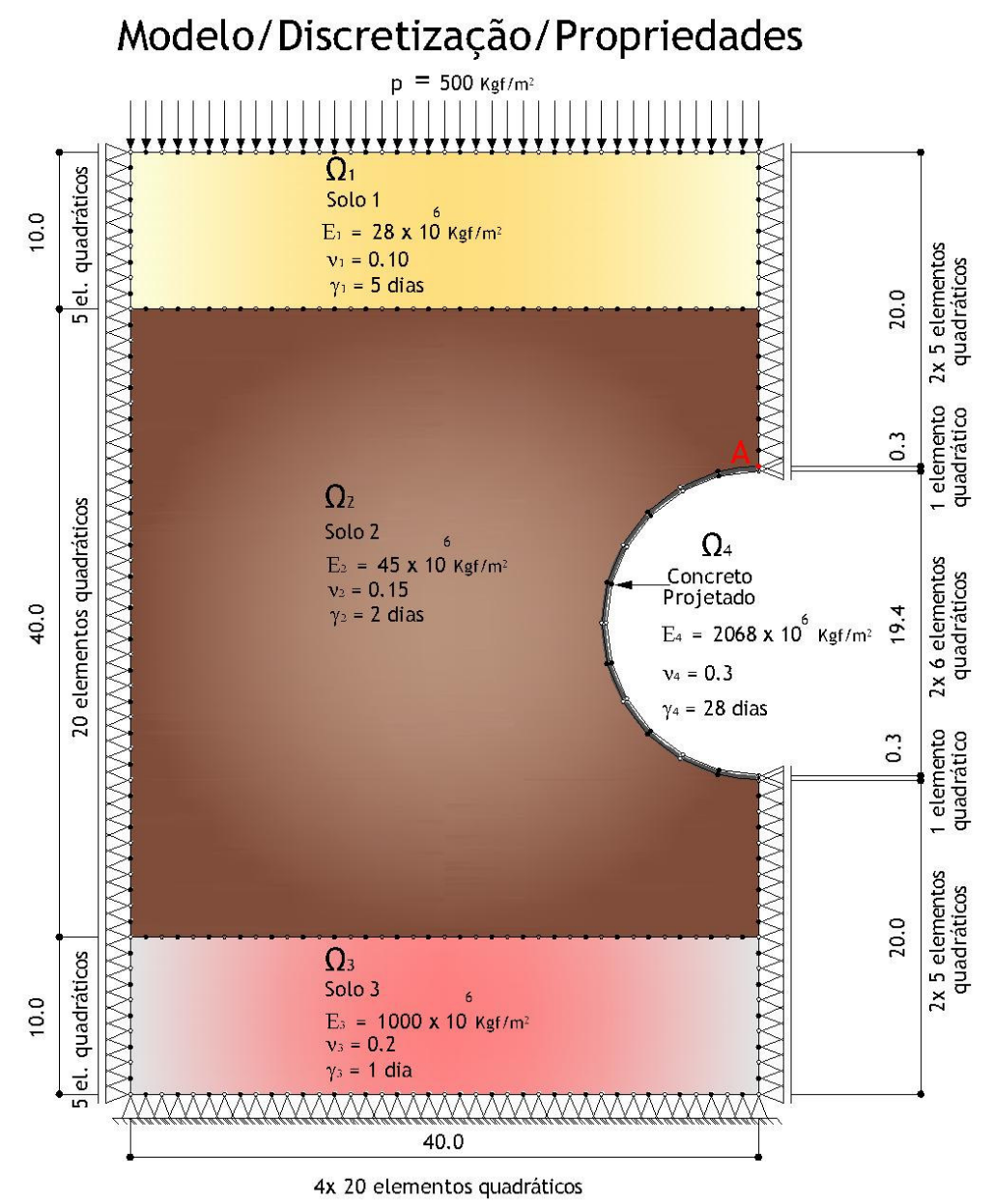

Figura 5.23 - Geometria, discretização e propriedades do túnel com quatro regiões. 
Os resultados para o deslocamento vertical do ponto $A$, que pertence a parede externa do túnel são apresentados na Figura 5.24, considerando o problema como estado plano de deformação e $\Delta_{t}=2$ dias .

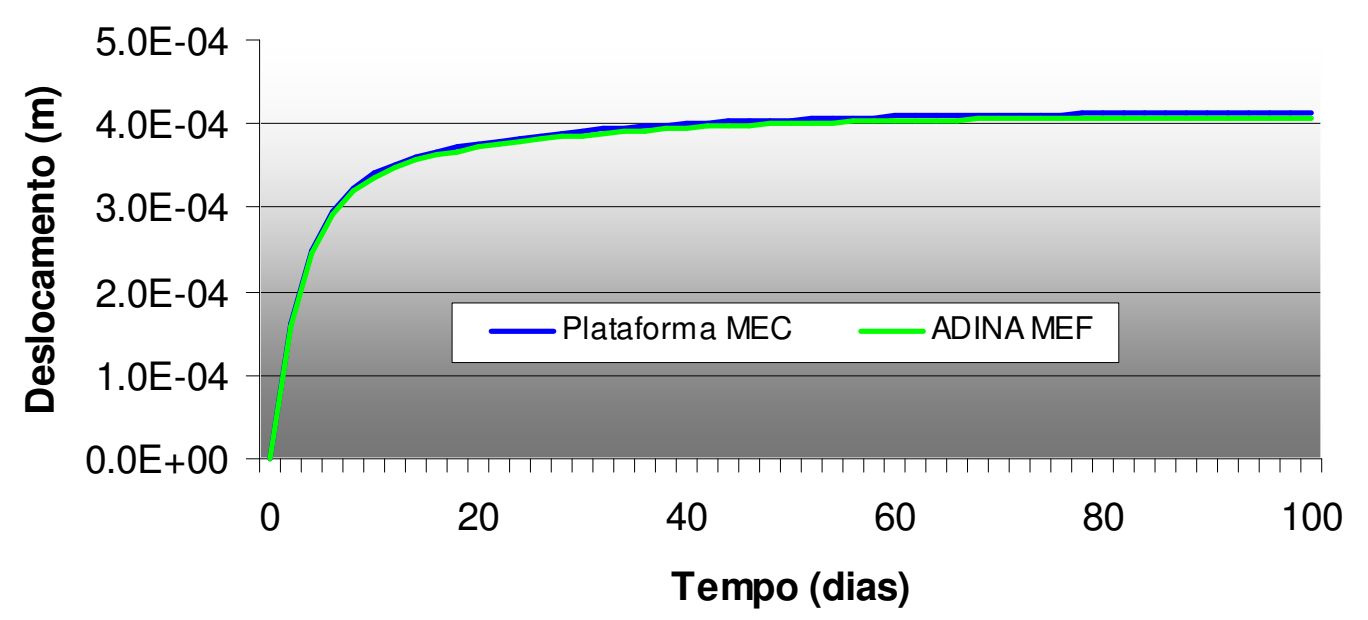

Figura 5.24 - Deslocamento vertical do ponto A.

A Tabela 5.10 compara o deslocamento vertical do ponto $A$ entre os dois métodos para $\mathrm{t}=100$ dias.

Tabela 5.10 - Deslocamento vertical do ponto A para $t=100$ dias.

\begin{tabular}{ccc}
\hline Análise & Discretização & $\begin{array}{c}\text { Deslocamento } \\
(\mathbf{m})\end{array}$ \\
\hline Plataforma - MEC & 190 elementos quadráticos \\
& -380 nós & 0.000408 \\
\hline ADINA - MEF & $\begin{array}{c}2392 \text { elementos } \\
\text { isoparamétricos de } 9 \text { nós - }\end{array}$ & 0.000413 \\
& 9777 nós & \\
\hline
\end{tabular}

O bom comportamento observado em todos os exemplos até aqui apresentados é novamente reproduzido. Vale lembrar que o algoritmo proposto não tem limitação quanto ao número de regiões no modelo.

Os resultados obtidos são bastante precisos até mesmo para grandes passos de tempo $\left(\Delta_{t}\right)$, conforme mostra a Figura 5.25. 


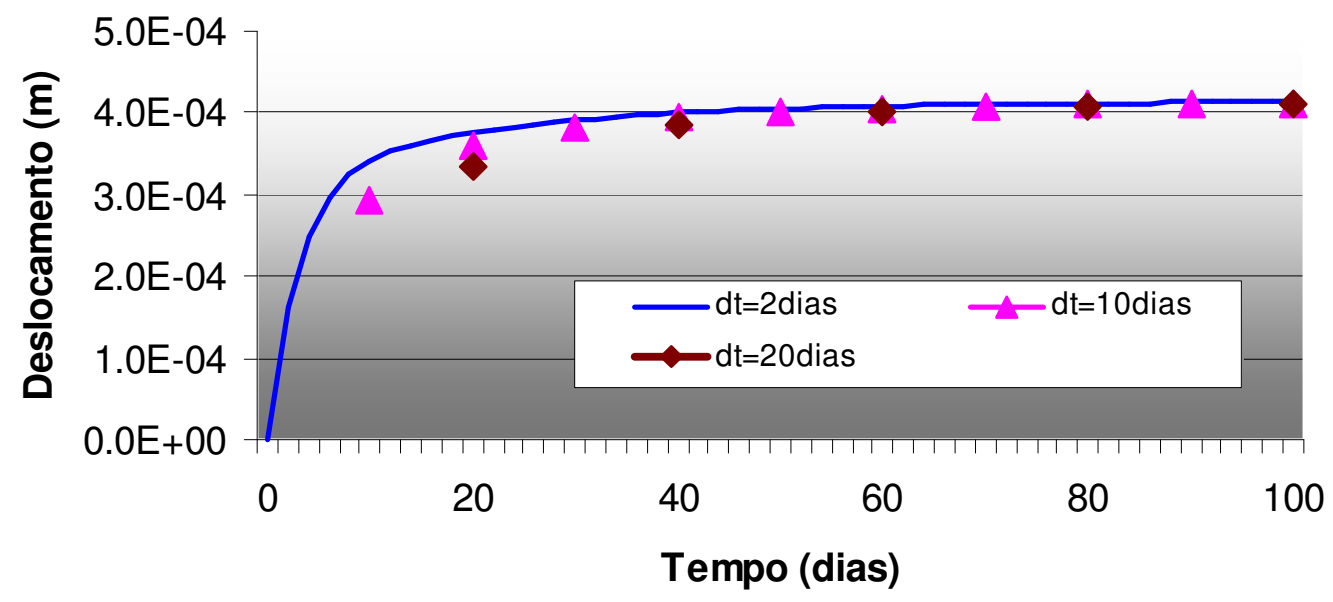

Figura 5.25 - Deslocamento vertical do ponto A para diversos $\Delta_{t}$.

A Figura 5.26 mostra a malha em elementos finitos realizada no software ADINA na configuração inicial e configuração deformada assim como o deslocamento vertical do modelo para $\mathrm{t}=100$ dias.
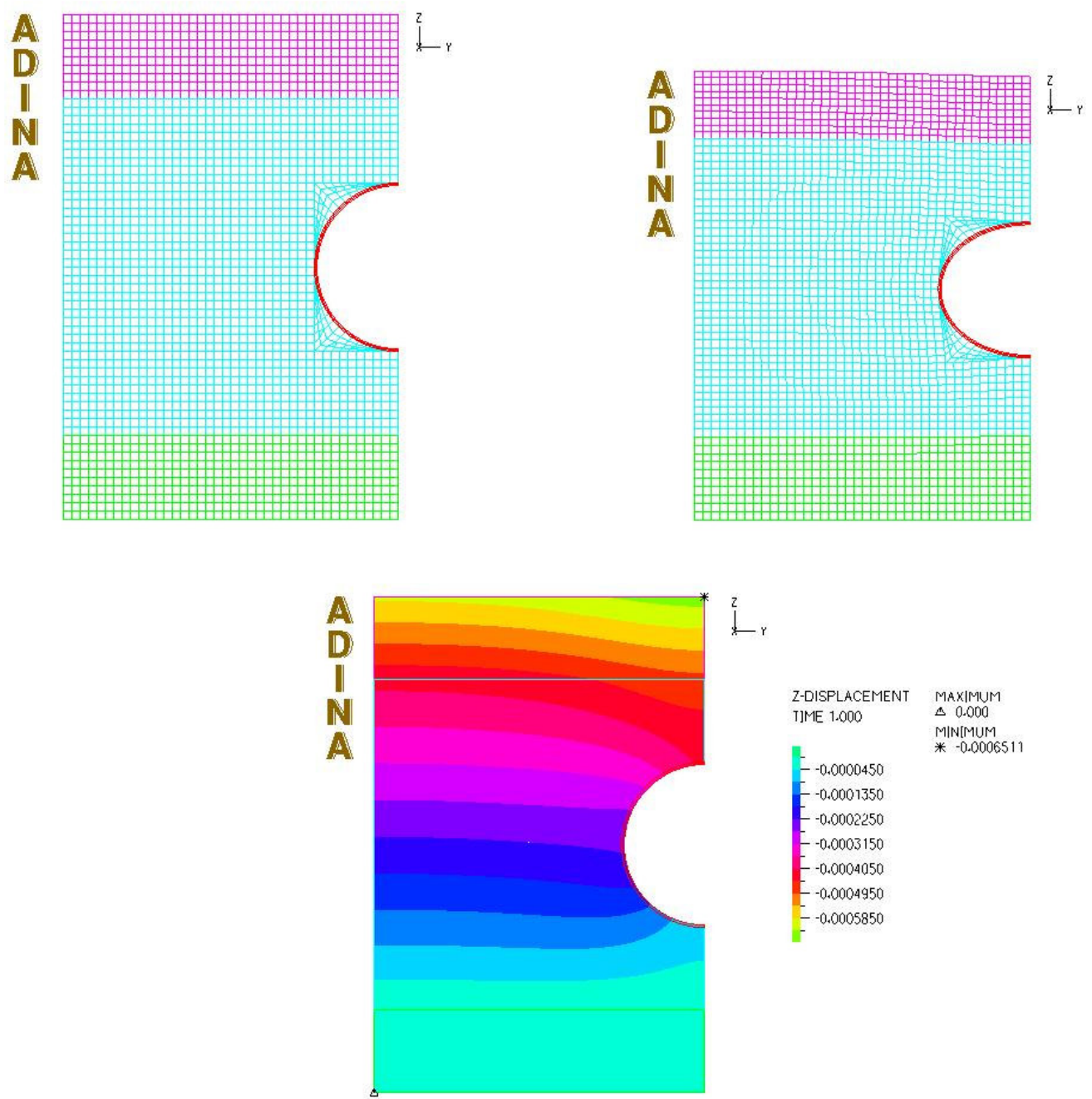

Figura 5.26 - Malha de elementos finitos e deslocamento vertical para $t=100$ dias. 


\section{CONCLUSÕES}

A proposta inicial deste trabalho foi inspirada nos problemas de escavação de túneis onde, apesar dos grandes avanços na aplicação de métodos numéricos, ainda temos dificuldades em prever o comportamento destes modelos. $O$ trabalho iniciou-se com uma introdução às principais características sobre o assunto. Em seguida, foi apresentada uma revisão histórica dos trabalhos acerca de simulação numérica em engenharia de túneis, Método dos Elementos de Contorno (MEC) e Programação Orientada a Objetos (POO). No âmbito dos conceitos necessários para o desenvolvimento da dissertação, foram apresentados no Capítulo 3, entre outras coisas, os principais sistemas de escavação de túneis, os modelos reológicos, a formulação do Método dos Elementos de Contorno e por fim problemas de multi-regiões. A forma como a modelagem computacional do suporte de túneis foi tratada neste trabalho também foi apresentada juntamente com uma pequena abordagem sobre análises bidimensionais e métodos de análise da interação entre o maciço e suporte.

O objetivo geral deste trabalho era a modelagem bidimensional da estrutura de suporte de túneis com comportamento viscoelástico usando como fundamentação teórica o MEC. Para realizar esta modelagem, fez-se necessário o desenvolvimento de um novo algoritmo para simulação da interação entre o maciço e o suporte em concreto projetado baseado no MEC. Muitos trabalhos já foram desenvolvidos nessa área, porém, com diferentes metodologias para a realização de tais análises. Assim, a proposta deste trabalho foi desenvolver uma metodologia capaz de garantir uma das principais vantagens da utilização do MEC em análises lineares e não-lineares, que é a discretização apenas do contorno do modelo.

Com o intuito de modelar o problema inicialmente proposto, era necessário adotar um modelo que levasse em conta a viscosidade do material, pois o comportamento viscoso está presente praticamente em todos materiais envolvidos. 
Através de observações dos modelos reológicos, foi possível identificar as relações constitutivas de cada modelo reológico. As relações constitutivas do modelo de Kelvin-Voigt introduzidas corretamente no desenvolvimento da equação integral do MEC, dão origem a sistemas de equações temporais que são solucionados através da adoção de algoritmo de integração temporal. A simplificação do modelo de Kelvin-Voigt, escrevendo este em função de apenas um parâmetro viscoso, permitiu obter a relação entre o amortecimento viscoso e o parâmetro representativo da viscosidade do material. Assim, pôde-se concluir que o amortecimento viscoso proporcional a matriz $H$ para o MEC resultava no mesmo parâmetro viscoso na relação reológica de Kelvin-Voigt.

A não implementação do modelo viscoelástico de três parâmetros num primeiro momento, se deveu ao fato do algoritmo que estávamos propondo usar como base o algoritmo proposto por Carbone (2007), e este em sua análise viscoelástica utiliza o modelo de Kelvin-Voigt, inclusive em sua análise viscoplástica. O trabalho de Carbone (2007) também considera o modelo viscoplástico sem comportamento instantâneo. Assim, como este algoritmo já foi testado e validado, a idéia inicial foi adaptar esse algoritmo para problemas de multi-regiões, possibilitando assim a modelagem do suporte de túneis com comportamento viscoelástico. O próximo passo do trabalho é introduzir aprimoramentos no modelo que representa o comportamento do concreto projetado, considerando modelos reológicos mais complexos, como por exemplo:

- Modelo de três parâmetros;

- Modelo de Maxwell em camadas;

- Modelo de Burger.

Além da viscosidade dos materiais, para modelar o problema inicialmente proposto, foi necessário adotar também um modelo que levasse em conta um domínio heterogêneo. A questão da multi-regiões foi solucionada inicialmente para plataforma Elastostática. A partir desta primeira implementação realizou-se a introdução do efeito de viscosidade na plataforma computacional com multi-regiões, uma vez que a mudança se resumiu na alteração da equação (3.50) para (3.70). 
Em síntese, todas as formulações desenvolvidas alcançaram o êxito esperado. Estas podem ser resumidamente descrita como:

- Formulação viscoelástica para o MEC considerando o modelo de Kelvin-Voigt;

- Formulação de multi-regiões para o MEC.

As análises numéricas realizadas no capítulo 5 mostram que os resultados obtidos com o algoritmo proposto neste trabalho apresentam grande conformidade com os resultados das análises realizadas com MEF, através do software ADINA e também com os resultados analíticos, validando o algoritmo abordado neste trabalho.

Com o desenvolvimento deste trabalho, novas e ricas frentes de pesquisas para 0 desenvolvimento de novas tecnologias com MEC são abertas. Abaixo seguem algumas sugestões para futuros trabalhos:

- Refinamento do modelo reológico para representação da estrutura de suporte em concreto projetado;

- Aplicação do algoritmo de visualização proposto por Noronha e Pereira (2003) para visualização dos resultados do algoritmo proposto;

- Configuração do algoritmo proposto pelo pré-processador da plataforma que vem sendo desenvolvida pelo grupo do Prof. Marcos Noronha

- Análises Viscoelásticas e Viscoplástica 3D, considerando o MEC sem discretização do domínio;

- Realização de novos estudos para melhorar o desempenho do algoritmo proposto e para determinar as suas características de precisão, esforço computacional, convergência e estabilidade de Maxwell em camadas. 


\section{REFERÊNCIAS}

BANERJEE, P.K.; BUTTERFIELD, R. Boundary Element Methods in Engineering Science, McGraw-Hill, London, 1981.

BANERJEE, P.K.; PAPE, D. A. Treatment of Body Forces in 2D Elastostatic BEM Using Particular Integrals, Winter Annual Meeting, Boston, MA , 1987.

BARTON, N. TBM Tunneling in Jointed and Fault Rock, Balkema, Rotterdam, 2000, $172 \mathrm{p}$.

BEER, G. Numerical Simulation in Tunnelling, Springer, Vienna, 2003.

BEER, G. Programming the Boundary Element Method, Wiley, Chichester, 2001.

BEER, G.; WATSON, J.; SWOBODA, G, Three-Dimensional Analysis of Tunnels using Infinite Boundary Elements, In: COMPUTERS AND GEOTECHNICS, 2., 1987. p. 37-58.

BEER, G., Finite Element, Boundary Element and Coupled Analysis of Unbounded Problems in Elasto-statics. In: INT. J. NUMER. ANAL. METHODS ENG, 19, 1983. p. 567-580,

BREBBIA, C. A. The boundary element method for engineers. London: Pentech Press, 1978.

BREBBIA, C. A.; TELLES, J. C. F.; WROBEL, L. C. Boundary Element Techniques, Berlin : Springer-Verlag, 1984.

BREBBIA, C. A; DOMINGUES, J., Boundary Elements: an Introductory Course, McGraw-Hill, $2^{a}$ ed, New York, USA, 1992.

CARBONE, N. Desenvolvimento de Um Novo Algoritmo Para Análise Viscoplástica com o Método dos Elementos de Contorno. 2007. 88 p. Dissertação de Mestrado, EPUSP, São Paulo, SP, 2007. 
CELESTINO, T. B. et al. Túneis do Brasil, Comitê Brasileiro de Túneis, São Paulo: Dórea Books and Art, 2006.

CRUSE, T. A. Numerical solution in three dimensioanl elastostatics, In: INT. J. SOLIDS STRUCT., 5., 1969. p. 1259-1274.

CRUSE, T. A. Mathematical foundations of the boundary integral equation method in solids mechanics. Pratt and Whitney Aircraft Group, 1977. (Report AFOSR-IR-1002)

CRUSE, T. A.; WILSON, R. B. Advanced applications of boundary integral equation methods, In: NUCLEAR ENGNG. DESIGN, 46., 1978. p. 223-234.

DE SOUZA, C. P. G. Análise de Alta Precisão em Modelos Tridimensionais de Elementos de contorno Utilizando Técnicas Avançadas de Integração Numérica. 2007. 144 p. Dissertação de Mestrado, EPUSP, São Paulo, SP, 2007.

DÜNSER, C. Simulation of Sequential Tunnel Excavation with the Boundary Element Metho. 2001. 156p. PhD Thesis, Technical University of Graz, Graz, Áustria, 2001.

FARIAS, M. M.; JUNIOR, A. H. M.; ASSIS, A. P. Displacement Control in Tunnels Excavated by the NATM: 3D Numerical Simulations. In: TUNNELLING AND UNDERGROUND SPACE TECHNOLOGY, 19., 2004, Inglaterra. p. 283-293.

FIGUeIREDO E ALMEIDA, L. P. C. P., Avaliação de Tensões em Peças PréFissuradas Usando o Método dos Elementos de Contorno. 2003. 81 p. Dissertação de Mestrado, UNICAMP, Campinas, SP, 2003.

FRANÇA, P. T. Estudo do Comportamento de Túneis: Análise Numérica Tridimensional com Modelos Elasto-Plásticos. 2006. 185 p. Dissertação de Mestrado, EPUSP, São Paulo, SP, 2006.

GALLI, G.; GRIMALDI, A.; LEONARDI, A. Three-Dimensional Modeling of Tunnel Excavation and Lining. In: COMP. AND GEOTECHNICS, 31., 2004. p. 171-183 GAO, X. W.; DAVIES, T. G. Boundary Element Programming in Mechanic, Cambridge University Press, 2002. 
GOLSER, H. The Application of Finite Element and Boundary Element Methods in Tunnelling. 2001. 125p. PhD Thesis - Technical University of Graz, Graz, Áustria, 2001.

GOMES, R. A. M. P. Análise Tridimensional de Túneis Considerando o Comportamento Dependente do Tempo na Interação Maciço-Suporte. 2006. 306 p. Tese (Doutorado) - EESC, Universidade de São Paulo, São Carlos, SP, 2006.

GONÇALVES, P. C. Estudo de Alternativas para Aplicação do Método dos Elementos de Contorno para Elasticidade. 2006. 132 p. Dissertação de Mestrado, UNICAMP, Campinas, SP, 2006.

HANSEN, E. B. Numerical solution of integro-differential and singular integral equations for plate bending problems. In: J. OF ELASTICITY, 6., 1976. p.39-56.

HUBER, O. et al. Evaluation of the Stress Tensor in 3-D Elastoplasticity Direct Solving of Hypersingular Integrals. In: INT. J. N. M. ENG, 39., 1996. p. 2555-2573.

KASPER, T.; MESCHKE, G. A 3D Finite Element Simulation Model for TBM Tunneling in Soft Ground, In: INT. J. NUMER. ANAL. METHODS GEOMECH., 28, 2004. p. 1441-1460.

KELLOGG, O. D. Foundations of Potential Theory, Springer, Berlin, 1929.

KUPRADZE, O. D. Potential methods in theory of elasticity. Daniel Davy, New York, 1965.

LACHAT, J. C., WATSON, J. O. A second generation boundary Integral equation program for three-dimensional elastic analysis. In: ASME - APPLIED MECHANICS NATIONAL CONFERENCE, 1975, New York, USA. Proceedings of ASME 1975 Conference.

LACHAT, J. C., WATSON, J. O. Effective numerical treatament of boundary integral equations: a formulation for three-dimensional elastostatics. In: INT. J. NUMER. METH. IN ENGNG, 10., 1976. p.991-1005.

MESQUITA, A. D. Novas Metodologias e Formulações Para o Tratamento de Problemas Inelásticos com o Acoplamento MEC/MEF Progressivo. 2002. 291 p. Tese (Doutorado) - EESC, Universidade de São Paulo, São Carlos, SP, 2002. 
MIKHLIN, S. G. Integral Equations, Pergamon Press, Oxford, 1957.

MÜLLER, A. S. Um Novo Algoritmo para Análises Não-Lineares Utilizando o Método dos Elementos de Contorno. 2004. 106 p. Dissertação de Mestrado, EPUSP, São Paulo, SP, 2004.

MUSKHELISVILI, N. I. Some Basic Problem of the Mathematical Theory of Elasticity, Noordhoff, Holland, 1953.

NORONHA, M. A. M. Mecânica Computacional Aplicada à Engenharia de Túneis, FAPESP 2007/05976-5, São Paulo, 2007.

NORONHA, M. A. M.; DÜNSER, C.; BEER, G. Accelerating Strategies to the Numerical Simulation of Large-Scale Models for Sequential Excavation. In: INTERNATIONAL JOURNAL FOR NUMERICAL AND ANALYTICAL METHODS IN GEOMECHANICS, 31., 2007. p.1071 - 1084.

NORONHA, M. A. M.; PEREIRA, A. M. B. A New Algorithm for Visualization of Domain Results in Analysis with the Boundary Element Method. In: 15th INTERNATIONAL CONFERENCE ON BOUNDARY ELEMENT TECHNOLOGY (BETECH), 2003, Detroit, USA.

OLIVEIRA, T. R. S. T.; SAMPAIO, M. A. B.; NORONHA, M. A. M. Software para Análise Numérica de Túneis com Visualização Usando Método dos Elementos de Contorno. In: $2^{\circ}$ CONGRESSO BRASILEIRO DE TÚNEIS E ESTRUTURAS SUBTERRÂNEAS, 2., 2008, São Paulo, Brasil.

OPRIESSNIG, G.; BEER, G. Visualisation in Tunnelling. In: IEEE INTERNATIONAL CONFERENCE ON INFORMATION VISUALISATION, 1998, London, UK. Proceedings of IEEE 1998 Conference.

OZDEMIR, L; NILSEN, B. Hard Rock Tunnel Boring Prediction and Field Performance. In: RETC - RAPID EXCAVATION AND TUNNELING CONFERENCE, 1993, Boston, USA. Proceedings of RETC 1993 Conference.

PALERMO JR., L. Análise de peças de seção delgada com associação de placas pelo método dos elementos de contorno. 1989. 152 p. Tese (Doutorado), EESC, Universidade de São Paulo, São Carlos, SP, 1989. 
PEREIRA, A. M. B. Avanços na Visualização, Análise Não-Linear e Programação com o Método dos Elementos de Contorno. 2004. 161 p. Dissertação de Mestrado, EPUSP, São Paulo, SP, 2004.

PIMENTA, P. M. Fundamentos da Mecânica dos Sólidos e das Estruturas. São Paulo, SP: Escola Politécnica, Universidade de São Paulo, 2002. 388 p. Notas de aula da disciplina de pós-graduação PEF5742 - Fundamentos da Mecânica das Estruturas II.

RIZZO, F. J. An integral approach to bondary value problems of classical elastostatics. In: QUAT. APPL. MATH., 25, 1967. p.83-92.

ROSTAMI, J.; OZDEMIR, L. Computer Modeling of Mechanical Excavators Cutterhead. IN: PROCEEDINGS OF THE WORLD ROCK BORING ASSOCIATION CONFERENCE, 1996, Ontario, Canda.

SAMPAIO, M. A. B.; OLIVEIRA, T. R. S. T.; NORONHA, M. A. M. Modelagem de Máquinas Tuneladoras Usando Mecânica do Contato com Método dos Elementos de Contorno. In: $2^{\circ}$ CONGRESSO BRASILEIRO DE TÚNEIS E ESTRUTURAS SUBTERRÂNEAS, 2., 2008, São Paulo, Brasil.

SCHWEIGER, H. F.; SCHULLER, H; PÖTTLER, R. Some Remarks on 2-D-Models for Numerical Simulation of Underground Constructions with Complex Cross Section. In: PROCEEDINGS OF THE NINTH INTERNATIONAL CONFERENCE ON COMPUTER METHODS AND ADVANCES IN GEOMECHANICS, 1997, Wuhan, China. Proceedings of ICCMAG 1997 Conference.

SIMÕES, R. Um Estudo de Placas sob Cargas Dinâmicas Estacionárias e com Efeito da Não Linearidade Geométrica sob Cargas Estáticas Usando o Método dos Elementos de Contorno. 2001. 222 p. Dissertação de Mestrado, Universidade Estadual de Campinas, Campinas, SP, 2001.

SMIRNOV, V. J. Integral Equations and Partial Differential Equations. In: COURSE IN HIGHER MATHEMATICS. London: Addison-Wesley, v.4, 1964.

SOUZA, J. N. V. A. Túneis em Maciços Terrosos. Comportamento e Modelação Numérica. 1998. 623 p. Tese (Doutorado), Universidade de Coimbra, Coimbra, 1998.

VENTURINI, W. S. Boundary Element Method in Geomechanics, Berlin: SpringerVerlag, 1983. 